\title{
Predictors of Foster Care Exits to Permanency: \\ A Competing Risks Analysis of \\ Reunification, Guardianship, and Adoption
}

by

Rebecca A. Akin

B.S.W., University of Kansas, 1991

M.S.W., University of Kansas, 1992

\begin{abstract}
Submitted to the School of Social Welfare and
The Faculty of the Graduate School of the

University of Kansas

in Partial Fulfillment of the Requirements for the

Degree of Doctor of Philosophy
\end{abstract}

\author{
Thomas P. McDonald, Ph.D. \\ Chairperson
}
John Poertner, Ph.D.
Methodologist

Deborah Adams, Ph.D.

Alice Lieberman, Ph.D.

Charles R. Epp, Ph.D.

Date Defended:

Copyright 2010

Rebecca A. Akin 
The Dissertation Committee for Rebecca Akin certifies that this is the approved version of the following dissertation:

\author{
Predictors of Foster Care Exits to Permanency: \\ A Competing Risks Analysis of \\ Reunification, Guardianship, and Adoption
}

Thomas P. McDonald, Ph.D.
Chairperson

John Poertner, Ph.D.

Methodologist

Deborah Adams, Ph.D.

Alice Lieberman, Ph.D.

Charles R. Epp, Ph.D.

Date Approved: 


\begin{abstract}
Nearly 800,000 children spend time in foster care each year, with many children experiencing lengthy stays and exiting without a permanent family. The main objective of this study was to identify which child and placement characteristics were significant predictors of foster care exit to three types of permanency: reunification, guardianship, and adoption. A nonexperimental longitudinal design was used to observe an annual entry cohort of 3,351 children who entered Kansas foster care in state fiscal year 2006. The sample was observed for 30 to 42 months. Data sources were two state administrative databases, one which tracks all children in foster care and one on mental health services. The primary data analysis was competing risks survival analysis. Study findings showed that children in foster care exit to different types of permanency at different rates. Reunification occurs the most quickly, followed by guardianship, and then adoption. While patterns of predictors varied by type of permanency, three major categories of important permanency predictors were identified: 1) demographic characteristics of age at entry and race, 2) clinical needs related to child disabilities and mental health problems, and 3) continuity and connections represented by kin placements, sibling placements, early stability, and absence of runaway events. Implications suggested that social work practice be age-differentiated and culturally appropriate, and that children's needs related to disabilities and mental health problems be addressed with thorough assessment and evidencebased services. Social work practices should also strive to keep children connected to family and in stable placements. The major social work theory implication suggested that permanency theory balance the primordial solidarities principle that stresses family connections with the bureaucratic institutions principle that emphasizes structures for ensuring stability. In addition,
\end{abstract}


this study's findings indicated the need to improve and expand timely permanency for more children. Policy implications included: using guardianship as a viable permanency option for more children; revising federal policy to promote the discovery and implementation of new, creative approaches to permanency; and, reforming the current financing structure to be more flexible and better aligned with the promotion of permanency outcomes. 


\section{Acknowledgments}

I am grateful for the tremendous support provided to me by the members of my dissertation committee. My chair, Tom McDonald, is due many thanks for the support he provided me throughout my entire doctoral program. First, he taught to understand and enjoy statistics. Then he took on the responsibility of being my chair with amazing integrity and commitment. Unlike many doctoral candidates, I actually found satisfaction and enjoyment in the dissertation process because Tom was a respectful and trustworthy chair. It has been an honor and pleasure to work under his direction. Alice Lieberman was a teacher and role model early in my educational career, influencing my perspectives and love for social work and child welfare. Her energy, insights, intellect, and commitment to social work are unmatched. I am thankful to have had her enthusiastic and articulate voice as part of my dissertation committee. Deborah Adams willingly accepted my request for mentoring as I returned to doctoral education after a leave of absence. She pushed me to think in new ways, always expected the highest standards, and inspired me to constantly consider the profession's foundations of equity and social justice. I am grateful for Deb's involvement in my graduate education and committee. John Poertner was available for what may have seemed like endless emails and questions. He was always generous with his time and completely thoughtful with his responses and suggestions. I was incredibly fortunate to receive guidance from someone with such vast knowledge and experience who was also a model scholar and mentor. Charles Epp stepped into my committee as an outside member with little knowledge or background information on me. He was always thoughtful in his participation on the committee, offering an interdisciplinary perspective and new ideas in a most encouraging and 
respectful manner. In sum, I was incredibly fortunate to have a committee of scholars who demonstrated both support and leadership on my behalf.

The path to completing my doctorate education was a long one in which I was influenced and supported by many different people at varying points in time. At the beginning of my doctoral program there were special friends with whom I shared two years of coursework; they were important supports during a pivotal time in my educational process. I am especially grateful for the friendship, encouragement, and support I received from Jennifer Propp and Ada SchmidtTieszen. Throughout my doctoral education I was fortunate to be taught and mentored by some of social work's most outstanding scholars. I thank these individuals particularly for how they challenged me to consider new paradigms and encouraged me to gain new knowledge and skills: Liane Davis, Ed Canda, Rosemary Chapin, Edith Freeman, Jean Peterson, Sue Pearlmutter, Charlie Rapp, Dennis Saleebey, and Ann Weick. I also wish to thank my colleagues at the School of Social Welfare who have supported me in various ways for a number of years: Jody Brook, Wanda Buck, Kathy Byrnes, Stephanie Bryson, Cheryl Holmes, Michelle Levy, Terry Moore, Sarah Potter, and Peggy Taylor. Finally, I need to acknowledge two individuals whose influence on my social work career was permanent and profound. Melissa Ness introduced me to social work and child welfare. It was because of the opportunities and respect she offered me that I found a passion and a career I love. Tom Gregoire is an extraordinary leader who exemplifies what it means to be an excellent scholar, mentor, and social worker. He is one of those rare individuals that knows how to teach while also demonstrating the utmost respect and care. I am grateful to have worked alongside him and to have had opportunities to learn from him. 
There are reasons an individual carries a passion to do one's best to improve the world for a vulnerable population of children and youth. My reasons reside in a foundation of knowledge and life lessons that were taught to me by multiple individuals. From my parents I learned persistence, self-discipline, and compassion. From my teachers and colleagues I acquired the knowledge and skills I needed. From my mentors I discovered a passion for research and social justice. Lastly, my husband and children provided lessons on everything else there is to know, and more. I am ever grateful to each of you.

I dedicate this dissertation to my husband and best friend, Bob; my beloved children, Zoë Mae and Zachary; and, to all children in foster care who too deserve a permanent family. 


\section{Table of Contents}

CHAPTER 1: INTRODUCTION AND OVERVIEW ..........................................................1

BACKGROUnd AND CONTEXT OF PERMANENCY IN Foster CARE ............................................ 2

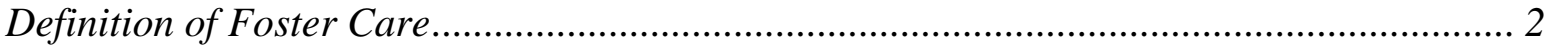

Historical and Policy Background of Foster Care and Permanency ................................. 3

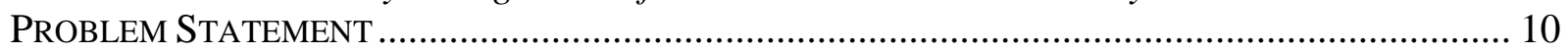

Scope of the Problem: Lack of Permanency ................................................................. 10

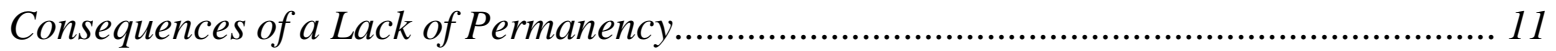

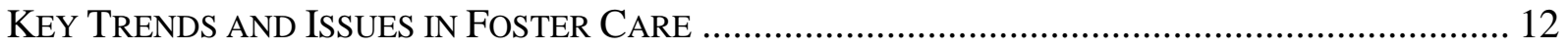

Demographics Trends and Service Needs .................................................................... 13

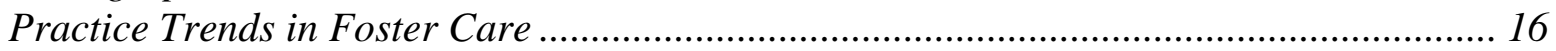

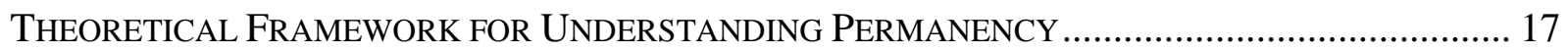

Primordial Solidarities and Bureaucratic Institutions ................................................. 17

Bio-ecological perspective ....................................................................................... 20

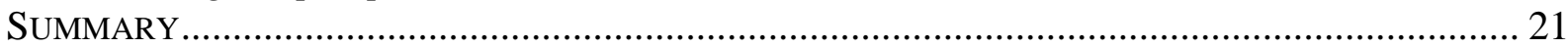

CHAPTER 2: $\quad$ LITERATURE REVIEW ...............................................................................22

DEPENDENT VARIABLES: Foster CARE EXITS TO PERMANENCY .......................................... 22

INDEPENDENT VARIABLES: PREDICTORS OF Foster CARE EXITS TO PERMANENCY ................ 23

Child Characteristics ............................................................................................ 24

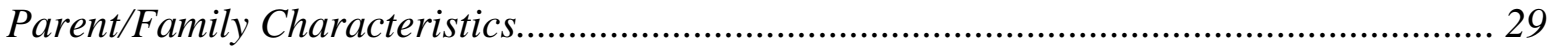

Placement Episode Characteristics ........................................................................... 31

Agency/Caseworker Characteristics.............................................................................. 36

SUMMARY OF INDEPENDENT AND DEPENDENT VARIABLES ............................................ 36

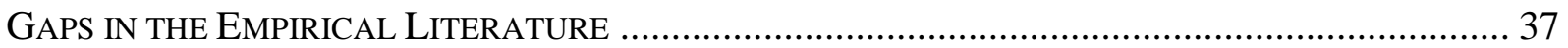

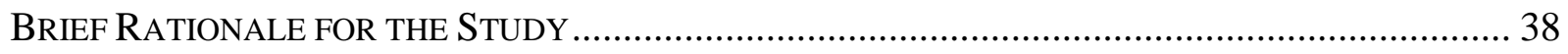

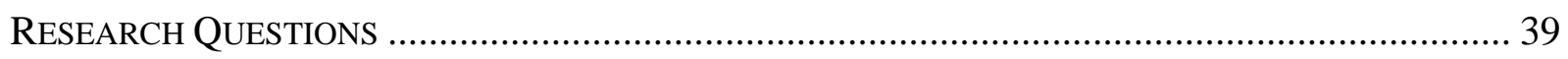

CHAPTER 3: $\quad$ METHODS ..................................................................................................40

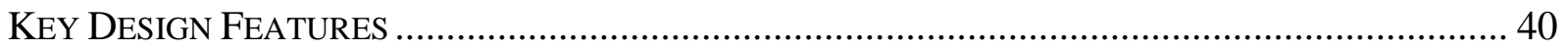

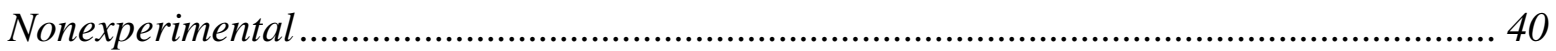

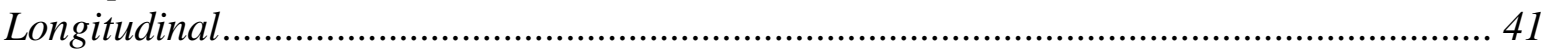

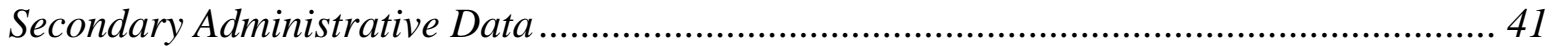

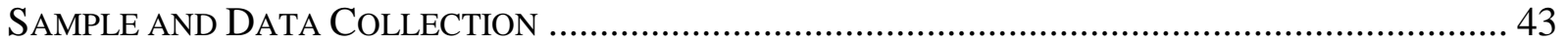

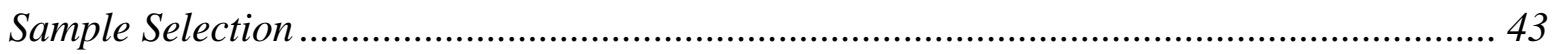

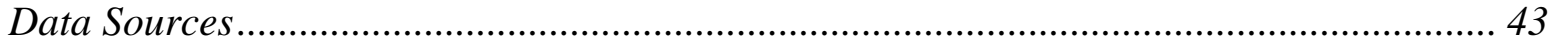

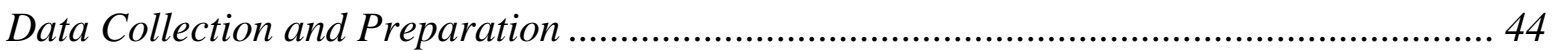

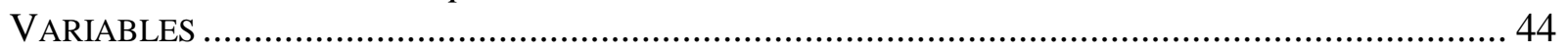

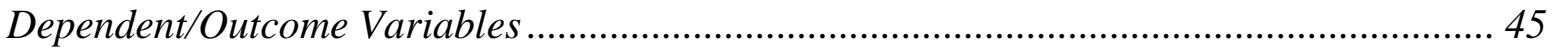

Independent/Predictor Variables............................................................................ 45

Measurement Reliability and Validity ..................................................................... 48 


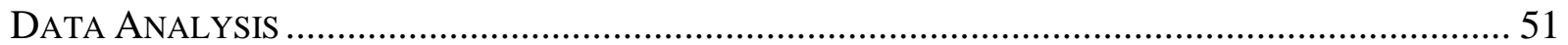

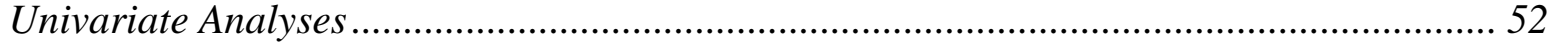

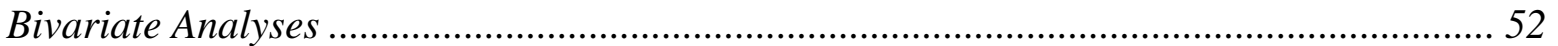

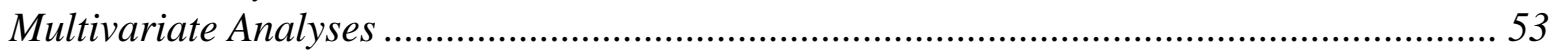

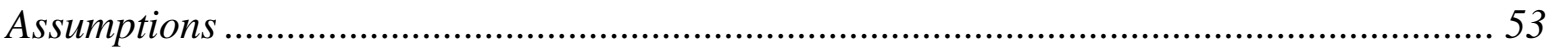

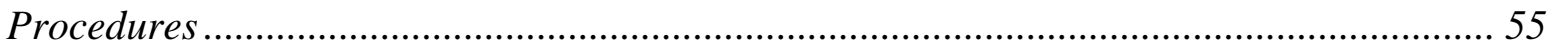

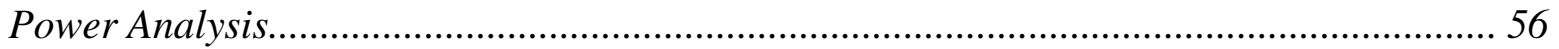

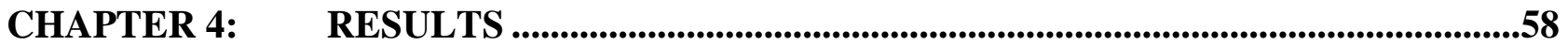

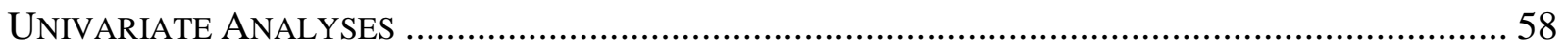

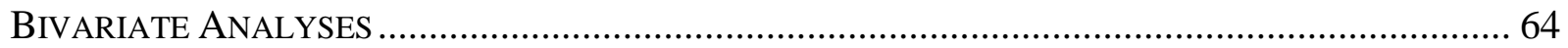

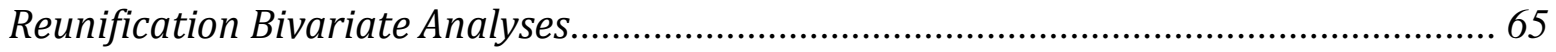

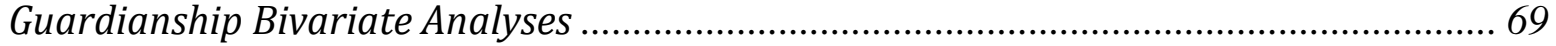

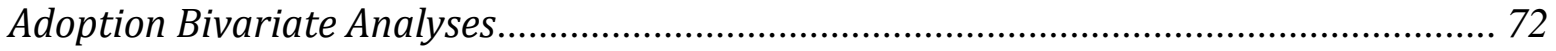

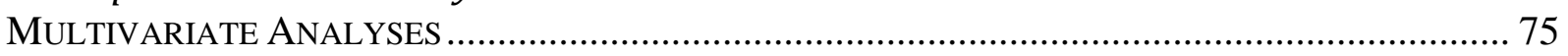

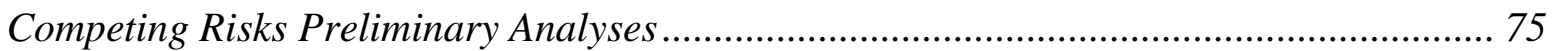

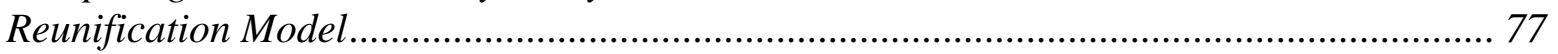

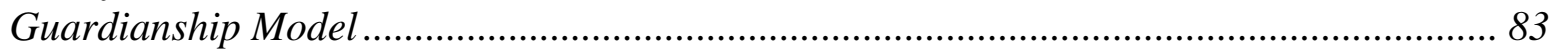

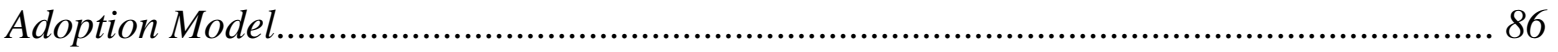

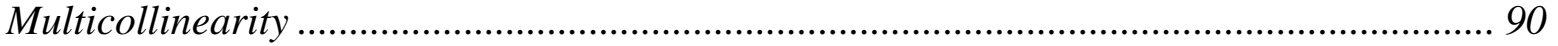

Comparison of Three Cox Regression Models ........................................................... 91

CHAPTER 5: $\quad$ DISCUSSION AND IMPLICATIONS .......................................................94

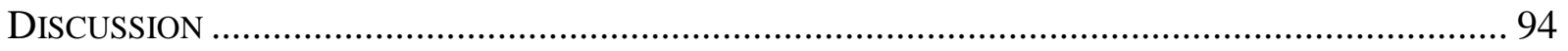

Important Predictors Within Permanency Outcomes .................................................. 94

Important Predictors Across Permanency Outcomes................................................... 95

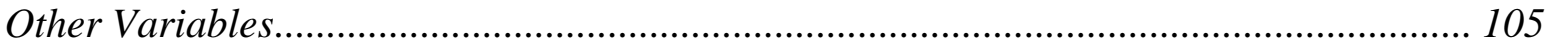

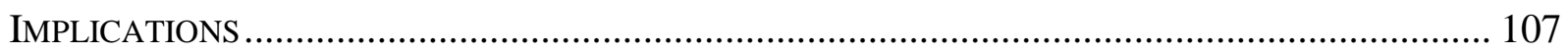

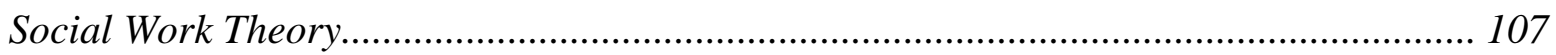

Social Work Practice ................................................................................................ 111

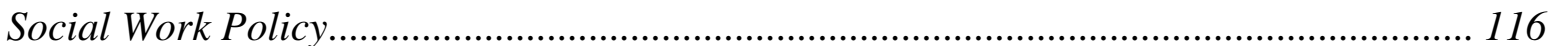

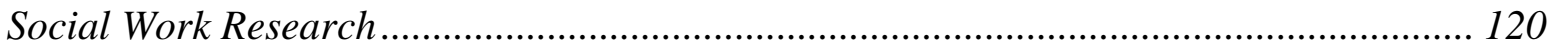

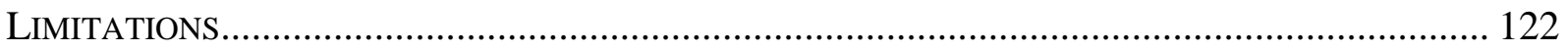

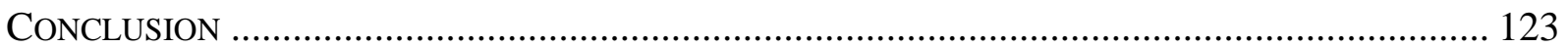




\section{List of Tables}

Table 3.1 Description of Dependent and Independent Variables .......................................... 48

Table 3.2 Powers for Specified Hazard Ratios in Three Cox Regression Models ...................... 57

Table 4.1 Descriptive Data for Each Type of Exit............................................................... 59

Table 4.2 Descriptive Data on Independent Variables for the Sample and By Outcome............ 63

Table 4.3 Cramer's V from Cross-Tabulations of Independent Variables ................................ 65

Table 4.4 Proportion of Exits to Reunification and Bivariate Survival Analysis ....................... 68

Table 4.5 Proportion of Exits to Guardianship and Bivariate Survival Analysis ...................... 71

Table 4.6 Proportion of Exits to Adoption and Bivariate Survival Analysis............................ 74

Table 4.7 Overall and Paired Comparisons of Permanency Exit Types................................... 76

Table 4.8 Likelihood-Ratio Chi-Square Statistics for Comparing Overall Model to Three

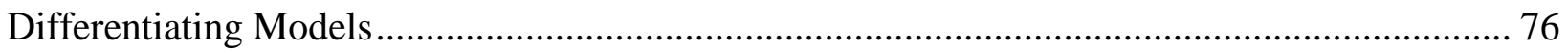

Table 4.9 Cox Regression Model for Exits to Reunification................................................ 82

Table 4.10 Cox Regression Model for Exits to Guardianship .............................................. 85

Table 4.11 Cox Regression Model for Exits to Adoption ...................................................... 89

Table 4.12 Hazard Ratios from Cox Regression Models of Reunification, Guardianship, and

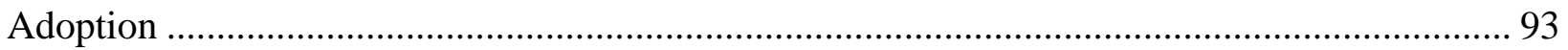

\section{List of Figures}

Figure 4.1 Permanency Status of SFY2006 Entry Cohort As of December 31, 2008............... 59

Figure 4.2 Smoothed Hazard Estimates for Reunification ................................................. 60

Figure 4.3 Smoothed Hazard Estimates for Guardianship..................................................... 60

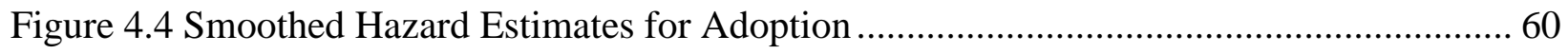

Figure 4.5 Time to Foster Care Exits to Permanency By Type Of Permanency ....................... 75 


\section{Chapter 1: Introduction and Overview}

Nearly 800,000 children spend time in foster care each year (U.S. Department of Health and Human Services Administration on Children Youth and Families, 2009b). Foster care is intended as an intervention of last resort that removes children from their biological parents when necessary to protect children's safety, health, and well-being. Foster care stays are supposed to be temporary and short-lived, lasting only until children can return to their own families or to an alternative family. An emphasis on the temporary nature of foster care is based in child welfare's fundamental assumption that children grow and function best in nurturing, stable, and lifelong families. Accordingly, child welfare policy asserts its primary purpose is to ensure children's safety, permanency, and well-being.

This study focuses on permanency outcomes for children in foster care. Permanency encapsulates the notions of stability and continuity of caregiving, which are seen as needs and rights of all children. In legal terms, the federal government designates permanency as exits from foster care to reunification with biological parents, custody of a relative, legal guardianship of non-relative or relative, or adoption to a family (U.S. Department of Health and Human Services Administration on Children Youth and Families, n.d.). Despite intentions for foster care to be temporary as well as an explicit policy objective for permanency, many children experience lengthy stays in foster care and do not exit to permanent living arrangements. About one half of children who enter foster care will exit within a year; however, states' median duration of foster care stays ranges from about 3 months to 28 months (Wulczyn, Chen, \& Hislop, 2007). An examination of children's current case plan goals further indicates a less-thanpromising outlook for permanency. Fifteen percent of the 510,000 children in foster care on September 30, 2006 had a non-permanent goal (i.e., long-term foster care or emancipation) (U.S. 
Department of Health and Human Services Administration on Children Youth and Families, 2008). Each year tens of thousands of youth exit foster care without a permanent living arrangement.

This study sought to identify the factors that support and inhibit children leaving foster care to a permanent home. The current chapter provides background and context for understanding the problem, including a review of history and policy as well as a theoretical framework for permanency. The second chapter reviews the empirical literature on foster care exits, identifies gaps in this literature, outlines the study's research questions, and presents a brief rationale for the study. The third chapter explains the study's methods. The fourth chapter presents the study's results. Finally, the fifth chapter discusses major findings and their implications for social work practice, policy, and theory.

\section{Background and Context of Permanency in Foster Care}

\section{Definition of Foster Care}

The federal Children's Bureau legally defines foster care for the purpose of annual reporting in the Adoption and Foster Care Analysis Review (AFCARS) as those children who have been removed from home for at least 24 hours where the child welfare agency has care and placement responsibility (45 CFR $\S 1355.40,1993)$. Foster care is also known as out-of-home care, out-ofhome placement, and substitute care. While "foster care" is sometimes used to refer to a particular type of placement setting (i.e., regular foster care versus relative foster care or treatment foster care), for this study "foster care" refers to children living in any type of out-ofhome care setting in the legal custody of the state child welfare agency. The settings that children reside in while in foster care are generically called "placement settings," and include family settings, such as family foster care and relative or kinship foster care, and non-family 
settings, such as residential treatment, group homes, and other congregate care settings. According to the January 2008 AFCARS report, the most common placement settings are family foster care at $46 \%$, followed by relative or kinship foster care at $24 \%$, and congregate care settings at $17 \%$ (U.S. Department of Health and Human Services Administration on Children Youth and Families, 2008). Thus, the majority of children in foster care reside in a family setting.

\section{Historical and Policy Background of Foster Care and Permanency}

Permanency is a relatively young concept in child welfare. Many scholars attribute Maas and Engler's 1959 study as a key historical marker because these scholars named the problem of "foster care drift" and drew significant attention the need for permanency. Another influential development was the Oregon Project in the early 1970s. This program was a federal waiver demonstration that showed permanency could be achieved even with children who had experienced long stays in foster care. Both of these activities were critical events that set the stage for a permanency planning movement. Still, the origins of permanency can be traced to earlier ideologies and influences in child welfare history. A historical review is outlined below to identify key historical markers and policies that trace the roots and foundations of permanency in the U.S. child welfare system.

During the American Colonial period, parents' rights took precedence over children, who were primarily viewed in economic terms. Society's response to dependent children was to indenture them through an apprenticeship with other families, which was used extensively (Jimenez, 1990; Kadushin \& Martin, 1988). This system was useful for both economic and social control purposes, and was thought to be a good method of disciplining children (Trattner, 1999). Kadushin and Martin (1988) point out that indenture, despite it permitting all sorts of 
abuses and exploitations, did provide many children with family life. Thus, indenture can be seen as an early form of foster care that established continuity of caregiving for children in families other than birth families.

The decline of indenture is attributed to multiple factors. Indenture had previously been used by all classes; then, a new urban middle class emerged with novel ways of thinking about childhood. Children were now considered vulnerable and in need of protection and nurture (Marten, 2004). By the early 1800s this new approach to children shifted indenture to use only for children from low-income families (Hacsi, 1995). Another important event was the passage of the Thirteenth Amendment in 1867, which abolished slavery and seriously challenged the practice of the indenture system (Kadushin \& Martin, 1988). Other factors that limited indenture and led to alternative approaches to the care of dependent children were the continued expansion of industrialization, the influx of immigrants, a surge in urban poverty, and the cholera epidemic of 1832 . Between 1830 and 1860 , society's primary response to dependent children shifted to institutionalizing them in orphan asylums. Yet, by the 1880s these institutions became costly and criticisms of orphanages grew (Hacsi; Kadushin \& Martin).

Events of the mid to late 1800 s mark a key milestone in the history of foster care. During the latter part of the 1800s the redefinition of childhood and the discovery of child abuse swung the pendulum toward child-saving. The Reverend Charles Loring Brace, who strongly opposed the use of institutions, formed the first Children's Aid Society in New York in 1853 and began the nation's first children's organization to use a form of foster care (Pecora, Whittaker, Maluccio, \& Barth, 2000; Trattner, 1999). Placing-out children to foster care-like homes emerged as a new approach for addressing dependent children. Brace claimed that urban areas were the source of the problem and promoted the placing out of children to rural homes (Cook, 1995; Hacsi, 1995). 
Between the 1850 s and 1920s the orphan trains moved as many as 150,000 children from city streets to farming communities in the West and South (Marten, 2004; Pecora, et al.).

By the late 1800s, placing-out became boarding-out, which was the practice of agencies paying adults who took in other people's children. While placing-out was a largely permanent living situation for children, boarding-out was conceived as temporary. Boarding-out was first promoted by Charles Birtwell, the leader of the Boston Children's Aid's Society from 1886 to 1911 (Kadushin \& Martin, 1988). Birtwell conceptualized foster care as a temporary arrangement that was used until the child could be reunited with his or her parents (Antler \& Antler, 1979). This approach to foster care remains central to modern foster care practice and policy.

The Progressive Era is noted as the next major milestone in the history of foster care and also points to the origins of permanency as a dominant theme in current child welfare. This era is distinguished by a rise in debates on the relative merits of institutions or families, the appropriate role of government, and whether children should be taken from destitute parents (Pecora, Whittaker \& Maluccio, 2000). Along with a variety of other children's issues, the Progressives' agenda included a more family-based approach to the care of dependent children. In contrast to the placing-out movement, Progressives advocated for children being raised by their own families. For example, at the First White House Conference on Children in 1909 the Conferences' executive committee urged:

Home life is the highest and finest product of civilization...Children should not be deprived of it except for urgent and compelling reasons. Children...should as a rule be kept with their parents, such aid being given as may be necessary to maintain suitable homes for the rearing of children...(Bremner, 1971, p. 365)

If children could not be kept with their own families, then Progressives turned to familybased foster care as an alternative to institutional care, stating that "the carefully selected foster 
home is, for the normal child, the best substitute for the natural home" (Kadushin \& Martin, 1988, p. 351). Importantly, during the Progressive Era, foster care was conceived as a means of preserving family values, not as an intervention that opposed or diminished family (Jimenez, 1990).

Progressive-era child welfare reforms were institutionalized in two public and private national organizations. The federal Children's Bureau was established in 1912 and the Child Welfare League of America, a private nonprofit organization, was founded in 1920. Again, these organizations stressed the temporary nature of foster care rather than permanent institutional care as well as the importance of rehabilitating or preserving the natural family whenever possible (Antler \& Antler, 1979).

The $20^{\text {th }}$ century continued to see a gradual expansion of foster care. By the 1930s boardingout, that is paid family foster care, had become the clear preference over institutional care and unpaid placing-out (Hacsi, 1995). The government's role grew as was evidenced by several key events, including state and county involvement in child protection. The assumption of a more diffuse scope of government was solidified with the passage of the Social Security Act of 1935, which provided the first federal financial grants to states specifically for child protection services (Antler \& Antler, 1979).

During the latter half of the $20^{\text {th }}$ century, the child welfare dialogue was altered from foster care being the solution to foster care being the problem. Multiple factors contributed to this new crisis in foster care and a shift toward child-saving. First, a rediscovery of child abuse occurred in the late 1950s and early 1960s, mainly from medical researchers (e.g., Kempe, Silverman, Steele, Droegemuller, \& Silver, 1962). Attention to child abuse and new federal legislation led to an increase in reports of alleged child maltreatment and subsequent placement in foster care 
during the 1970s. In 1974, The Child Abuse Prevention and Treatment Act (CAPTA Public Law 93-247) became law. CAPTA required each state to adopt specific procedures to prevent, identify, and treat victims of child maltreatment. Subsequently, more children came to the attention of child protective agencies and more children were placed into foster care (Antler \& Antler, 1979; Jimenez, 1990).

The passage of CAPTA and the growth in foster care coincided with the social work profession identifying and examining the issue of foster care drift (Jimenez, 1990). Maas and Engler's 1959 study described children remaining in foster care with no plan for discharge, little contact with their parents, and severely lacking a sense of permanency or stability. While the study has been criticized for methodological limitations related to using a cross-sectional sample, which biases toward longer foster care stays, it was the first national study of children in foster care and was considered the definitive foster care study at the time (Waldfogel, 2000). Importantly, Maas and Engler described what became known as "foster care drift;" that is, children lingering in foster care with no plan to reunite with their birth family or to find another permanent option. Major policy and practice shifts developed, in large part, in response to this newly named problem of foster care drift.

Several other factors also contributed to the urgent call for changes in the child welfare system. Besides the rediscovery of child abuse, the civil rights movement was growing at this time and influenced the child advocacy movement. Additionally, the concept of caring for individuals in the "least restrictive environment" emerged during this period. Pecora and colleagues (2000) identify the Oregon Project as a landmark project in contributing to the promotion of permanency planning as a large-scale national movement. This project targeted 
children in long-term foster care and eventually demonstrated that systematic planning and intensive services could result in many children being reunified with their families of origin.

Ultimately, the Adoptions Assistance and Child Welfare Reform Act of 1980 (AACWA Public Law 96-272) was passed to address growing concerns about foster care. AACWA was aimed at realigning foster care with society's value of family and parental rights. The new law was designed to require states to make reasonable efforts at preventing removal of children from parents. If children had to be removed, the law specified that the state reunite them expeditiously. In sum, to be eligible for federal monies, states had to provide preventive services, make reasonable efforts to prevent removals, review cases every six months, and hold a dispositional hearing at 18 months. For children who could not be reunited, permanency was to be sought through adoption, guardianship, or long-term foster care (Gordon, 1999).

Although AACWA initially decreased the number of children in foster care, the 1990s saw the foster care census rise again. Curtis (1999) states that the reasons for the dramatic increases in foster care were multiple and included:

...how child welfare is funded by the federal government, population and poverty, the number of minorities in the child population, single-mother households, misuse of alcohol and other drugs, homelessness, and the ever increasing number of children reported as victims of child abuse and neglect. (p. 5)

The number of children in foster care may have initially decreased after the passage of AACWA, but that the needs of the children in foster care were troubling. This population of children in foster care included more older children, more children with physical disabilities, more children of color, and more children returning to foster care after leaving (Fein, Maluccio, \& Kluger, 1990). 
Criticism of AACWA and foster care grew along with the foster care rosters. Evidence of these concerns included media attention to horrific accounts of children reunified and then killed, stories of the plight of children waiting for years in foster care, and 21 class action law suits against states charged with having inadequate child welfare systems (Gendell, 2001). A central issue emerged: Should the focus of governmental intervention in cases of child protection be the rights of the parents or the safety and interests of the child?

In response to the growing foster care crisis, the Adoption and Safe Families Act of 1997 (ASFA, Public Law 105-89) amended AACWA and established in law that the national goals of child welfare were safety, permanency, and well-being (Murray, 2004). ASFA instituted three key changes to the AACWA. First, the law allows a waiver of reasonable efforts in certain situations in which child safety is at stake. Second, ASFA addresses foster care drift by establishing timeframes for child welfare agencies and courts in an effort to promote expedient permanency plans. Specifically, if a court determines that reasonable efforts are not required, then a permanency hearing is to be held within 30 days to make reasonable efforts at finding another permanent placement for the child. If a child has been in care for 15 of the last 22 months, then the child welfare agency must either file for termination of parental rights or document compelling reasons why it is not the best interest of the child to do so. Agencies are also expected to implement concurrent planning as a means to expedite the adoption process if attempts at reunification fail (Gordon, 1999). Third, ASFA implements several changes to promote adoption, including a new provision to authorize state use of adoption subsidies.

In addition to specific provisions related to permanency as stated above, ASFA is also noted for its attempts to create a system of accountability by requiring annual data reports and periodic reviews of state child welfare agencies on child and family outcomes, known as Child and 
Family Service Reviews, CFSRs. The purpose was to increase outcomes accountability not just for safety, but for permanency and well-being as well (Webb \& Harden, 2003).

\section{Problem Statement}

\section{Scope of the Problem: Lack of Permanency}

On any given day approximately 500,000 children are in foster care in the United States (U.S. Department of Health and Human Services Administration on Children Youth and Families, 2008). Although nearly three decades of child welfare policy have stressed preventing the removal of children from their families and reducing the length of time children spend in foster care, many children continue to experience extended foster care stays. A recent federal report showed that among children in foster care on September 30, 2007, the average length of stay for this point-in-time cohort was 28 months. About one quarter of these children had been in foster care for three or more years (U.S. Department of Health and Human Services Administration on Children Youth and Families, 2009a). Another national report by the Chapin Hall Center for Children indicated that among first-time entry cohorts of 2000 to 2005, one half of all children exited care within 12 months. However, one quarter of these children were still in care as of December 31, 2005 (Wulczyn, et al., 2007).

One component of permanency is related to the duration and timing of foster care exits. Another component is related to whether the foster care exit is to a permanent, family-like situation. Although family reunification accounts for the highest proportion of foster care exits (54.5\%), many children still discharge from foster care for non-permanent reasons. The Chapin Hall report showed that $61 \%$ of the 2000 to 2005 entry cohorts exited to permanency, while $25 \%$ remained in foster care and nearly $15 \%$ exited foster care by aging-out, running away, or by some other non-permanent path (Wulczyn, et al., 2007). Federal reports indicate that every year 
about 40,000 children and youth leave foster care with no legal permanent living arrangement (U.S. Department of Health and Human Services Administration on Children Youth and Families, 2009a).

Recent analyses of AFCARS data have demonstrated that dramatic variations in foster care dynamics exist among states. For example, the shortest median duration was less than 5 months for entry cohorts in one state; the longest median duration was over 27 months for entry cohorts in another state (Wulczyn, et al., 2007). Furthermore, differences in duration and exit types were attributed to age, race, type of first placement, locality/urbanicity, and state policy differences (Wulczyn, et al., 2007). The fact that duration and exit types differ by subgroups of children and that these differences vary by state lends itself to efforts aimed at identifying which factors are at play in specific states.

\section{Consequences of a Lack of Permanency}

Permanency is important because the failure to experience it is associated with a wide range of negative consequences. From the child's perspective, entering foster care means experiencing losses and disruptions in caregivers, school, peer relationships, neighborhood, healthcare providers, and belongings. Being removed from one's own home and into foster care where one may experience moves from place to place has been described as bewildering, unsettling, and dehumanizing (Ellerman, 2007; Festinger, 1983; Whiting \& Lee, 2003). Placement instability in foster care has been correlated with declining developmental trajectories, significant emotional and behavioral problems, increased mental health costs, educational challenges, and juvenile delinquency (Fanshel \& Shinn, 1978; Pecora et al., 2006; Newton, Litrownik \& Landsverk, 2000; Pardeck, 1984; Rutter, 2000; Wulczyn, Kogan \& Harden, 2003). Likewise, lengthy foster care stays have been correlated with higher risk for reentry to foster 
care, increased emotional and behavioral problems, poor academic performance, and higher foster care costs (Courtney, 1994; Newton, Litrownik, \& Landsverk, 2000; Usher, Randolph, \& Gogan, 1999; Wells \& Guo, 1999; Zima et al., 2000). As compared to the general population, foster alumni are at higher risk of poverty, homelessness (Park, Metraux, \& Culhane, 2005), substance abuse, unemployment (Massinga \& Pecora, 2004; McDonald, Allen, Westerfelt, \& Piliavin, 1996), health problems, mental health issues, criminal activity, and financial difficulties (Courtney et al., 2007).

The bottom line is that many children spend a substantial part of their childhood being raised in foster care, a system designed to be temporary, which often fails to provide children with the continuity and stability they need. The urgency of this problem is further illustrated by understanding the dynamics of foster care stays. For example, the longer children stay in foster care, the less likely they are to leave (Wulczyn, et al., 2007). Also, the longer children stay in foster care, the more likely they are to experience multiple placement changes (Webster, Barth, \& Needell, 2000), and multiple placement changes have been shown to be associated with several negative consequences as outlined above. The prevalence of lengthy foster care stays and the seriousness of the consequences indicate a need to better understand what impedes and facilitates permanency.

\section{Key Trends and Issues in Foster Care}

In order to understand the challenges of achieving permanency, it is useful to understand the current issues affecting children in foster care and their families. Recent decades have witnessed changing foster care demographics and growing needs of children that place increasing demands on the foster care system. This section describes some of the major factors impacting foster care 
as important background information for understanding permanency in the current child welfare context.

\section{Demographics Trends and Service Needs}

Age. In relation to age, the two groups of children that are frequently mentioned as facing unique challenges in foster care are very young children and adolescents (Bass, Shields, \& Behrman, 2004). The proportion of infants in the foster care population increased significantly in the 1980s and 1990s. Currently, infants are the largest group of children entering foster care, constituting about $20 \%$ of all foster care entries from 0 to 17 year olds, from 2000 to 2005. They have the highest entry rate of all age groups with an average of 8.9 per 1,000 per year from 2000 to 2005 as compared to an average of 2.6 per 1,000 children for all age groups for the same time period (Wulczyn, et al., 2007). Macluccio, Fein, and Olmstead (1986) identified infants as a group of children at high-risk of foster care drift and impermanence, stating that early and intense permanency planning efforts are urgent for infants because of the fact that a few months in an infant's life can shift them into a "hard to place" category.

On the other end of the age spectrum are adolescents, who may also experience unique challenges and needs in terms of exiting foster care and achieving permanency. On September 30,2006 , approximately $27 \%$ of children in foster care were 11 to 15 years old, and another $21 \%$ were 16 or older (U.S. Department of Health and Human Services Administration on Children Youth and Families, 2008). Older children are more likely to experience more extensive disruptions in living situations and schools than younger children, and face different concerns about preparing to age out of foster care and establishing a viable relationship with their birth families (Massinga \& Pecora, 2004). Thus, the focus on this group of youth is how to assist them in an effective transition out of foster care so that they leave with a solid foundation to 
move successfully into their future with connections to their birth families and other significant relationships.

Race, ethnicity, and disproportionality. Historically, children of color have been overrepresented in the foster care population, particularly African American children. The recent Chapin Hall report shows a slight decline from 2000 to 2005 in the proportion of African American children in foster care. The proportion of Latino children has remained mostly stable at $8 \%$ to $10 \%$, while the proportion of White children has increased from $45 \%$ to $50 \%$ during the years 2000 to 2005 (Wulczyn, et al., 2007).

Despite the recent decline in the proportion of African American children in foster care, concerns about disproportionality ${ }^{1}$ are still warranted. In a review of current literature on disproportionality in child welfare, Hill (2006) concluded that:

...[M]ost studies on the scope and nature of disproportionality...show that Black or African American children are more likely to be reported, investigated, substantiated, and placed in care, and that they stay longer in care and are less likely to be reunified with their families. (p. 17)

The issues related to disproportionality extend to service disparities for children of color (Barbell \& Freundlich, 2001; Hill, 2006). For example, fewer African American children receive mental health services than White children even when controlling for need (Burns et al., 2004; Leslie et al., 2005). Hill's 2006 report further states:

There is widespread agreement that, compared to white children and families in the child welfare system, children of color and their families have less access to services and their outcomes are poorer. This is especially true for children of color living with relatives. (p. 5)

Health status. Children and youth in foster care experience medical, developmental, and mental health needs that surpass those of other children, even peers of similar age,

\footnotetext{
${ }^{1}$ Disproportionality means that the proportion of a particular group of children in foster care (or the larger child welfare system) is not equal to the proportion of this group of children occurring in the general child population.
} 
socioeconomic status, and maltreatment background (Rosenfeld et al., 1997). In testimony to Congress in May 2008 a physician representing the American Academy of Pediatrics provided the following statement:

Compared with children from the same socioeconomic background, children in foster care have much higher rates of birth defects, chronic physical disabilities, developmental delays, serious emotional and behavioral problems, and poor school achievement. In fact, nearly half of all children in foster care have chronic medical problems, about half of children ages $0-5$ years in foster care have developmental delays, and up to $80 \%$ of all children in foster care have serious emotional problems. (Utilization of psychotropic medication for children in foster care, 2008, p. 1)

In addition to documenting significant health, developmental, and mental health needs among children in foster care, researchers have also described the foster care system itself as possibly worsening their problems. One study identified a relationship between the number of placements children experienced and the level of hostility they displayed (Fanshel, Finch, \& Grundy, 1989). Multiple other studies on placement instability have documented its negative effects, including harming children's continuity of care with health and mental health providers and worsening behavioral and emotional problems (Brown \& Bednar, 2006; Geenen \& Powers, 2007; McMillen et al., 2004; Raghavan, Inkelas, Franke, \& Halfon, 2007; D. M. Rubin, O'Reilly, Luan, \& Localio, 2007).

Educational issues. Children in foster care face substantial educational challenges, but whether this is associated with out-of-home placement or poverty is unclear (Stone, 2007). In a fifteen year review of foster care and academic vulnerability, Stone (2007) found that $30 \%$ to $60 \%$ of foster youth complete high school diplomas. Although youth with a history of foster care are less likely than the general population to attain a high school diploma, their rates are comparable to those living below the poverty level (Stone, 2007). This article also noted that 
placement changes and movement in and out of the foster care system have been identified as impacting children's educational progress.

Environmental and parental issues. A range of complex environmental and parental issues impact children in foster care and the systems that serve them. First and foremost, poverty is a prevalent and significant issue for the foster care population. Low family income is the largest risk factor for entry into the foster care system (Chipungu \& Bent-Goodley, 2004; Jonson-Reid, Drake, \& Kohl, 2009; Lindsey, 1991). Other key environmental and parental issues include homelessness, parental substance abuse, adolescent parenthood and single parent families, parental mental illness, domestic violence, HIV/AIDS, and a growing incarceration rate (Barbell \& Freundlich, 2001; Chipungu \& Bent-Goodley, 2004; Curtis, 1999). Not only are many of these factors precursors to a child's placement in foster care, they are complicating factors for achieving permanency. In addition, as pointed out by Chipungu and Bent-Goodley (2004), many of these challenges "coexist and interact, presenting a complex family dynamic and a complicated set of service needs" (p. 79). Hindering factors include the need for concrete resources such as affordable housing, living wage employment, and affordable health care. Thus, reunification is frequently contingent upon changes to improve significant, complicated, and multifaceted problems in fragile families and a fragmented service delivery system (Chipungu \& Bent-Goodley, 2004).

\section{Practice Trends in Foster Care}

Numerous practice changes have occurred in foster care since the passage of ASFA. Many reforms reflect efforts to improve outcomes for children and families. Indeed, foster care, and child welfare in general, has entered an era of heightened accountability. Noteworthy practice reforms include the increased reliance on kin, the use of concurrent planning, the expansion of 
permanency options, the increase in family-centered models such as family group decisionmaking, the growth in specialized foster care placements, the development of court reforms to promote timely and effective decision making, and revitalized efforts to improve the child welfare workforce. As a whole, these reform efforts demonstrate the dynamic nature and ongoing evolution of foster care policy and practice.

\section{Theoretical Framework for Understanding Permanency}

This study's theoretical framework is presented below, consisting of two major strands. The first strand frames child welfare policy and practice around the contrasting principles of primordial solidarities and bureaucratic institutions. The second strand illustrates the bioecological perspective as it relates to understanding permanency outcomes in child welfare.

\section{Primordial Solidarities and Bureaucratic Institutions}

The social organization and structure of public child welfare is anchored between two contrasting principles: primordial solidarities and bureaucratic institutions (Testa, 2008a; Testa \& Poertner, 2010). The primordial solidarities principle emphasizes that family, kin, community, and tribe should be critical considerations when making decisions about the care of children in foster care. Two examples of child welfare policy that reflect this perspective is the Indian Child Welfare Act of 1978 (ICWA) and policy that promotes the use of kinship care. The second contrasting principle, bureaucratic institutions, holds that the care of children should not be based upon ascribed status or heritage but should consider the best means for advancing a child's well-being. This principle is observed in the Multiethnic Placement Act of 1994 which disallows the use of race, color, or national origin to delay or deny children's placement in racially or ethnically diverse foster and adoptive homes. 
Another dimension of this framework incorporates social capital theory, which posits social relations are a resource that contribute to individual's growth and development (Fram \& Altshuler, 2009; Testa, 2008a). An important distinction can be made about two types of social capital which are relevant to the foster care context. Bonding social capital is drawn from the social ties of like groups, such as family and kin, and is hypothesized to generate "better expressive outcomes, such as emotional security, group solidarity, and psychological belongingness, than does bridging social capital" (Testa, 2008a, p. 119). Conversely, bridging social capital is drawn from social networks between unlike groups and is hypothesized to have advantages for societies, governments, individuals, and communities (Fram \& Altshuler, 2009). Bridging social capital is thought to "promote better instrumental outcomes, such as educational opportunities, job references, and social contacts that facilitate social advancement, than does bonding social capital” (Testa, 2008a, p. 119). Testa and Poertner (2010) extend social capital theory to their analytical framework and apply it to the child welfare setting. When families do not meet minimum standards of care and protection from harm, the state's first response is to attempt to resolve the issues, support the family, and keep children with parents, siblings, neighbors, and friends. These efforts prioritize the primordial solidarities and try to enliven bonding social capital in children's favor. If attempts at family preservation fail, the principle of bureaucratic solidarities is drawn upon and the state uses bureaucratic institutions - foster homes, group homes, or other residential care - to provide children with stability. The latter approach to policy and practice interventions relies upon bridging social capital (Testa and Poertner, 2010).

Recent child welfare policy reforms further demonstrate the ongoing tensions between primordial solidarities and bureaucratic institutions. ASFA is an example of child welfare policy that is largely embedded in the principles of bureaucratic institutions, but with some countering 
influence of primordial solidarities. For instance, ASFA instructs states to begin legal procedures for terminating parental rights for any child who has been in foster care for the last 15 of 22 months. ASFA's timelines articulate an approach in which governmental intervention overrides the role of family, kin, and community. On the other hand, principles of primordial solidarities are also interwoven into ASFA. The policy suggests a hierarchy of permanency with reunification as the first priority, followed by adoption, and then legal guardianship. While ASFA did not provide for subsidized legal guardianship, its recognition of legal guardianship as a legitimate permanency option was the first time Congress defined it in statute (Testa, 2008a). Another recent law, Fostering Connections to Success and Improving Adoptions Act of 2008, (Public Law 110-351) clearly embodies the principles of primordial solidarities in a variety of provisions, most notably its provisions for subsidized relative guardianship which legitimize extended family as a permanency option. At the same time, the principles of bureaucratic institutions can also be observed in the Fostering Connections law. Its provisions for "educational stability" and "health oversight and coordination plan" draw upon bureaucratic institutions to address child well-being.

These examples of child welfare law show that the tensions between primordial solidarities and bureaucratic institutions are longstanding and ongoing, but that neither principle can singularly represent the diversity of values in child welfare (Testa \& Poertner, 2010). The complexity of problems and challenges faced by the child welfare system also run counter to any approach that "polarizes the principles of primordial solidarities and bureaucratic institutions" (Testa and Poertner, 2010, p. 51). Hence, attempts to address lengthy foster care and to promote permanency outcomes should consider these two principles and how best to keep them balanced and well-coordinated. 


\section{Bio-ecological perspective}

The second major strand of this study's theoretical framework is drawn from the bioecological perspective. Although social capital theory and the principles of primordial solidarities and bureaucratic institutions explain the larger systems and structures of child welfare, the bio-ecological perspective is needed to address the individual, family, and community levels. The bio-ecological perspective is a theory of human development that has been well-established as compatible and useful for understanding child welfare outcomes (Mallon \& Hess, 2005; Pecora, 2006; Wulczyn, Barth, Yuan, Harden, \& Landsverk, 2005). It is also known as the life course approach and is often attributed to developmental psychologist, Urie Bronfenbrenner (1979). The bio-ecological perspective posits that child development is explained by the complex interactions between a child and his or her environment (Bronfenbrenner, 1979). The environment is viewed with the child at the center of nested concentric, or interconnected, systems with each influencing the person and one another. The systems include the microsystem, the mesosystem, the exosystem, and the macrosystem. The microsystem consists of the people and settings most immediate to and directly experienced by the child, such as self, family, and friends. The mesosystem is comprised of the interrelationships between people and settings of the microsystem. An example of the mesosystem is the relationships between parents and school personnel or between parents and a caseworker. The exosystem influences the child but does not interact directly with the child. It includes external events and activities that affect the child's environment, such as availability of a continuum of social services in a community. Finally, the macrosystem includes the policies, history, cultural ideologies, and other institutional patterns that shape the other subsystems. Societal beliefs about poverty, work, and parental rights are examples of macrosystem 
influences. Thus, the bio-ecological perspective premises that child outcomes are influenced by multiple characteristics of the individual as well as family, social, cultural, and political factors that interact with the child and one another (Tilbury \& Osmond, 2006). Children's attainment of permanency outcomes, then, will be influenced by the individual child, such as his or her developmental stage, as well as family relationships and cultural norms. Importantly, permanency will also be influenced by larger community and environmental factors such as quality of neighborhoods, communities, and social policies (Wulczyn, et al., 2005).

\section{Summary}

Foster care is designed to be a temporary intervention for children when their parents are unable to provide for their care. One of the primary intended outcomes of foster care is permanency. Despite a strong foundation in foster care history and policy reforms, permanency is an outcome that many children in foster care do not attain, putting them at high-risk for serious consequences. Due to the centrality of permanency as a child welfare outcome, this study seeks to better understand the factors that may contribute to permanency. The next chapter turns to the empirical literature to establish the current knowledge base on foster care exits to permanency, to identify possible gaps in the literature, and define this study's research questions. 


\section{Chapter 2: Literature Review}

This chapter synthesizes information from a review of the empirical literature on foster care exits. The first section discusses permanency as an outcome or dependent variable. This is followed by a review of four categories of independent variables relevant to foster care exits. Finally, the chapter concludes with a summary of the gaps in the literature, a rationale for the proposed study of foster care exits to permanency, and the study's research questions.

\section{Dependent Variables: Foster Care Exits to Permanency}

Permanency, as one of the primary desired outcomes of foster care, is the concept underlying the dependent variables of interest to this study. Permanency was defined here as legal permanence, which refers to exiting foster care to reunification with biological parents, adoption, relative custody, or legal guardianship (U.S. Department of Health and Human Services Administration on Children Youth and Families, n.d.). Examples of exits from foster care that were not considered permanency outcomes include running away, aging out, and transferring to another state agency such as the juvenile justice authority or a psychiatric hospital.

The literature review shows that permanency was frequently defined in a manner consistent with legal permanency, though the measurement of these outcomes was more variable. Appendix A presents a table that summarizes key methodological information on each of the reviewed studies, including a description of the dependent variable(s) used by each study. This table shows that most studies specified their outcome of interest in one of two ways. The first approach was to focus on a single outcome, which was most frequently reunification or, less frequently, adoption. The second approach was to examine two or more of the permanence outcomes simultaneously. For example, a study may have identified factors associated with 
foster care exits to reunification and factors associated with foster care exits to adoption. Results then were provided for each type of exit. In contrast, a number of studies defined the dependent variable as any exit or any exit to permanency, with varying definitions of permanency. These latter studies did not present findings by type of exit; thus, they were limited in the specificity of information on factors that contributed to the permanent outcomes of reunification, adoption, relative custody, or guardianship.

While studies that differentiated types of exit have an advantage over studies that grouped different types of exit, direct comparisons were still constrained by varied definitions of the dependent variables. For example, some researchers combined termination of parental rights and adoption while others did not.

Guardianship, in particular, was handled in contrasting ways. Among these studies, guardianship was defined as a single type of exit, or it was combined with reunification, adoption, and even with exits that were not considered under the definition of legal permanence (e.g., running away). This definitional ambivalence may reflect changing views and a growing acceptance of guardianship as well as discrepancies in state policy. Nonetheless, if pathways through foster care were unique to a type of exit, then grouping guardianship or grouping other dissimilar exit types could present a major study limitation.

\section{Independent Variables: Predictors of Foster Care Exits to Permanency}

This review looked across studies to identify the range of independent variables used in the empirical literature, as well as common and inconsistent findings across studies. In addition, the review sought to understand the methodological issues that exist for researching foster care exits to permanency. Overall, the independent variables identified across the studies were categorized as characteristics of the child, parent or family, placement episode, and agency/caseworker. 
Findings from the literature are summarized below for each of these independent variable categories.

\section{Child Characteristics}

Nearly all studies of foster care exit included children's demographic characteristics. Age, race/ethnicity, and child health/mental health were three of the most consistently studied and statistically significant variables with respect to exits to permanency.

Age. Age was often found to be a significant predictor of foster care exits. Specifically, most studies found that older children were less likely to exit to any type of permanency; while infants were less likely to be reunified than older children, but more likely to be adopted (Barth, 1997; Becker, Jordan, \& Larsen, 2007; Connell, Katz, Saunders, \& Tebes, 2006; Courtney, 1994; Courtney, et al., 2007; Courtney \& Wong, 1996; Goerge, 1990; Harris \& Courtney, 2003; Koh \& Testa, 2008; McDonald, Poertner, \& Jennings, 2007; Park \& Ryan, 2009; Romney, Litrownik, Newton, \& Lau, 2005; Rosenberg \& Robinson, 2004; Smith, 2003; Snowden, Leon, \& Sieracki, 2008; Vogel, 1999; Wells \& Guo, 1999; Yampolskaya, Armstrong, \& Vargo, 2007;

Yampolskaya, Kershaw, \& Banks, 2006). Some studies, however, did not find a significant relationship between age and foster care exits (Benedict \& White, 1991; Davis, Landsverk, Newton, \& Ganger, 1996; Glisson, Bailey, \& Post, 2000; McMurtry \& Lie, 1992; PabustanClaar, 2007; Potter \& Klein-Rothschild, 2002).

While findings across multiple studies indicated a few contradictory findings on the relationship of age and foster care exits, the most frequent finding was that age has a strong relationship with the pace of exits from foster care. Among 25 studies that included age as an independent variable, 19 of them found it was statistically significant. Furthermore, age operated differently depending on the specific path on which a child exited. Some researchers concluded 
that age was one of the most important predictors of foster care exits. Two examples are provided below.

Courtney and Wong (1996) used event history analysis (aka, survival analysis) to compare the timing of exits from foster care for a randomly selected entry cohort of 8,625 California children in foster care for the first time. The children in the sample were restricted to those between the ages of 0 to 16 at the time of entry. This longitudinal study assessed whether children exited to family (i.e., reunification or guardianship), adoption, or running away. The observation period was a minimum of four and one-half years after entry to foster care.

Courtney and Wong (1996) concluded that age had the greatest overall impact on all three types of exit they studied. Infants were less likely than older children to be discharged to family or guardian. Children who were four- to six-years old had the highest likelihood of reunification or guardianship. As for adoption, older children and youth were very unlikely to be adopted.

In another study, Snowden, Leon, Sieracki (2008) used national AFCARS data to examine foster care exits to adoption. They selected a random sample of 30,000 adopted children and 30,000 non-adopted children in 2003. They used a classification tree analysis approach known as Optimal Data Analysis. While their findings revealed complex relationships among several factors, age was found to be a robust predictor of adoption. Snowden and colleagues (2008) determined that children older than 11.7 years old were much less likely to exit foster care to adoption.

Race. Race and ethnicity were frequently cited as significant predictors of length of stay in foster care, with African American children having the lowest probability of foster care exit as compared to White and Latino children, and other children of color. More specifically, studies that examined exits to reunification almost always found that African American children were 
less likely to reunify than White and Latino children (Barth, 1997; Connell, et al., 2006;

Courtney, 1994; Courtney, Piliavin, \& Wright, 1997; Courtney \& Wong, 1996; Goerge, 1990;

Harris \& Courtney, 2003; McDonald, et al., 2007; McMurtry \& Lie, 1992; Romney, et al., 2005;

Rosenberg \& Robinson, 2004; Wells \& Guo, 1999), noting that some studies showed that the

effect size was very small (McDonald, et al., 2007). Only two studies that specified the exit type found an non-significant association between race and reunification (Davis, et al., 1996;

Landsverk, Davis, Ganger, Newton, \& Johnson, 1996). Among studies that observed exits to adoption, findings were also quite consistent. Race was shown as having a significant association with adoption (Barth, 1997; Courtney \& Wong, 1996; Kapp, McDonald, \& Diamond, 2001; Kemp \& Bodonyi, 2000; McDonald, et al., 2007; Smith, 2003; Snowden, et al., 2008). Two studies did not find this significant relationship between race and adoption (Connell, et al., 2006; McMurtry \& Lie, 1992).

Two studies that were specifically focused on the influence of race and ethnicity are noted for providing additional insight on this topic. Barth (1997) examined the role of age and race on exits to permanency with a California sample of 3,873 children who were under the age of 6 and had entered care in 1988. This sample was followed for six years. Barth concluded that race was a stronger predictor of reunification and adoption than age in this sample of young children. African American children were significantly less likely to be reunified or adopted as compared to White and Latino children. Thus, within a sample of young children race was clearly important to both reunification and adoption.

Harris and Courtney (2003) added to this line of research by examining the interaction of race, ethnicity, and family structure. They followed a cohort of 9,162 California children who entered foster care for the first time between 1992 and 1996. Like other studies, their findings 
revealed that African American children experienced the lowest rates of reunification; however, they found that the lowest rates of reunification were among African American children from single parent families.

Gender. Child's gender was not typically associated with foster care exits to permanency when other child or placement characteristics were included (Barth, 1997; Becker, et al., 2007; Benedict \& White, 1991; Connell, et al., 2006; Courtney, 1994; Courtney, et al., 1997; Courtney \& Wong, 1996; Davis, et al., 1996; Glisson, et al., 2000; Landsverk, et al., 1996; Leathers, 2005; McMurtry \& Lie, 1992; Pabustan-Claar, 2007; Park \& Ryan, 2009; Potter \& Klein-Rothschild, 2002; Romney, et al., 2005; Rosenberg \& Robinson, 2004; Wells \& Guo, 1999; Yampolskaya, et al., 2007; Yampolskaya, et al., 2006). However, there were a few exceptions to this general finding, most of which pointed to exits to permanency favoring girls (Harris \& Courtney, 2003; Kemp \& Bodonyi, 2000; Snowden, et al., 2008; Vogel, 1999). For example, Kemp and Bodonyi (2000) examined adoption rates in the state of Washington among a sample of 458 infants legally free for adoption. They found that female infants were more likely to be adopted than male infants while controlling for age and race. Harris and Courtney (2003) studied reunification exits among a California sample of 9,162 children, identifying girls as more likely to reunify than boys while controlling for a range of variables.

Health status. Health status was defined and measured in various ways among the reviewed studies. Health status encompassed cognitive disabilities, developmental disabilities, physical disabilities or other physical health problems, and/or emotional and behavioral problems. Despite the discrepancies in definition and measurement, health status was an independent variable that was frequently found to have an association with foster care exits. Among the 21 reviewed studies that included some form of health status as an independent variable, all of them 
found a statistically significant relationship with foster care exits. In general, health problems decreased the likelihood of timely exit from foster care (Becker, et al., 2007; Connell, et al., 2006; Courtney \& Wong, 1996; Glisson, et al., 2000; Koh \& Testa, 2008; Landsverk, et al., 1996; Park \& Ryan, 2009; Potter \& Klein-Rothschild, 2002; Romney, et al., 2005; Rosenberg \& Robinson, 2004; Wells \& Guo, 1999; Yampolskaya, et al., 2006). More specific findings on the type of health problems and type of exit were less clear and consistent.

The definition and measurement of health status may account for some of the discrepant findings. For example, several studies used disability status as recorded in state child welfare administrative databases to indicate the type of health problems children had. Some researchers used a dichotomous variable representing the presence or absence of any health problem(s) or disability, while others defined the variable with several subgroups that indicated type of disability (e.g., physical disability, emotional/behavioral problems, mental retardation, etc.). A few studies define child's health status by including diagnoses from Medicaid behavioral health claims (Becker, et al., 2007), history of inpatient treatment from Medicaid claims (Park \& Ryan, 2009), and assessments conducted by researchers (Landsverk, et al., 1996; Romney, et al., 2005). Among the studies using Medicaid claims and/or assessments, all of them found that mental health problems reduced the likelihood that children would exit from foster care.

A few other patterns can be identified about specific types of disabilities by reviewing findings of studies that defined disability with more specificity. Physical disabilities were found to slow reunification in two studies (McDonald, et al., 2007; Romney, et al., 2005), but were found as non-significant in one study (Landsverk, et al., 1996). As for the relationship with adoption, Snowden, Leon and Sieracki (2008) identified physical disabilities as predicting adoption exits. 
Developmental or cognitive disabilities were identified were associated with lower reunification rates in three studies (McDonald, et al., 2007; Romney, et al., 2005; Rosenberg \& Robinson, 2004), while one study showed developmental disabilities were not related to reunification exits (Landsverk, et al., 1996). Developmental disabilities were found to be associated with a decreased likelihood of adoption in two studies (McDonald, et al., 2007; Romney, et al., 2005).

Emotional and/or behavioral problems were found to predict lower rates of reunification (Connell, et al., 2006; Landsverk, et al., 1996; McDonald, et al., 2007; Romney, et al., 2005). McDonald and colleagues also identified emotionally disturbed children as less likely to exit through relative custody and relative guardianship. As for adoption, only one study found that emotional and/or behavioral problems were associated with lower rates of adoption (Snowden, et al., 2008).

\section{Parent/Family Characteristics}

Various parent and family characteristics were studied, but with much less frequency than child characteristics. About one half of the reviewed studies included parent or family characteristics. This lack of attention to parent variables is likely a reflection of the lack of parent related data captured by state administrative child welfare information systems. Some researchers have used available data as proxies for parent characteristics, while only a few researchers have engaged in primary data collection efforts. Major findings related to four categories of parent variables are summarized below.

Parental visits. Parental visits were usually associated with a higher likelihood of foster care exit (Benedict \& White, 1991; Leathers, 2005; McMurtry \& Lie, 1992). Potter and KleinRothschild's (2002) study was the only other study that included parental visitation, and while 
they identified parent visits as important at the bivariate level, visits were not significant in their final multivariate model.

Family structure. Among the parent and family characteristic variables, family structure was the most frequently included characteristic in the reviewed studies, included in 14 studies. Several studies showed that children from single parent families took longer to exit foster care to reunification when compared to children from two-parent families (Courtney, 1994; Courtney, et al., 1997; Davis, et al., 1996; Harris \& Courtney, 2003; Landsverk, et al., 1996; McDonald, et al., 2007; Wells \& Guo, 1999). One study did not find a significant association between family structure and reunification (Courtney \& Wong, 1996). Three studies included family structure, but did not specify type of exit. Of these three studies, one found children from single parent families were less likely to exit foster care (Glisson, et al., 2000), while the other two studies did not find a significant association between family structure and exit to permanency (Yampolskaya, et al., 2007; Yampolskaya, et al., 2006).

Harris and Courtney's (2003) study was noted for an in-depth examination of family structure. As described under the topic of child's race, Harris and Courtney looked closely at the relationships among race, ethnicity, and family structure. Like other studies cited above, they found that single parent families were less likely to reunify than two parent families. More specifically, children in African American single parent families experienced the lowest rates of reunification. Children from Caucasian and Latino single-parent families were less likely to go home than those in two-parent families, but more likely than children from single-parent African American families. Hence, Harris and Courtney concluded that the interaction between race and family structure was important to understanding foster care exits to reunification. 
Family poverty. Family poverty was included as an independent variable in less than one third of the reviewed studies. It was typically measured by using eligibility for public cash assistance as a proxy for family poverty. The findings were mixed. Two studies found that children from families receiving public cash assistance experienced lower rates of reunification or adoption (Courtney, 1994; Courtney \& Wong, 1996). One study identified family poverty as having a significant relationship only for children initially placed with relatives, but not for children initially placed in non-kin foster care (Courtney, et al., 1997). Two studies, neither of which specified the type of exit, found that family poverty was not significant in models that included multiple other independent variables (Becker, et al., 2007; Glisson, et al., 2000).

Parental mental health and substance abuse. Parental substance abuse was included in only six of the reviewed studies. Two studies found that children who entered foster care for reasons of parental substance abuse were less likely to exit to reunification (McDonald, et al., 2007; Rosenberg \& Robinson, 2004). McDonald and colleagues also found that children that entered foster care for reasons of parental substance abuse were more likely to exit to relative guardianship. As for adoption, Snowden, Leon, and Sieracki (2008) found that parental substance abuse was associated with a decreased likelihood of adoption. Three studies' findings indicated that parental mental health and substance abuse problems were not significant in models that included multiple other variables; however, none of these three studies specified type of exit (Benedict \& White, 1991; Glisson, et al., 2000; Potter \& Klein-Rothschild, 2002).

\section{Placement Episode Characteristics}

Expansion of child welfare information systems has improved data availability and assisted with information on placement episodes (Rosenberg \& Robinson, 2004; Vogel, 1999). Six 
categories of placement episode characteristics were reviewed below for their association with foster care exit.

Reason for removal. Reason for removal was included in nearly two-thirds of the reviewed studies. Most of the time, reason for removal as a general category was found to have a significant association with foster care exits. However, findings on the specific reason for removal, the direction of the relationships, and the type of exit were inconsistent, contradictory, and difficult to interpret. For example, neglect has been shown as associated with lower reunification rates (Connell, et al., 2006; Wells \& Guo, 1999), higher reunification rates (Courtney \& Wong, 1996; Harris \& Courtney, 2003), and a higher probability of adoption (Connell, et al., 2006). Removal due to sexual abuse was found to increase the probability of reunification (Davis, et al., 1996), but to lower the probability of adoption (Connell, et al., 2006; McDonald, et al., 2007). One reason for inconsistent findings is that removal reason was defined in different ways. Federal AFCARS reporting allows up to 15 removal reasons. Researchers have grouped these 15 reasons in several different ways; hence, complicating comparisons across studies.

Prior removals. Most studies included only the first foster care episode; thus, excluding prior removal history as a variable. One reason prior removals were not included is related to an assumption of the statistical procedures that were frequently used to analyze these data. Nonetheless, studies have shown that having a history of foster care placements was associated with lower rates of reunification (Connell, et al., 2006; Goerge, 1990; McDonald, et al., 2007) and adoption (Smith, 2003; Snowden, et al., 2008). McDonald and colleagues also found that prior removals were associated with a decreased probability of exit to all types of permanent exits that they studied, showing the strongest effect with relative custody. 
Type of placement. Nearly one half of the reviewed studies included information on type of placement. Placement type was frequently defined as the type of initial placement, to include non-kin foster care, kinship foster care, group homes, and, sometimes, emergency shelters. In general, placement type was almost always found to have a significant association with foster care exits, (Connell, et al., 2006; Courtney \& Wong, 1996; Goerge, 1990; Harris \& Courtney, 2003; Park \& Ryan, 2009; Smith, 2003; Vogel, 1999; Wells \& Guo, 1999; Winokur, Crawford, Longobard, \& Valentine, 2008) though the specifics vary by type of exit and type of placement, and a few studies found contradictions (Courtney, et al., 1997; Koh \& Testa, 2008; PabustanClaar, 2007; Potter \& Klein-Rothschild, 2002). Specifically, initial placement in group home settings or emergency shelters lowered the likelihood of reunification (Connell, et al.; Courtney \& Wong; Park \& Ryan, 2009) and adoption (Connell, et al.).

One type of foster care placement that has received a good deal of attention was kinship care. Kinship care is foster care provided by relatives or persons with significant relationships with the child. Given the high interest in kinship care, it was the most extensively studied type of placement among the reviewed studies. Several studies have found that kinship care delayed reunification (Connell, et al., 2006; Courtney, 1994; Courtney \& Wong, 1996; Goerge, 1990; Harris \& Courtney, 2003; Wells \& Guo, 1999; Winokur, et al., 2008), but this was not always the case (Courtney, et al., 1997; Koh \& Testa, 2008). Others found kinship care did not delay exits to adoption and guardianship (Connell, et al.; Koh \& Testa; Winokur, et al.). Among the reviewed studies, two used matched comparison groups to examine the differences in foster care exits between children in kin and non-kin foster care placements (Koh \& Testa, 2008; Winokur, et al., 2008). Below, Koh and Testa's findings are highlighted because they used advanced 
statistical techniques for matching the samples and examining outcomes (i.e., propensity score matching and event history analysis).

Koh and Testa (2008) used Illinois AFCARS data to follow an entry cohort of 3,000 children for at least three years. Using propensity score matching, 1,500 children in kin and 1,500 children in nonkin placements were matched on child's age, gender, race, disability status, reason for removal, primary foster caregiver's race, the locality of services, and year of entry. Koh and Testa demonstrated that the unmatched sample and the matched sample resulted in different findings. When the analysis was based on the matched sample, differences on exits to permanency found in previous studies diminished. Children in kin and nonkin placements were just as likely to experience reunification and adoption or guardianship. For example, at the end of the three years follow up, $28.2 \%$ of children in kinship foster homes and $26.8 \%$ of children in nonkin foster homes were reunified. Similar findings were found for the outcome of adoption or guardianship. In sum, Koh and Testa's study was important because it challenged prior findings that kinship care delays legal permanence by showing that neither reunification nor adoption/guardianship were significantly postponed by kinship care.

Sibling placements. The role of sibling placements were seldom included in studies of foster care exits, although it has been cited as an important topic (Wulczyn \& Zimmerman, 2005). Among the reviewed studies that included sibling placements, the findings were mixed, partly due to differences in definitions of dependent and independent variables. One study, which defined the dependent variable as any exit from foster care, found that having a sibling in a foster care lowered the likelihood of any foster care exit (i.e., not necessarily exits to permanency)(Glisson, et al., 2000). Two studies that defined the dependent variable as any permanent exit from foster care had conflicting results. Park and Ryan (2009) found that having 
a sibling in a foster care placement improved a child's chance of exiting to permanency, while Potter and Klein-Rothschild (200) did not find a significant relationship for siblings. With reunification as the dependent variable, three studies did not find a relationship with sibling placements (Landsverk, et al., 1996; Leathers, 2005; McMurtry \& Lie, 1992), while one study did (Albert \& King, 2008). Adoption was a possible outcome in two studies, both of which found that sibling placements were associated with adoption, but in contradictory ways. First, McMurtry and Lie defined an independent variable as the number of siblings in foster care and found that it was associated with a reduction in exits to adoption. Leathers (2005) developed a more complex sibling measure by determining whether siblings were placed together for an entire foster care episode, for part of the episode, or never together during the episode. This study found that youth placed alone, either for an entire foster care episode or after a history of sibling placements, were less likely to exit to adoption or subsidized guardianship.

Placement stability. Placement stability was another variable rarely used as a predictor of foster care exits. The typical definition of stability was the number of placement settings a child experienced. When using the dependent variable of any permanent exit, two studies found that the number of placement settings did not have a significant relationship to this general outcome (Park \& Ryan, 2009; Potter \& Klein-Rothschild, 2002). In contrast, Goerge (1990) and Smith (2003) found that number of placement settings was associated with lower rates of reunification and adoption. Conversely, Pabustan-Claar (2007) found that a higher number of placements was associated with a higher probability of reunification. 


\section{Agency/Caseworker Characteristics}

A few studies included agency or caseworker characteristics. The most common variable in this category is caseworker turnover. Caseworker turnover was predictive of slower time to exit and lower rates of reunification (Davis, et al., 1996; Ryan, Garnier, Zyphur, \& Zhai, 2006).

\section{Summary of Independent and Dependent Variables}

A review of the literature revealed that multiple studies have been conducted during the last two decades in an attempt to identify the key characteristics that were associated with foster care exits. The dependent, or outcome variables, most frequently included reunification, followed by adoption. Guardianship was most often combined with other exit types and seldom included as an outcome of its own. In contrast to studies that identified a specific permanency exit, several studies used any permanent exit or any exit from foster care as the dependent variable. This latter group of studies, while providing general information on foster care exits, was less valuable for understanding the foster care paths to the specific permanency outcomes of reunification, adoption, or guardianship. More specific knowledge was gained when research examined these paths simultaneously, comparing and contrasting factors that contribute to unique types of permanency. However, this approach has not been the norm and only a few studies have accomplished this (Connell et al., 2006; Courtney \& Wong, 1996; McDonald et al., 2007).

The independent variables used in this line of foster care exit research covered a wide range of child, parent/family, placement episode, and caseworker characteristics. Among these categories of independent variables, child characteristics were included most frequently, followed by placement characteristics, then parent/family characteristics, and, lastly, caseworker characteristics. While studies indicated that many of these variables have a significant 
association with foster care exits to reunification and/or adoption, the relationships were often inconsistent and difficult to interpret. Even less is known about the relationship between these variables and guardianship because guardianship was frequently combined with adoption or reunification. Overall, specific variables with the most consistent findings of significant association with foster care exit were child's age, race, and health status. However, this review revealed many inconsistencies in the specific type of exit studied, the variables included, how they were measured, and related findings of significant associations.

\section{Gaps in the Empirical Literature}

The empirical literature on foster care exits and permanency has made significant strides in expanding knowledge of permanency. Studies have pointed to a variety of factors as potential predictors of permanency. Nonetheless, the literature review revealed several gaps. First, few variables were consistently included across studies and few findings offered consistent interpretations (McDonald, et al., 2007). Second, the research was limited by many studies' narrow focus on particular characteristics, such as kin placements, young age, or mental health problems. In doing so, these studies truncated samples, making them dissimilar to the foster care population as a whole and diminishing generalizability of findings. A third drawback was that studies frequently examined a single type of exit (e.g., adoption or reunification) or grouped exits as a singular outcome. While informative, they were limited in describing how predictive factors might differentially influence dissimilar exits (Courtney \& Wong, 1996). Only a handful of researchers have taken a different approach with a broad, generalizable sample. These researchers postulated that different types of exits are predicted by different factors and, therefore, analyzed exits as competing risks (Connell, et al., 2006; Courtney \& Wong; McDonald, et al.). Fourth, a notable gap in the research on foster care exits was the near absence 
of placement stability and sibling relationships as potential predictors. In light of the multitude of studies that speak to the importance of placement stability (Oosterman, Schuengel, Slot, Bullens, \& Doreleijers, 2007) and growing realization of the influence of sibling connections (Wulczyn \& Zimmerman, 2005), these two characteristics warrant further examination in quantitative studies of foster care exits.

\section{Brief Rationale for the Study}

Empirical foster care studies have affirmed the importance of permanency and demonstrated that a variety of variables can be used to predict foster care exits. While a fair amount of attention has been paid to permanency, the literature review identified several deficiencies that this study aims to address. This research will contribute to knowledge of permanency and foster care in three important ways. First, unlike most prior research, this study will identify the differential factors important for achieving dissimilar types of foster care exit with a broad, representative sample of children. Second, this study will incorporate placement stability and sibling relationships as potential influential factors of foster care exits, which has been lacking in many previous studies. Third, this study will be conducted in a new setting, offering statewide and state-specific information on predictors of foster care exits for the first time in Kansas.

The purpose of this study was to explore selected child and placement variables that differentially contribute to three types of permanent exit from foster care: reunification, adoption, and guardianship. A better understanding of the child and placement predictors of foster care exits may help identify service needs and policy shortcomings, and provide knowledge for targeting practice strategies that respond to children's unique situations. Ultimately, this research has the potential to inform improvements in child welfare practice and policy so that children leave foster care to stable, permanent homes more quickly. 


\section{Research Questions}

This study's research questions build on existing literature by including many variables shown to be associated with permanency. In addition, the research questions address gaps identified in the literature by: 1 ) assessing the differential contribution of child and placement characteristics for three types of foster care exits, 2) incorporating placement stability and sibling placements as a potential predictor of foster care exits and, 3) conducting this research in a new setting (i.e., the state of Kansas). This research will expand upon the current literature and offer a more complete understanding of foster care exits. The research questions are as follows:

1) Which child and placement characteristics predict foster care exit to reunification, adoption, and guardianship?

Child Characteristics

- Age

- Race

- Gender

- Disability

- Mental health
Placement Characteristics

- Reason for removal

- Prior removals

- Initial type of placement setting

- $\quad$ Sibling placements

- Placement stability

2) What are the similarities and differences among the child and placement characteristics that predict reunification, adoption, and guardianship? 


\section{Chapter 3: Methods}

This chapter describes the methods used to implement the present study. Information on key design features, sample selection, data collection and preparation, variables, and data analysis is presented below.

\section{Key Design Features}

This study employed a nonexperimental longitudinal design. Several choices were made to ensure the research design fits the research questions and current state of research as established by the literature review. The following summarizes the rationale of this study's design on three key features.

\section{Nonexperimental}

A nonexperimental research design was selected because it is the most appropriate and fitting choice for the study of foster care exits using a broad foster care sample. Experimental designs clearly offer benefits, particularly for research that seeks to assess the impact of programs and interventions. Nonetheless, this study's research questions are best addressed by a nonexperimental design because they are concerned with patterns and trends in the entire foster care population, which cannot be studied in an experimental setting due to the nature of child welfare work. That is, controlled studies that allow for between-group designs to study causal relationships are often not practical or ethically appropriate with children in foster care. Moreover, many of the independent variables in this study could not be manipulated. Nonexperimental research permits predictive relationships to be utilized in different ways than causal relationships and serve a useful practice and policy function in the current context. 


\section{Longitudinal}

The present study used a foster care entry cohort to examine longitudinal data. This approach was purposely chosen over the alternative, a cross-sectional study, because of the research design advantages it affords (Testa, 2010a), particularly in the foster care context (D'Andrade, Osterling, \& Austin, 2008). Cross sectional census samples overrepresent children with longer stays in foster care. Cross sectional exit cohort samples are biased in the opposite direction; they misrepresent the proportion of children who exit care and overstate shorter stays. Longitudinal designs with an entry cohort sample avoid these biases (Courtney, Needell, \& Wulczyn, 2004; D'Andrade, et al., 2008; Wulczyn, 1996; Wulczyn, et al., 2007; Zeller \& Gamble, 2007). Entry cohort studies use a cohort of children who enter foster care during a defined period, observe them over time, and thereby provide a more complete and accurate picture of which children attain permanency.

\section{Secondary Administrative Data}

Secondary administrative data were this study's primary data source. Secondary data were selected because of their fit with the other characteristics discussed above. Yet, other types of secondary data exist. For example, the National Survey of Child and Adolescent Well-Being (NSCAW) consists of multiple surveys that collect national, longitudinal data on families involved in child welfare. Such large-scale datasets are valuable because they are designed for research purposes and offer a wide scope of information. However, they lack some advantages held by state administrative data. Namely, state data are easily-identifiable and believable by state-level policy makers and practitioners. Local stakeholders may view national data as less relevant, while seeing state data as individualized and generalizable to the local foster care context. 
Secondary data present other advantages and disadvantages as well. On the positive side, secondary administrative data frequently provide large samples with extensive amounts of information, making it a very efficient approach for getting data (A. Rubin \& Babbie, 1989). Still, secondary data are constrained in several ways. One limitation is that administrative data are often collected for organizational or management purposes, not research purposes. Thus, the data may not meet all of the researcher's needs or include all of the variables of interest (Courtney \& Wong, 1996). This study was constrained by a lack of information on parental and caseworker characteristics. For example, there are no variables for parental visits, family socioeconomic status, or caseworker turnover.

Secondary data may also present reliability or validity concerns if data are not accurately or consistently recorded. Concerns could be raised about differential data entry in a privatized child welfare environment, which lacks a single source of data collection and standardization. It is noted that about half of the data fields used to construct study variables would have been entered by state child protection staff, not staff of privatized foster care agencies. Moreover, potential measurement problems are thought to be countered by using simple and straightforward variables such as gender, age, and race. Beyond these, most other variables are tied to reimbursement and more likely to be accurate (e.g., mental health as SED or not SED, placement settings). The disability variable is the only variable for which reliability issues might be a concern. However, this issue is not specific to Kansas or to privatized child welfare systems as it has been documented in a federal bulletin as a data entry issue for all states (U.S. Department of Health and Human Services Administration on Children Youth and Families, 2007).

In sum, the research design was selected after thorough review of the literature and careful consideration of key design characteristics. The process included assessing the benefits and 
drawbacks of each design characteristic as well as how it would fit the study's research questions and current state of research on foster care exits.

\section{Sample and Data Collection}

\section{Sample Selection}

The study sample was a purposive sample of children who entered Kansas foster care during state fiscal year (SFY) 2006 (i.e., July 1, 2005 to June 30, 2006). Sample selection occurred in January 2009, so the length of the observation period was a minimum of 30 months for the entire sample. A single inclusion criterion was used; that is, children who were in out-of-home care during SFY2006 for at least eight days. This eight-day cut point was used because it is consistent with permanency measures used by the Administration for Children and Youth in its reporting on child welfare outcomes (U.S. Department of Health and Human Services Administration on Children Youth and Families, n.d.). In addition, cases that stay in foster care for less than a week are typically court-vacated protective custody cases. Sixty-seven children were excluded from the SFY2006 study sample due to the eight-day criterion. The result was a foster care entry cohort sample of 3,351 children.

\section{Data Sources}

Two state administrative data sources were used in this study. The first was the state of Kansas administrative database for tracking children in foster care, called the Family and Child Tracking Systems (FACTS). FACTS is maintained by the Kansas Department of Social and Rehabilitation Services (SRS), Division of Children and Family Services (CFS). This database tracks the entire population of children in foster care for the duration of each placement episode. FACTS includes child and case information such as child demographic information, reason for removal from parents, the date of removal, dates and types of placements, and the date that the 
child was discharged from foster care. Information for the dependent variables and all but one of the independent variables were captured in the FACTS dataset.

The second data source was a state administrative database called the Automated Information Management System (AIMS). The AIMS dataset holds data on mental health consumers served by local Community Mental Health Centers (CMHCs) in Kansas. The dataset was comprised of 85 fields that provide demographic, client status, and mental health service utilization data for the CMHCs and state administrators. The data fields of interest to this study were related to the child's mental health. These data fields indicated whether a child has been determined by a qualified mental health provider to have a serious emotional disorder (SED).

\section{Data Collection and Preparation}

Data collection involved acquiring data extracts from the two state administrative databases. Data were provided by the state agency as Microsoft Access 2007 or Microsoft Excel 2007 files. Next steps involved data preparation in Access 2007, which included de-duplicating the data, matching children in both data sets on a unique identifier as well as other cleaning steps, such as checking for invalid dates. Several variables required calculations and/or aggregations into variables' subcategories. Following data preparation, a single flat file was exported to Stata 10.0 (StataCorp, 2007) for quantitative analyses.

\section{Variables}

This section defines the study's dependent and independent variables. In general, the rationale for selecting these variables and definitions was based on available data sources and an attempt to be consistent with recent studies and federal child welfare measures in order to promote comparisons across studies. Measurement issues are also discussed below. 


\section{Dependent/Outcome Variables}

Foster care exits to permanency. Permanency is a key concept related to foster care exits. For the purposes of this research, permanency was comprised of two important pieces. First, children must have exited foster care to achieve permanency. Second, children must have exited foster care to one of the following: reunification with biological parents, relative custody, legal guardianship, or adoption. Leaving foster care due to "aging out" (i.e., turning 18 years old while in care), running away, being transferred to another agency such as the juvenile justice authority, or death, was not considered permanency. Thus, both discharge date and discharge reasons were used to determine type of exit and duration of time to exit.

This study operationalized permanency with three specific dependent/outcome variables. They were the number of days in foster care until exiting to: 1) reunification; 2) guardianship or relative custody; and, 3) adoption. Exits to relative custody were included with guardianship because of their conceptual compatibility. However, it is noted that national child outcome measures of permanency combine relative custody and reunification. In Kansas, children exiting foster care to relative custody was rare (e.g., fewer than $1 \%$ of all exits).

\section{Independent/Predictor Variables}

Independent, or predictor, variables were grouped as child characteristics or placement characteristics. Table 3.1 displays the names, description, and categories of the study's variables.

Child characteristics. Gender was coded as a dichotomous variable representing male (1) or

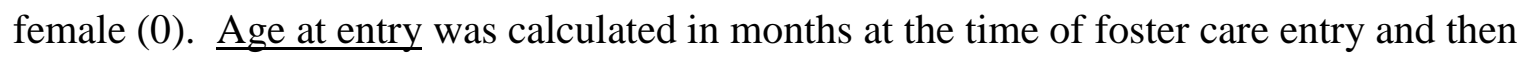
aggregated into five groupings to include: $0-1,2-5,6-9,10-13,14-17$ years of age. A couple of rationales supported these groupings. First, Kansas policy related to guardianship as a 
permanency option was generally restricted to children who are 14 years or older. Second, these groupings permitted comparison of groups of children that have been identified in prior research as high risk of not attaining permanency (i.e., infants and older adolescents). $\underline{\text { Race was defined }}$ as three categories: White, African American, and other. The "other" category was used because the number of children in racial groups other than White and African American is small. Children in the "other" category were largely Native American or Asian/Pacific Islander. Ethnicity was not used because it was not available in the study's dataset. Mental health was defined as SED (1) or not SED (0). SED stands for serious emotional disturbance. Disability was coded as a dichotomous variable representing child has been diagnosed with a disability (1) and child has not been diagnosed with a disability (0).

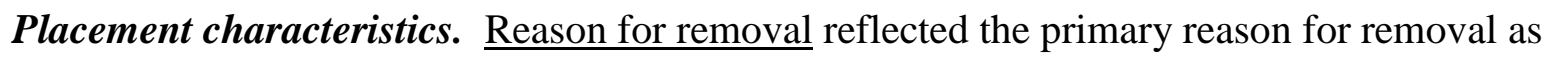
recorded in the placement dataset. It included four categories: 1) neglect, 2) physical abuse, 3) sexual abuse, and 4) other reasons. Prior removal history was coded as a dichotomous variable indicating yes, the child had a prior removal (1) or, no, the child did not have a prior removal (0). Initial placement type included three categories: 1) kinship placement, 2) (nonkin) family foster care, and 3) group home or residential setting. Siblings in placement included four categories that represent whether siblings were placed together during the episode: 1) completely intact, 2) partially intact, 3) completely separated, and 4) no siblings in placement. Completely intact sibling placements included siblings being placed with all of their siblings in placement for their entire placement episode. Partially intact placements were those in which children had siblings in placement, but they were separated from some or all of their siblings for some part of their placement episode. Separations of less than one week were not counted. Completely separated sibling placements were those in which children had siblings in placement with whom they were 
never placed together. Early stability was defined as children experiencing two or fewer placement settings during the first 100 days of foster care. If children exited foster care with two or fewer placements prior to their $100^{\text {th }}$ day in care, the variable was coded as stable (1). Approximately $6 \%$ of the sample exited care by day $100(n=213)$. The cut-point of two-orfewer placements was used because it is consistent with federal measures of placement stability. Also following federal guidelines, changes in placement due to acute hospital stays, runaway events, or trial home placements were not counted as a change in placement setting. Runaway was another type of placement instability. Since it is not included in the federal measures for placement stability, it was treated as its own independent variable. It was coded as a dichotomous variable indicating yes, child ran away one or more times during this placement episode (1) or, no, child did not runaway during this episode (0). 
Table 3.1 Description of Dependent and Independent Variables

\begin{tabular}{|c|c|c|}
\hline Variable & Description & Categories \\
\hline \multicolumn{3}{|l|}{ Dependent Variables } \\
\hline Reunification & Child exited foster care to reunification & $0=$ no, $1=$ yes \\
\hline Guardianship & Child exited foster care to guardianship & $0=$ no, $1=$ yes \\
\hline Adoption & Child exited foster care to adoption & $0=$ no, $1=$ yes \\
\hline \multicolumn{3}{|l|}{ Independent Variables } \\
\hline Gender & Child's gender & $0=$ female, $1=$ male \\
\hline Race & Child's race & $0=$ White, $1=$ African American, $2=$ Other \\
\hline Age at entry & Child's age at entry to foster care & $\begin{array}{l}0=0 \text { to } 1 \mathrm{yrs}, 1=2 \text { to } 5 \mathrm{yrs}, 2=6 \text { to } 9 \mathrm{yrs} \\
3=10 \text { to } 13 \mathrm{yrs}, 4=14 \text { to } 17 \mathrm{yrs}\end{array}$ \\
\hline Disability & Whether child had any disability & $0=$ no disability, $1=$ disability \\
\hline Mental health problems & $\begin{array}{l}\text { Whether child's had a serious mental } \\
\text { health problem/SED }\end{array}$ & $0=$ no SED, $1=\mathrm{SED}$ \\
\hline Reason for removal & Primary reason child was removed & $\begin{array}{l}0=\text { neglect }, 1=\text { physical abuse } \\
2=\text { sexual abuse, } 3=\text { other }\end{array}$ \\
\hline Prior removal & $\begin{array}{l}\text { Whether child has a history of prior } \\
\text { removals }\end{array}$ & $0=$ none, $1=$ one or more prior removals \\
\hline Initial placement type & $\begin{array}{l}\text { Type of placement as child entered foster } \\
\text { care }\end{array}$ & $\begin{array}{l}0=\text { kinship care }, 1=\text { family foster care } \\
2=\text { group or residential-type setting }\end{array}$ \\
\hline Sibling placements & $\begin{array}{l}\text { Child's experience with siblings who had } \\
\text { co-occurring foster care episodes }\end{array}$ & $\begin{array}{l}0=\text { completed separated, } 1=\text { partially intact } \\
2=\text { completely intact, } 3=\text { no siblings in care }\end{array}$ \\
\hline \multirow[t]{2}{*}{ Early stability } & $\begin{array}{l}\text { Whether child experienced early } \\
\text { placement stability }\end{array}$ & $\begin{array}{l}0=\text { no early stability ( } 3 \text { or more placements } \\
\text { by day } 100 \text { ) }\end{array}$ \\
\hline & & $\begin{array}{l}1=\text { early stability ( } 2 \text { or fewer placements at } \\
\text { day } 100)\end{array}$ \\
\hline Runaways & $\begin{array}{l}\text { Whether child had runaway events while } \\
\text { in foster care }\end{array}$ & $0=$ none, $1=$ one or more runaway events \\
\hline
\end{tabular}

\section{Measurement Reliability and Validity}

Reliability and validity are both important issues for measurement. Reliability is concerned with the amount of error in a measure (A. Rubin \& Babbie, 1989) and is generally thought of as the consistency and dependability of data. In this study of foster care exits, the most relevant reliability issue is consistency of the data. Data used in this study were state administrative data. Since these data were entered by many different people in several different agencies, issues of accuracy and consistency may threaten reliability. This concern was countered by using 
variables likely to have high reliability because of clear definitions (e.g., age, gender) or because they were used for contract or reimbursement purposes (e.g., dates, types of placement settings).

Validity refers to measures being not only reliable, but also true and accurate. Classification of validity related to measurement includes: content, criterion, and construct validity (Pedhazur \& Schmelkin, 1991). The one of highest concern for this study is content validity. Content validity refers to how well a measure fully covers the range of meanings with a concept (A. Rubin \& Babbie, 1989). For this study, content validity is considered for five independent variables: race, mental health, disability, reason for removal, and placement stability. The specific measurement issues related to content validity on each of these are discussed below.

Race/ethnicity contained limitations because the dataset did not record ethnicity. Thus, the specificity of the study was limited in relation to findings that are relevant to children of different ethnic groups. In particular, this study could not address findings for Latino children. About $9 \%$ of the Kansas population is Latino (U.S. Census Bureau, 2009). The findings were not able to discern unique patterns of foster care exit and permanency for Latino children.

Mental health is mentioned because it may also contain some error. The definition of SED varies across the nation and across service systems. In the state of Kansas certain behavioral health services require that a child be determined to have an SED by a qualified mental health professional. This information was available in the state administrative database (i.e., AIMS). For this study, SED status was a proxy for mental health severity. That is, children determined to have an SED have more severe mental health problems than children not determined to have an SED. It should be noted that the "not SED" designation was coded for both children who had been determined by a mental health professional to not have an SED and children for whom SED status was unknown (i.e., these children were not in the mental health database). Again, children 
who were not in the mental health database and whose SED status, therefore, was unknown were likely to have either no mental health problems or significantly less severe mental health problems than children who had been determined to be SED. Furthermore, since children may enter in and out of SED designation, if a child ever had an SED designation during the study period then this variable was coded as SED. Despite some potential error in the SED variable, it is thought to be a strong because of state guidelines for SED status. Furthermore, as a measure of mental health, it was also strong in comparison to those used in many other foster care exit studies.

Disability status and removal reason are two other variables that may have reliability issues, as has been noted in other foster care research (Courtney \& Wong, 1996). Disability status was recorded by caseworkers and was likely to be underreported as suggested by federal bulletins (U.S. Department of Health and Human Services Administration on Children Youth and Families, 2007). For this reason, disability should be thought of as the most easily identified disabilities. Reason for removal represented only the primary reason for removal as recorded by the caseworker, although this information was supposed to come from the child protection petition that was filed with the court system to initiate foster care. Still, this variable was limited in that it may lack complexity. Many children in foster care will have experienced multiple types of abuse beyond the single type recorded for this variable.

Content validity is also raised as an issue for the measure of early placement stability. Placement stability is defined in multiple ways throughout the literature (Oosterman, et al., 2007) and has been of significant debate among child welfare researchers (Herrick, Williams, \& Pecora, 2004). The issue has primarily revolved around which placement settings should be counted as a move. For example, some states count respite care and others do not; some count 
runaways and others do not. This study will generally follow the current federal definition of placement stability for consistency reasons. Still, the federal definition excludes some movements in placement (e.g., acute hospital stays, respite care, runaways) and must be acknowledged as capturing only part of the movement and instability experienced by children in foster care. Furthermore, this study limited the measurement of placement stability to a measure of stability in the first 100 days of foster care. This operationalization of early placement stability, while limiting in some ways, was selected based upon prior research that suggested its importance (James, Landsverk, \& Slymen, 2004; D. M. Rubin et al., 2008; D. M. Rubin, et al., 2007) and an attempt to avoid a measure of placement stability that would be confounding with a dependent variable's measure of duration of foster care. Early stability could be operationalized as placement stability during the first 45 days, 90 days, 100 days, or 180 days. The precise number of days varies across studies. One hundred days was selected for this study based upon the author's discussions with Kansas foster care providers and other key stakeholders who convened over a number of years to address child welfare issues, such as placement instability. Additionally, some of the constraints to measuring placement instability were addressed by also including the independent variable, runaways, as another proxy for placement instability.

\section{Data Analysis}

Data analysis included univariate, bivariate, and multivariate analyses. All analyses were performed in Stata 10 (StataCorp, 2007). This software package was selected because of its flexibility and advanced features for fitting statistical models to the data used in this study. For example, Stata provides marginal models that handle issues with auto correlation and can run extended Cox regression models with multiple interaction variables (see further explanation on page 54). 


\section{Univariate Analyses}

Univariate analyses included observing frequency distributions, measures of central tendency, and variation. Both visual and statistical approaches were used to detect outliers and influential cases. This step provided an overall description of the sample and the distribution of variables (Hardy, 2004).

\section{Bivariate Analyses}

Bivariate analyses were conducted to observe relationships between variables. Crosstabulations were conducted with all eleven independent variables with observation of the Pearson chi-square for statistical significance and Cramer's V for a measure of association. The statistical significance level was Bonferroni-corrected and set at $p \leq .001$ (.05/55 tests).

The primary bivariate technique was the use of the Kaplan-Meier method which allowed observing bivariate relationships between independent and dependent variables. The KaplanMeier method was used for several reasons. First, it is appropriate for time-to-event data when there are censored data (i.e., subjects that have yet to experience the event of interest). Second, the Kaplan-Meier method is considered useful as preliminary analysis that can be used to screen independent variables before estimating multivariate survival models (Allison, 1995). Third, the Kaplan-Meier method was selected instead of life tables because it is most appropriate for data sets in which the time to event is precisely measured and because it can handle both small and large datasets (Allison, 1995; Singer \& Willett, 2003). Log-rank $\chi^{2}$ and its $p$ values were used to assess significance of the bivariate associations. The statistical significance level was Bonferroni-corrected and set at $p \leq .005(.05 / 11)$. 


\section{Multivariate Analyses}

Multivariate analyses were conducted using competing risk analysis, a type of survival analysis, also known as event history analysis and Cox proportional hazards model. According to Allison (2004), "event history analysis is a term commonly used to describe a variety of statistical methods that are designed to describe, explain or predict the occurrence of events" (p. 369). This method of analyzing data is useful when the time to event has yet to occur for some cases. Survival analysis has advantages over other methods because it incorporates information from censored cases, those cases for which survival time is yet unknown (i.e., children who have yet to exit foster care); utilizes duration information in the model; controls for effects of independent variables (also called covariates), as with other regression models; and permits both categorical and continuous independent variables (Steffensmeier \& Jones, 2004). With multiple applications of Cox regression, competing risk analysis extends survival analysis in order to examine which of several mutually exclusive outcomes occur based on independent variables, thereby ascertaining a profile of influential factors for each possible outcome (Allison, 2004; Singer \& Willet, 1991). Competing risks modeling is an appropriate specification for Cox regression analysis when these conditions are met: the dependent variable includes unique types of outcomes (events), outcomes can occur at different points in time, and independent variables could be expected to vary in their associations with different outcomes (Allison, 1995; McDonald et al., 2007).

\section{Assumptions}

The Cox proportional hazard model makes several assumptions, three of which are specifically addressed here because of their importance and possible violation in foster care research (Guo \& Wells, 2003). First, the assumption of proportionality of hazards assumes that 
changes in levels of the independent variables, also known as covariates, will produce proportionate changes in the hazard function across time (Allison, 1995). Although Allison (1995) has also suggested that violation of this proportional hazards assumption does not interfere with model estimation and significance testing, it can be handled through inclusion of interaction terms with time. The proportionality assumption was first tested by inspecting plots of the $-\log$ (estimated survival function) against $\log$ (failure time) for each independent variable against each outcome (i.e., reunification, guardianship, and adoption). A lack of proportionality was indicated by departures from parallelism between strata. Second, a formal test of the proportionality assumption was used by creating a time interaction term for each independent variable and running it in each multivariate model (Allison, 1995; Tabachnick \& Fidell, 2001). Time interactions were created by crossing the independent variable by the natural logarithm of time (i.e., $\ln (\mathrm{t}))$ because using the natural logarithm is recommended when time variables take on large values) (Cantor, 2003). Time interactions were retained if the term significantly improved model fit and/or its coefficient was significant in the multivariate model with a Bonferronicorrected $p$-value of .005 (.05/11) (Allison, 2004; Garson, 2008).

Another assumption of Cox regression requires independent observations. Data from the same unit (such as a person, sibling group, or family) violates the assumption of independent event data (Guo \& Wells, 2003, p. 5). The resulting problem is known as autocorrelation. In the present study, children with siblings in foster care with concurrent episodes present autocorrelation issues. Autocorrelation was addressed by using a marginal model available in the Stata software package that estimates robust standard errors (Kelly, 2004).

The third assumption that could present major concern is the assumption of no high multicollinearity. Multicollinearity does not actually bias model results, but it can produce large 
standard errors in the related variables and lead to falsely concluding that a variable does not have a statistically significant relationship with the dependent variable (Pedhazur, 1982). The multicollinearity assumption was assessed by observing the correlation matrix of regression coefficients for each Cox regression model (Garson, 2008).

\section{Procedures}

After key assumptions were assessed, the competing risks survival analysis was implemented to assess whether foster care exit rates differ by type of exit. This involved observing the median length of stay for each exit type, plots of survival data, and overall and paired comparisons with a Wilcoxon (Gehan) test of statistical significance. The results of these procedures are presented in the next chapter on page 75. After finding statistically significant results in the overall and paired comparisons, the next step of the competing risk analyses was to determine whether differentiating exit type would result in statistically significant improvements of the multivariate regression models as compared to the model that does not differentiate type of exit. So, four Cox regression models were run: one that does not distinguish between exit types and one for each type of exit - reunification, guardianship, and adoption. Each model was run treating children who experienced the other types of exits as censored. A likelihood-ratio chi-square statistic was calculated to determine whether the overall model was improved upon by the differentiating models. This chi-square is derived by taking -2 times the log likelihood chi-square value provided in the output of the model that does not distinguish exit types and comparing it to the sum of the same fit measure for the three models that distinguish exit type. If the difference in these two chi-square values is statistically significant (with degrees of freedom equal to the sum of $d f$ for each exit type model, subtracted from the degrees of freedom for the overall model), then the outcomes should be modeled separately (Allison, 1995). A statistically significant chi- 
square indicated that the differentiating models were better than the overall model. Results are provided in the proceeding chapter on page 76.

The next step of the competing risks analyses compared Cox regression models for each of the three types of exit. The fit of each model was assessed with the Wald chi-square and the likelihood ratio (LR) test statistics. The LR test is the preferred method because of stability and consistency (Steffensmeier \& Jones, 2004). This LR tests the null hypothesis that covariate coefficients are not different from zero. If the LR test is significant, the researcher concludes that the covariates are contributing to prediction. Larger values demonstrate a better overall performance of the predictors as a whole. The results of each model were considered by reviewing the estimates of regression coefficients corresponding to each independent variable, standard errors, hazard ratios, and $p$-values for testing the significance of each coefficient. The hazard ratio was used to assess the effect size, or strength of association, for each independent variable. The Cox regression model provides a hazard ratio, which is similar to an odds ratio as a measure of effect size, for each independent variable in the model. A hazard ratio greater than one indicates an increased likelihood of experiencing an outcome, and a hazard ratio less than one indicates a decreased likelihood or experiencing the outcome (Garson, 2008). In conclusion, the competing risks approach allowed a determination of model fit for each exit type as well as observation of which independent variables were important for each exit type. Results of the final models are presented in chapter 4 .

\section{Power Analysis}

Power analyses were conducted in Stata 10.0 (StataCorp, 2007) to assess how likely the Cox regression models would detect certain effect sizes given the sample size of the current study ( $\mathrm{N}$ $=3,351$ ). Statistical power refers to the probability that a null hypothesis will be correctly 
rejected, and is expressed by a value ranging between zero and one (Cohen, 1988). In general, power of .80 is considered adequate. With Cox regression, power increases with effect size, or hazard ratio, and with the frequency of the outcome of interest, or event rate.

Power analyses were conducted for three Cox regression models (one for each of the outcomes) at alpha level .05. Actual sample size and event rates were used to estimate statistical power of specified hazard ratios that ranged from weak to medium (1.3 to 3.0). Table 3.2 shows the results of the power analyses. The hazard ratios and corresponding power were observed to identify when the models achieved the .80 adequacy standard for power. For a weak effect size (i.e., hazard ratio of 1.3), only the reunification model exceeded the .80 adequacy standard. This .80 threshold was met by all three models when the hazard ratio was at least a small effect size of 1.8. Thus, these analyses had low power to detect less frequent outcomes (i.e., guardianship event rate $=9.2 \%$ and adoption event rate $=13.9 \%)$ when the effect size, or hazard ratio, associated with an independent variable was small. Power increased considerably when the outcome had a higher event rate (i.e., reunification event rate $=52.1 \%$ ) or with an increase in hazard ratio (e.g., hazard ratio of 1.8 or higher). The results of this power analysis informed judgments about the performance of independent variables and their corresponding hazard ratios. The output of the adoption and guardianship modes were carefully examined and cautiously interpreted when hazard ratios were $\leq 1.8$ or $\geq$ the reverse value of approximately 0.61 .

Table 3.2 Powers for Specified Hazard Ratios in Three Cox Regression Models

\begin{tabular}{rrr|rrrrr}
\hline & & \multicolumn{4}{|c}{ Powers for Specified Hazard Ratios } \\
& & & & & \multicolumn{2}{c}{ medium } \\
Model & Sample & Event rates & HR=1.3 & HR = 1.5 & HR =1.8 & HR = 2.0 & HR $=3.0$ \\
\hline Reunification & 3,351 & 0.52 & 0.88 & 0.99 & 1.00 & 1.00 & 1.00 \\
Guardianship & 3,351 & 0.09 & 0.26 & 0.52 & 0.83 & 0.93 & 1.00 \\
Adoption & 3,351 & 0.14 & 0.37 & 0.50 & 0.81 & 0.92 & 1.00 \\
\hline
\end{tabular}




\section{Chapter 4: Results}

\section{Univariate Analyses}

Univariate analyses included observing frequency distributions, measures of central tendency, and variation. Table 4.1 provides descriptive data on the three outcome variables: foster care exits to reunification, guardianship, and adoption. Among the SFY2006 entry cohort sample of 3,351 children that were observed for a minimum of 30 months, 2,522 children (75.3\%) exited to one of these permanency outcomes. The most common type of permanency was reunification $(\mathrm{n}=1,747,52.1 \%)$, followed by adoption $(\mathrm{n}=467,13.9 \%)$, and then guardianship $(n=308,9.2 \%)$. One quarter of the study sample did not exit to a permanent living arrangement during the study period $(n=829,24.7 \%)$. Figure 4.1 presents the permanency status of the entire entry cohort as of December 31,2008 as well as the breakdown among children who did not attain permanency.

Measures of central tendency and variation were observed from the Kaplan Meier procedures because it adjusts for censored data. Although restricted means are provided by the KaplanMeier method in Stata, they are not presented here because they are seriously biased by underestimating the true mean since censored cases have yet to exit foster care. Median values are considered more accurate as they are less likely to be influenced by large values and censoring (Allison, 1995; Shlonsky, Festinger, \& Brookhart, 2006).

The estimated median time to each type of permanency was progressively larger, with reunification having the shortest median time to exit of 366 days $\left(C_{95 \%}=352-380\right)$, followed by guardianship median time to exit of 474 days $\left(C I_{95 \%}=437-495\right)$. The longest time to exit was adoption, which had a median time to exit of 737 days $\left(C I_{95 \%}=705-758\right)$. For all types of permanency exits combined, the median time to exit was $546\left(C I_{95 \%}=536-561\right)$. 
The timing of different types of permanency was observed with plots of the kernel-smoothed hazard estimates, presented in Figures 4.2, 4.3, and 4.4. These figures show the overall likelihood that a child will exit to the specified type of exit, given that the child was at risk of that exit. As mentioned in chapter 3 (p. 55), children in the sample are treated as at risk of all three types of permanency exit until they have exited. The reunification graph shows the highest likelihood for reunification exits occurs at about 15 to 18 months, declining thereafter. The likelihood of guardianship peaked at about 20 months, followed by a decline and then a slight upturn around the $32^{\text {nd }}$ month. The greatest likelihood for adoption occurred at about 36 months. Table 4.1 Descriptive Data for Each Type of Exit

\begin{tabular}{rrrrrr}
\hline Type of Exit & $\mathrm{N}$ & $\%$ & $\begin{array}{r}\text { Median } \\
\text { (days) }\end{array}$ & $\begin{array}{r}\text { Std. } \\
\text { Error }\end{array}$ & $\begin{array}{r}\text { Median, } \\
95 \% \text { CI }\end{array}$ \\
\hline Reunification & 1,747 & 52.1 & 366 & 7.24 & $352-380$ \\
Guardianship & 308 & 9.2 & 474 & 14.87 & $437-495$ \\
Adoption & 467 & 13.9 & 737 & 14.71 & $705-758$ \\
No permanent exit & 829 & 24.7 & - & - & - \\
\hline Total & 3,351 & 100.0 & 546 & 8.23 & $536-561$ \\
\hline
\end{tabular}

Note: Medians estimated from Kaplan-Meier method.

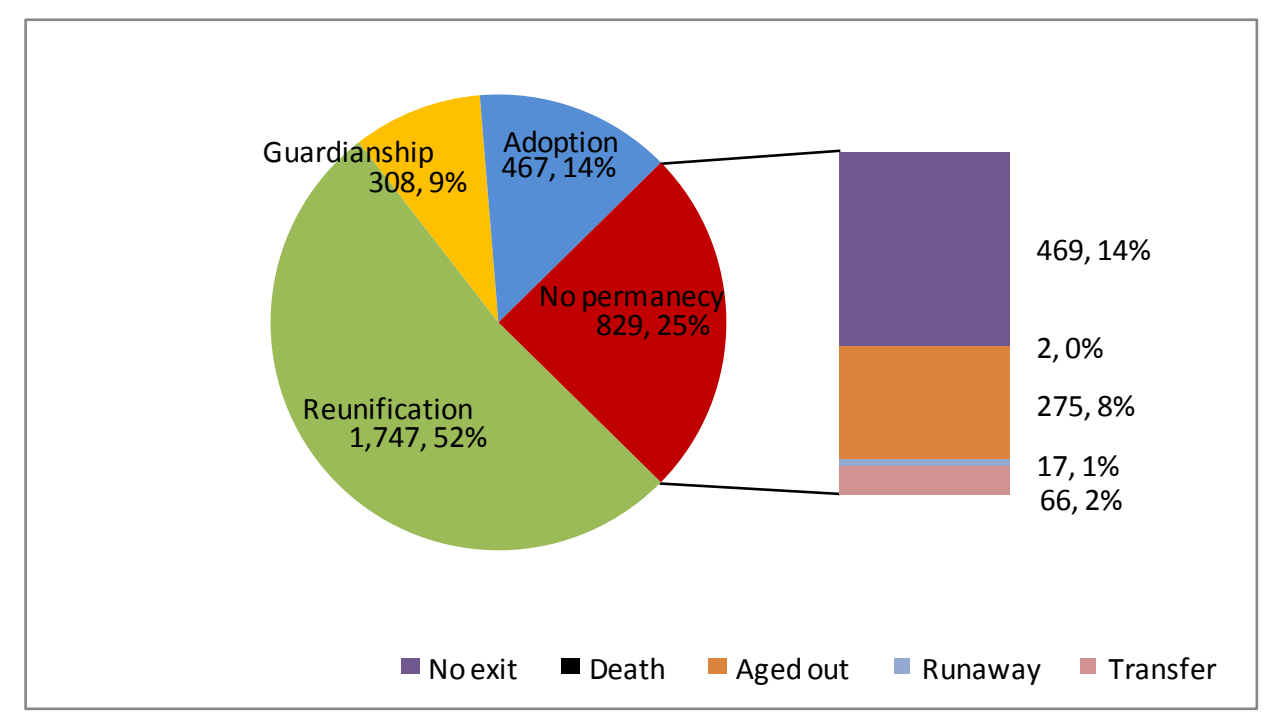

Figure 4.1 Permanency Status of SFY2006 Entry Cohort As of December 31, 2008 


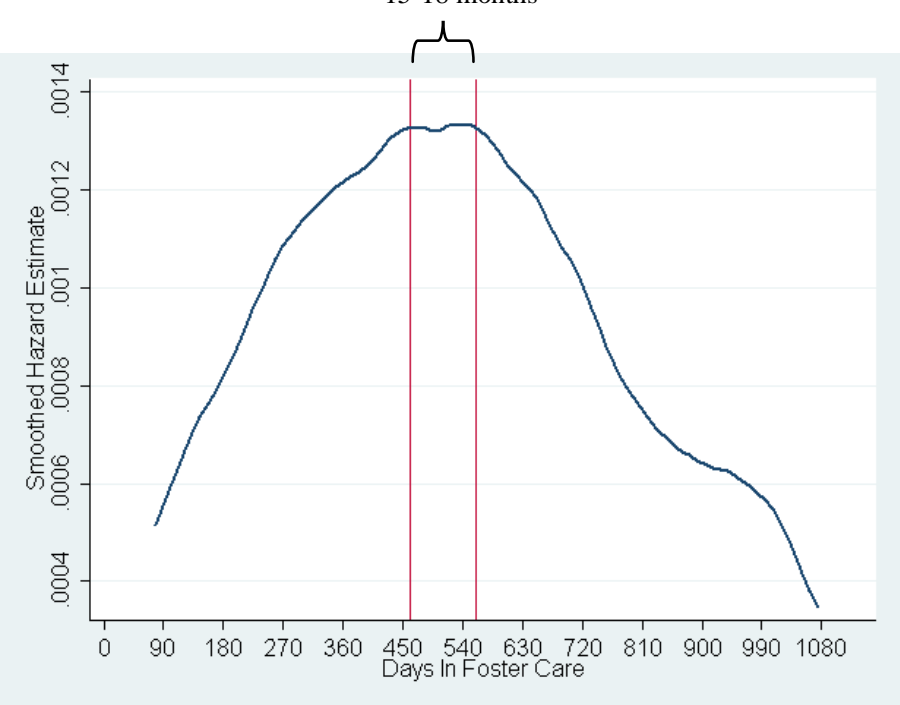

Figure 4.2 Smoothed Hazard Estimates for Reunification

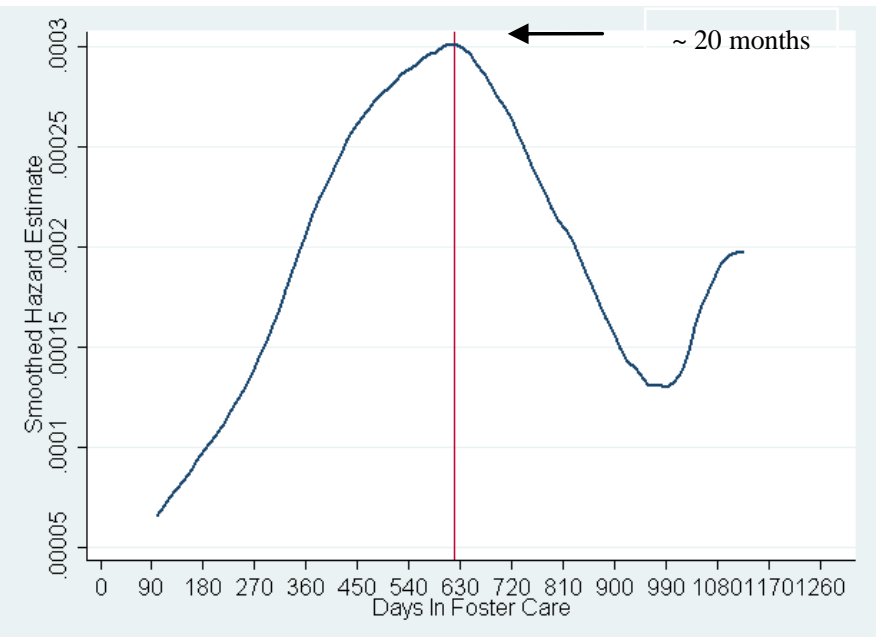

Figure 4.3 Smoothed Hazard Estimates for Guardianship

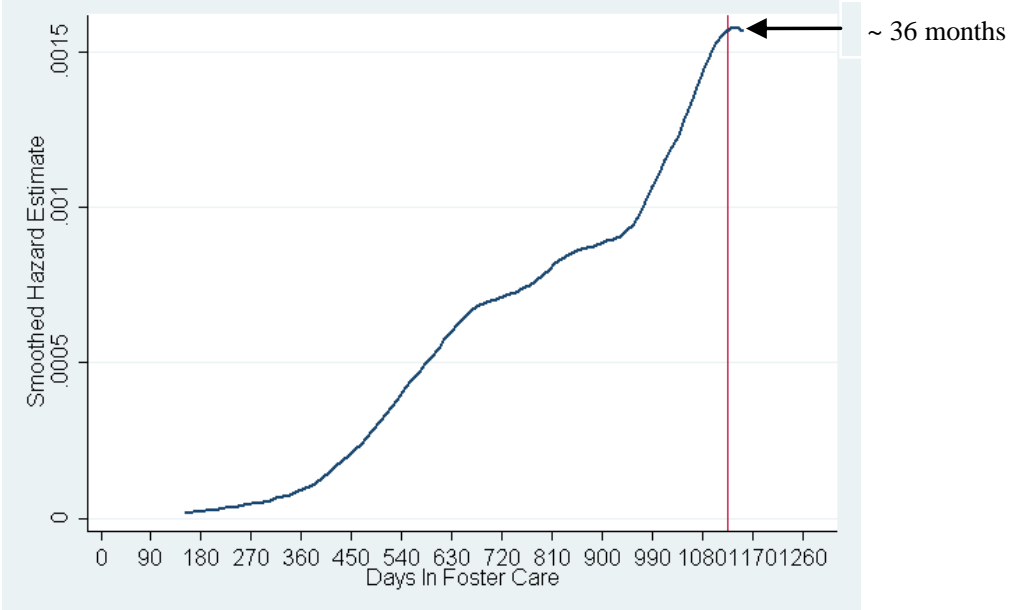

Figure 4.4 Smoothed Hazard Estimates for Adoption 
The frequencies and proportions of each independent variable were also observed. These are shown in Table 4.2. Below is a summary of each independent variable.

This sample of children in foster care had slightly more boys than girls (boys, $\mathrm{n}=1,717$, $51.2 \%$; girls, $\mathrm{n}=1,634,48.8 \%)$.

In regards to race, the majority of children were White $(n=2,721,81.2 \%)$. African American children made up $15.8 \%(n=531)$ of the sample, while children of other races represented $3.0 \%(n=99)$ of the sample.

Nearly one fifth of the sample entered foster care as an infant $(n=618,18.4 \%)$. Children who were 2 to 5 years old when they entered foster care represented $19.9 \%(n=668)$ of the sample, while 6 to 9 year olds made up $15.8 \%(n=531)$, and 10 to 13 year olds were $16.4 \%$ of the sample. The largest age group was youth who entered foster care when they were 14 to 17 years old, consisting of nearly one third of the sample $(29.5 \%, \mathrm{n}=985)$.

Almost one quarter of the sample's children had some kind of disability $(23.5 \%, \mathrm{n}=788)$, while the variable on child's mental health showed that $39.0 \%$ had been determined to have a serious emotional disturbance $(\mathrm{SED})(\mathrm{n}=1,307)$.

The variable representing the primary reason for removal into foster care showed that the most common reason was the "Other" category at $56.9 \%(\mathrm{n}=1,907)$, followed by neglect $(\mathrm{n}=$ $806,24.1 \%)$, physical abuse $(\mathrm{n}=467 ; 13.9 \%)$, and sexual abuse $(\mathrm{n}=171,5.1 \%)$.

The vast majority of children had not experienced a prior removal into foster care $(n=3,063$, 91.4\%). Conversely, about one in twelve children had experienced prior removal(s) $(\mathrm{n}=288$, $8.6 \%)$ 
The most common initial placement setting as children entered foster care was (nonkin) family foster care $(n=2,701,80.6 \%)$, followed by kinship care $(n=480,14.3 \%)$, and group or residential settings $(\mathrm{n}=170,5.1 \%)$.

About one half of the sample did not have a sibling in placement $(n=1,568,46.8 \%)$. One quarter of the sample were characterized as having completely intact sibling placements; that is, they had siblings in placement and were placed with all of their siblings in placement for their entire placement episode $(\mathrm{n}=854,25.5 \%)$. About another quarter of the sample experienced partially intact placements with siblings $(n=757,22.6 \%)$. This means that they had siblings in placement, but they were separated from some or all of their siblings for some part of their placement episode. A small group of children were completely separated from siblings because they had siblings in placement with whom they were never placed together $(n=172,5.1 \%)$.

Early placement stability was experienced by the majority of children in this sample $(\mathrm{n}=$ $2,718,81.1 \%)$. Yet, a sizable proportion of the sample had experienced three or more placements by their $100^{\text {th }}$ day in foster care $(n=633,18.9 \%)$.

Most children in this sample did not runaway while in foster care $(n=3,041,90.7 \%)$. Fewer than $10 \%$ of the children experienced one or more runaway events $(n=310 ; 9.3 \%)$. 
Table 4.2 Descriptive Data on Independent Variables for the Sample and By Outcome

\begin{tabular}{|c|c|c|c|c|c|c|c|c|c|c|}
\hline \multirow[b]{2}{*}{ Independent Variable } & \multicolumn{2}{|c|}{ Sample } & \multicolumn{2}{|c|}{ Reunification } & \multicolumn{2}{|c|}{ Guradianship } & \multicolumn{2}{|c|}{ Adoption } & \multicolumn{2}{|c|}{ No Perm } \\
\hline & $\mathrm{N}$ & $\%$ & $\mathrm{n}$ & $\%$ & $\mathrm{n}$ & $\%$ & $\mathrm{n}$ & $\%$ & $\mathrm{n}$ & $\%$ \\
\hline Total Sample & 3,351 & 100.0 & 1,747 & 52.1 & 308 & 9.2 & 467 & 13.9 & 829 & 24.7 \\
\hline \multicolumn{11}{|l|}{ Gender } \\
\hline Female & 1,634 & 48.8 & 820 & 46.9 & 158 & 51.3 & 238 & 51.0 & 418 & 50.4 \\
\hline Male & 1,717 & 51.2 & 927 & 53.1 & 150 & 48.7 & 229 & 49.0 & 411 & 49.6 \\
\hline \multicolumn{11}{|l|}{ Age } \\
\hline 0 to $1 \mathrm{yrs}$ & 618 & 18.4 & 262 & 15.0 & 34 & 11.0 & 234 & 50.1 & 88 & 10.6 \\
\hline 2 to $5 \mathrm{yrs}$ & 668 & 19.9 & 359 & 20.5 & 60 & 19.5 & 131 & 28.1 & 118 & 14.2 \\
\hline 6 to $9 \mathrm{yrs}$ & 531 & 15.8 & 314 & 18.0 & 57 & 18.5 & 62 & 13.3 & 98 & 11.8 \\
\hline 10 to $13 \mathrm{yrs}$ & 549 & 16.4 & 315 & 18.0 & 77 & 25.0 & 32 & 6.9 & 125 & 15.1 \\
\hline 14 to $17 \mathrm{yrs}$ & 985 & 29.4 & 497 & 28.4 & 80 & 26.0 & 8 & 1.7 & 400 & 48.3 \\
\hline \multicolumn{11}{|l|}{ Race } \\
\hline White & 2,721 & 81.2 & 1,439 & 82.4 & 260 & 84.4 & 384 & 82.2 & 638 & 77.0 \\
\hline African American & 531 & 15.8 & 242 & 13.9 & 41 & 13.3 & 74 & 15.8 & 174 & 21.0 \\
\hline Other & 99 & 3.0 & 66 & 3.8 & 7 & 2.3 & 9 & 1.9 & 17 & 2.1 \\
\hline \multicolumn{11}{|l|}{ Disability } \\
\hline No dis ability & 2,563 & 76.5 & 1,530 & 87.6 & 270 & 87.7 & 214 & 45.8 & 549 & 66.2 \\
\hline Has disability & 788 & 23.5 & 217 & 12.4 & 38 & 12.3 & 253 & 54.2 & 280 & 33.8 \\
\hline \multicolumn{11}{|l|}{ Mental health } \\
\hline No SED & 2,044 & 61 & 1,132 & 64.8 & 192 & 62.3 & 348 & 74.5 & 372 & 44.9 \\
\hline Has SED & 1,307 & 39 & 615 & 35.2 & 116 & 37.7 & 119 & 25.5 & 457 & 55.1 \\
\hline \multicolumn{11}{|l|}{ Reason for removal } \\
\hline Neglect & 806 & 24.1 & 385 & 22.0 & 86 & 27.9 & 173 & 37.0 & 162 & 19.5 \\
\hline Physical abuse & 467 & 13.9 & 274 & 15.7 & 39 & 12.7 & 46 & 9.9 & 108 & 13.0 \\
\hline Sexual abuse & 171 & 5.1 & 102 & 5.8 & 15 & 4.9 & 15 & 3.2 & 39 & 4.7 \\
\hline Other & 1,907 & 56.9 & 986 & 56.4 & 168 & 54.5 & 233 & 49.9 & 520 & 62.7 \\
\hline \multicolumn{11}{|l|}{ Prior removal history } \\
\hline No prior removal(s) & 3,063 & 91.4 & 1,625 & 93.0 & 274 & 89.0 & 445 & 95.3 & 719 & 86.7 \\
\hline Has prior removal(s) & 288 & 8.6 & 122 & 7.0 & 34 & 11.0 & 22 & 4.7 & 110 & 13.3 \\
\hline \multicolumn{11}{|l|}{ Initial placement type } \\
\hline Kinship care & 480 & 14.3 & 301 & 17.2 & 124 & 40.3 & 19 & 4.1 & 36 & 4.3 \\
\hline Family foster care (nonkin) & 2,701 & 80.6 & 1,344 & 76.9 & 173 & 56.2 & 434 & 92.9 & 750 & 90.5 \\
\hline Group or residential & 170 & 5.1 & 102 & 5.8 & 11 & 3.6 & 14 & 3.0 & 43 & 5.2 \\
\hline \multicolumn{11}{|l|}{ Sibling placements } \\
\hline Completely separated & 172 & 5.1 & 80 & 4.6 & 15 & 4.9 & 14 & 3.0 & 63 & 7.6 \\
\hline Partially intact & 757 & 22.6 & 367 & 21.0 & 74 & 24.0 & 98 & 21.0 & 218 & 26.3 \\
\hline Completely intact & 854 & 25.5 & 516 & 29.5 & 101 & 32.8 & 162 & 34.7 & 75 & 9.0 \\
\hline No siblings in placement & 1,568 & 46.8 & 784 & 44.9 & 118 & 38.3 & 193 & 41.3 & 473 & 57.1 \\
\hline \multicolumn{11}{|l|}{ Early placement stability } \\
\hline 0-2 placements@100days & 2,718 & 81.1 & 1,435 & 82.1 & 266 & 86.4 & 426 & 91.2 & 591 & 71.3 \\
\hline $\geq 3$ placements@100days & 633 & 18.9 & 312 & 17.9 & 42 & 13.6 & 41 & 8.8 & 238 & 28.7 \\
\hline \multicolumn{11}{|l|}{ Runaways } \\
\hline No runaway events & 3,041 & 90.7 & 1,639 & 93.8 & 290 & 94.2 & 465 & 99.6 & 647 & 78.0 \\
\hline Has runaway events & 310 & 9.3 & 108 & 6.2 & 18 & 5.8 & 2 & 0.4 & 182 & 22.0 \\
\hline
\end{tabular}


Univariate analyses also included visual and statistical procedures to examine possible outliers and influential cases. Box plots were examined for the three types of permanency exits using a continuous variable that represented the number of days to exit. The box plot of reunification indicated seven outlier cases out of a total of 1,747 exits to reunification. These seven cases had episode lengths that were about three times the median time to reunification. The guardianship box plot showed four outlier cases out of a total of 308 exits to guardianship. These four cases' time to guardianship was about two to two-and-one-half times the median time to guardianship. The box plot of adoption indicated two outlier cases out of a total of 467 exits to adoption. These two cases experienced foster care episodes of less than three months as compared to the median time to adoption of about two years. All possible outlier cases were reviewed and found to represent valid measurement; therefore, no cases were removed from the analyses.

\section{Bivariate Analyses}

Bivariate analyses included examination of the relationships between the independent variables as well as bivariate survival analyses. First, relationships between independent variables were observed using cross-tabulations. Statistical significance was assessed with the Pearson chi-square statistic and its corresponding $p$-values. The statistical significance level was Bonferroni-corrected and set at $p \leq .001$ (.05/55 tests). The Cramer's V was used as a measure of association following guidelines described by Cohen (1988), with values under .10 indicating a weak association, values between .11 and .29 indicating a small association, values between .30 and .49 indicating a moderate association, and values .50 and above indicating a large association. As shown below in Table 4.3, many associations between the independent variables were statistically significant, most at levels considered weak or small. Three associations were 
observed as being moderate: 1$)$ age at entry and mental health $\left(\chi^{2}=406.43, d f=4, p=.000\right.$, Cramer's $\mathrm{V}=0.35) ; 2)$ age at entry and runaway $\left(\chi^{2}=505.34, d f=4, p=.000\right.$, Cramer's $\mathrm{V}=$ $0.39)$; and, 3) early stability and runaways $\left(\chi^{2}=336.55, d f=1, p=.000\right.$, Cramer's $\left.\mathrm{V}=0.32\right)$.

Table 4.3 Cramer's V from Cross-Tabulations of Independent Variables

\begin{tabular}{|c|c|c|c|c|c|c|c|c|c|c|c|}
\hline & Gender & $\begin{array}{l}\text { Age at } \\
\text { entry }\end{array}$ & Race & Disability & $\begin{array}{l}\text { Mental } \\
\text { health }\end{array}$ & $\begin{array}{l}\text { Removal } \\
\text { reason }\end{array}$ & $\begin{array}{l}\text { Initial } \\
\text { place }\end{array}$ & $\begin{array}{l}\text { Prior } \\
\text { removal }\end{array}$ & $\begin{array}{l}\text { Sibling } \\
\text { placemen }\end{array}$ & $\begin{array}{l}\text { Early } \\
\text { stability }\end{array}$ & Runaway \\
\hline Gender & - & & & & & & & & & & \\
\hline Age at entry & $0.10^{*}$ & & & & & & & & & & \\
\hline Race & $0.05 \dagger$ & $0.06^{*}$ & - & & & & & & & & \\
\hline Disability & $0.03 \dagger$ & $0.10^{*}$ & $0.05 \dagger$ & - & & & & & & & \\
\hline Mental health & $0.01 \dagger$ & $0.35^{* * * *}$ & $0.07 *$ & $0.19 * *$ & - & & & & & & \\
\hline Removal reason & $0.09 *$ & $0.19^{* *}$ & $0.03 \dagger$ & $0.03 \dagger$ & $0.10^{*}$ & - & & & & & \\
\hline Initial place type & $0.05 \dagger$ & $0.17 * *$ & $0.06^{*}$ & $0.15^{* *}$ & $0.14 * *$ & $0.07 *$ & ( & & & & \\
\hline Prior removal & $0.02 \dagger$ & $0.15^{* *}$ & $0.04 \dagger$ & $0.05 \dagger$ & $0.06^{*}$ & $0.05 \dagger$ & $0.05 \dagger$ & & & & \\
\hline Sibling placement & $0.03 \dagger$ & $0.22 * *$ & $0.09 *$ & $0.06 \dagger$ & $0.16^{* *}$ & $0.13^{* *}$ & $0.10^{*}$ & $0.10^{*}$ & & & \\
\hline Early stability & $0.02 \dagger$ & $0.20^{* *}$ & $0.06 \dagger$ & $0.01 \dagger$ & $0.13^{* *}$ & $0.10^{*}$ & $0.19 * *$ & $0.03 \dagger$ & $0.14 * *$ & & \\
\hline Runaways & $0.06^{*}$ & $0.39 * * *$ & $0.08^{*}$ & $0.00^{\dagger}$ & $0.15^{* *}$ & $0.15^{* *} *$ & $0.12^{* * *}$ & $0.06^{*}$ & $0.20^{* * *}$ & $0.32 * * *$ & \\
\hline
\end{tabular}

Notes:

$\mathrm{N}=3,351$.

Statistical significance was Bonferroni-corrected and set at $p \leq .001$.

$\dagger$ - indicates the Pearson $\chi^{2}$ was not statistically significant.

Asterisks indicate the strength of the association; * - weak, ** - small; *** - moderate (Cohen, 1988).

Next, bivariate survival analyses were conducted for the eleven independent variables on each of the three dependent variables. Specifically, analyses were performed using the KaplanMeier method which produces estimates of survivor functions. This method tests the equality of survivor functions across two or more groups. The statistical significance of the associations was assessed using the log-rank $\chi^{2}$ statistic and its corresponding $p$-values. The statistical significance level was Bonferroni-corrected and set at $p \leq .005(.05 / 11)$.

\section{Reunification Bivariate Analyses}

Slightly more than half of the sample exited foster care to reunification during the study period $(n=1,747,52.1 \%)$. Table 4.4 shows that nine of the eleven independent variables were significantly associated with an increased risk for reunification $(p \leq .005)$ in bivariate analyses. 
Gender was statistically significant, with males being more likely to exit through reunification than females, $54.0 \%$ vs. $50.2 \%\left(\chi^{2}=7.81, d f=1, p=.005\right)$.

Bivariate analyses indicated that age at entry was important to reunification rates $\left(\chi^{2}=53.41\right.$, $d f=4, p<.001)$. Children who entered as 6 to 9 year olds were the most likely to be reunified $(59.1 \%)$. The age group with the second highest rate of reunification was 10 to 13 year olds (57.4\%), followed by 2 to 5 year olds $(53.7 \%)$, and then 14 to 17 year olds $(50.5 \%)$. Children entering foster care as infants were the least likely to be reunified (42.4\%).

Race was statistically significant at the bivariate level $\left(\chi^{2}=32.90, d f=2, p<.001\right)$. Children in the "other" category experienced the highest rate of reunification at $66.7 \%$, compared to African American children reunifying at a rate of $45.6 \%$, and White children at a rate of $52.9 \%$.

Children with a disability were less likely to exit to reunification than children without a disability $(27.5 \%$ vs. $59.7 \%)\left(\chi^{2}=308.75, d f=1, p<.001\right)$. Similarly, children with an SED had lower reunification rates than children without an SED $(47.1 \%$ vs. $55.4 \%)\left(\chi^{2}=74.26, d f=\right.$ $1, p<.001)$.

Among primary reasons for removal, sexual abuse had the highest proportion of children exiting to reunification (59.6\%), closely followed by physical abuse (58.7\%). About half of the children who entered foster care with the primary reason of neglect or "other" exited to reunification $($ neglect $=47.8 \%$; other $=51.7 \%)\left(\chi^{2}=17.30, d f=3, p=.001\right)$.

Children whose initial placement setting was a kinship placement had the highest rate of reunification $(62.7 \%)$, closely followed by those whose first placement was in a group or residential setting $(60.0 \%)$. Children who entered foster care and were initially placed in nonkin family foster care experienced the lowest rate of reunification $(49.8 \%)\left(\chi^{2}=120.01, d f=2, p<\right.$ $.001)$. 
Information on sibling placements showed that the lowest reunification rate occurred for children who had siblings in placement but were completely separated (46.5\%). Those who had partially intact sibling placements had a slightly higher reunification rate $(48.5 \%)$. Children without siblings in placement experienced the next highest reunification rate $(50.0 \%)$, while children who had siblings in placement and who experienced a completely intact placement with their siblings had the highest rate of reunification $(60.4 \%)\left(\chi^{2}=57.07, d f=3, p<.001\right)$.

Children who never experienced a runaway event were more likely to exit to reunification than children who did experience a runaway event ( $53.9 \%$ vs. $34.8 \%$, respectively) $\left(\chi^{2}=28.46\right.$, $d f=1, p<.001)$

The two variables that did not have a statistically significant bivariate association with reunification were prior removals $\left(\chi^{2}=5.74, d f=1, p=.017\right)$ and early stability $\left(\chi^{2}=4.55, d f=\right.$ $1, p=.030)$. 
Table 4.4 Proportion of Exits to Reunification and Bivariate Survival Analysis

\begin{tabular}{|c|c|c|c|c|c|}
\hline & $\begin{array}{r}\text { Sample } \\
\mathrm{N} \\
\end{array}$ & $\begin{array}{r}\text { Reunified } \\
\mathrm{n} \\
\end{array}$ & $\begin{array}{r}\text { Reunified } \\
\% \\
\end{array}$ & $\begin{array}{r}\text { Log-rank } \\
\chi^{2}(\mathrm{df}) \\
\end{array}$ & $p$-value \\
\hline & 3,351 & 1,747 & 52.1 & - & - \\
\hline Gender & & & & $7.81(1)$ & .005 \\
\hline Female & 1,634 & 820 & 50.2 & & \\
\hline Male & 1,717 & 927 & 54.0 & & \\
\hline Age at entry & & & & $53.41(4)$ & $<.001$ \\
\hline 0 to $1 \mathrm{yrs}$ & 618 & 262 & 42.4 & & \\
\hline 2 to $5 \mathrm{yrs}$ & 668 & 359 & 53.7 & & \\
\hline 6 to $9 \mathrm{yrs}$ & 531 & 314 & 59.1 & & \\
\hline 10 to $13 \mathrm{yrs}$ & 549 & 315 & 57.4 & & \\
\hline 14 to $17 \mathrm{yrs}$ & 985 & 497 & 50.5 & & \\
\hline Race & & & & $32.90(2)$ & $<.001$ \\
\hline White & 2,721 & 1,439 & 52.9 & & \\
\hline African American & 531 & 242 & 45.6 & & \\
\hline Other & 99 & 66 & 66.7 & & \\
\hline Disability & & & & $308.75(1)$ & $<.001$ \\
\hline No disability & 2,563 & 1,530 & 59.7 & & \\
\hline Has disability & 788 & 217 & 27.5 & & \\
\hline Mental health & & & & $74.26(1)$ & $<.001$ \\
\hline Not SED & 2,044 & 1,132 & 55.4 & & \\
\hline SED & 1,307 & 615 & 47.1 & & \\
\hline Reason for removal & & & & $17.30(3)$ & .001 \\
\hline Neglect & 806 & 385 & 47.8 & & \\
\hline Physical abuse & 467 & 274 & 58.7 & & \\
\hline Sexual abuse & 171 & 102 & 59.6 & & \\
\hline Other & 1,907 & 986 & 51.7 & & \\
\hline Prior removal history & & & & $5.74(1)$ & .017 \\
\hline No prior removal(s) & 3,063 & 1,625 & 53.1 & & \\
\hline Has prior removal(s) & 288 & 122 & 42.4 & & \\
\hline Initial placement type & & & & $120.01(2)$ & $<.001$ \\
\hline Kinship care & 480 & 301 & 62.7 & & \\
\hline Family foster care & 2,701 & 1,344 & 49.8 & & \\
\hline Group or residential & 170 & 102 & 60.0 & & \\
\hline Sibling placements & & & & $57.07(3)$ & $<.001$ \\
\hline Completely separated & 172 & 80 & 46.5 & & \\
\hline Partially intact & 757 & 367 & 48.5 & & \\
\hline Completely intact & 854 & 516 & 60.4 & & \\
\hline No siblings in placement & 1,568 & 784 & 50.0 & & \\
\hline Early stability & & & & $4.55(1)$ & .030 \\
\hline No early stability & 633 & 312 & 49.3 & & \\
\hline Early stability & 2,718 & 1,435 & 52.8 & & \\
\hline Runaways & & & & $28.46(1)$ & $<.001$ \\
\hline No runaway events & 3,041 & 1,639 & 53.9 & & \\
\hline Runaway events & 310 & 108 & 34.8 & & \\
\hline
\end{tabular}




\section{Guardianship Bivariate Analyses}

Exits to guardianship occurred for $9.2 \%(\mathrm{n}=308)$ of the children in the study sample. Table 4.5 displays the proportion of children exiting to guardianship and Log-rank $\chi^{2}$ statistics. At the bivariate level and using a Bonferroni-corrected alpha $=.005$, six of eleven independent variables were statistically significant with an increased risk for guardianship.

Age was significantly associated with exits to guardianship at the bivariate level $\left(\chi^{2}=27.46\right.$, $d f=4, p<.001)$. The age group most likely to exit to guardianship was children who entered foster care between the ages of 10 and $13(14.0 \%)$, followed by 6 to 9 year olds $(10.7 \%), 2$ to 5 year olds $(9.0 \%)$, and 14 to 17 year olds $(8.1 \%)$. Infants were least likely to experience guardianship with a $5.5 \%$ guardianship rate.

Guardianship occurred at a significantly lower rate for children with disabilities as compared to children without a disability $(4.8 \%$ vs. $10.5 \%)\left(\chi^{2}=63.63, d f=1, p<.001\right)$.

The relationship between mental health and guardianship was also statistically significant $\left(\chi^{2}\right.$ $=10.27, d f=1, p=.001)$, indicating that children with emotional and behavioral problems were less likely to exit to guardianship than children without emotional and behavioral problems (8.9\% vs. $9.4 \%)$.

The significant bivariate association between initial placemen type and guardianship $\left(\chi^{2}=\right.$ 323.25, $d f=2, p<.001)$ showed that children initially placed in kinship care were more likely to exit to guardianship $(25.8 \%)$ than children initially placed in family foster care $(6.4 \%)$ or a group/residential setting $(6.4 \%)$.

Children's experience of sibling placement significantly influenced rates of guardianship at the bivariate level $\left(\chi^{2}=15.24, d f=3, p=.002\right)$. Children that experienced completely intact sibling placements had the highest rate of guardianship (11.8\%), followed by children that 
experienced partially intact placements (9.8\%), and children who were completely separated from siblings with a concurrent foster care episode $(8.7 \%)$. The lowest rate of guardianship occurred for children who did not have siblings in placement (i.e., no concurrent foster care episode) $(7.5 \%)$.

The bivariate association between early stability and guardianship was also statistically significant $\left(\chi^{2}=7.89, d f=1, p=.005\right)$. Children who experienced early stability had higher rates of guardianship than children who did not have early stability (9.8\% vs. $6.6 \%)$.

Independent variables that did not have a statistically significant association with guardianship were: gender $\left(\chi^{2}=0.04, d f=1, p=.839\right)$, race $\left(\chi^{2}=32.9, d f=2, p=.08\right)$, reason for removal $\left(\chi^{2}=1.03, d f=3, p=.795\right)$, prior removal history $\left(\chi^{2}=2.56, d f=1, p=.110\right)$, and runaways $\left(\chi^{2}=6.51, d f=1, p=.011\right)$. 
Table 4.5 Proportion of Exits to Guardianship and Bivariate Survival Analysis

\begin{tabular}{|c|c|c|c|c|c|}
\hline & $\begin{array}{r}\text { Sample } \\
\mathrm{N} \\
\end{array}$ & $\begin{array}{r}\text { Guardian. } \\
\mathrm{n}\end{array}$ & $\begin{array}{r}\text { Guardian. } \\
\% \\
\end{array}$ & $\begin{array}{r}\text { Log-rank } \\
\chi^{2}(\mathrm{df}) \\
\end{array}$ & $p$-value \\
\hline & 3,351 & 308 & & - & - \\
\hline Gender & & & & $.04(1)$ & .839 \\
\hline Female & 1,634 & 158 & 9.7 & & \\
\hline Male & 1,717 & 150 & 8.7 & & \\
\hline Age at entry & & & & $27.76(4)$ & $<.001$ \\
\hline 0 to $1 \mathrm{yrs}$ & 618 & 34 & 5.5 & & \\
\hline 2 to $5 \mathrm{yrs}$ & 668 & 60 & 9.0 & & \\
\hline 6 to $9 \mathrm{yrs}$ & 531 & 57 & 10.7 & & \\
\hline 10 to $13 \mathrm{yrs}$ & 549 & 77 & 14.0 & & \\
\hline 14 to $17 \mathrm{yrs}$ & 985 & 80 & 8.1 & & \\
\hline Race & & & & $32.9(2)$ & .077 \\
\hline White & 2,721 & 260 & 9.6 & & \\
\hline African American & 531 & 41 & 7.7 & & \\
\hline Other & 99 & 7 & 7.1 & & \\
\hline Disability & & & & $63.63(1)$ & $<.001$ \\
\hline No disability & 2,563 & 270 & 10.5 & & \\
\hline Has disability & 788 & 38 & 4.8 & & \\
\hline Mental health & & & & & \\
\hline Not SED & 2,044 & 192 & 9.4 & $10.27(1)$ & .001 \\
\hline SED & 1,307 & 116 & 8.9 & & \\
\hline Reason for removal & & & & $1.03(3)$ & .795 \\
\hline Neglect & 806 & 86 & 10.7 & & \\
\hline Physical abuse & 467 & 39 & 8.4 & & \\
\hline Sexual abuse & 171 & 15 & 8.8 & & \\
\hline Other & 1,907 & 168 & 8.8 & & \\
\hline Prior removal history & & & & $2.56(1)$ & .110 \\
\hline No prior removal(s) & 3,063 & 274 & 8.9 & & \\
\hline Has prior removal(s) & 288 & 34 & 11.8 & & \\
\hline Initial placement type & & & & $323.25(2)$ & $<.001$ \\
\hline Kinship care & 480 & 124 & 25.8 & & \\
\hline Family foster care & 2,701 & 173 & 6.4 & & \\
\hline Group or residential & 170 & 11 & 6.5 & & \\
\hline Sibling placements & & & & $15.24(3)$ & .002 \\
\hline Completely separated & 172 & 15 & 8.7 & & \\
\hline Partially intact & 757 & 74 & 9.8 & & \\
\hline Completely intact & 854 & 101 & 11.8 & & \\
\hline No siblings in placement & 1,568 & 118 & 7.5 & & \\
\hline Early stability & & & & $7.89(1)$ & .005 \\
\hline No early stability & 633 & 42 & 6.6 & & \\
\hline Early stability & 2,718 & 266 & 9.8 & & \\
\hline Runaways & & & & $6.51(1)$ & .011 \\
\hline No runaway events & 3,041 & 290 & 9.5 & & \\
\hline Runaway events & 310 & 18 & 5.8 & & \\
\hline
\end{tabular}




\section{Adoption Bivariate Analyses}

Among the 3,351 children in the sample, $13.9 \%(n=467)$ of them exited to adoption. The Log-rank $\chi^{2}$ statistics for bivariate analyses are displayed in Table 4.6. With a Bonferronicorrected alpha $=.005$, eight of the eleven independent variables were statistically significant with an increased risk for adoption at the bivariate level.

The significant relationship between age at entry and adoption $\left(\chi^{2}=295.58, d f=4, p<.001\right)$ showed a distinct trend of progressively lower rates of adoption for each increase in age (infants $=37.9 \%, 2$ to 5 years old $=19.6 \%, 6$ to 9 year olds $=11.7 \%, 10$ to 13 year olds $=5.8 \%, 14$ to 17 year olds $=0.8 \%$.

Children with a disability were significantly more likely to exit to adoption than children without a disability $(32.1 \%$ vs. $8.1 \%)\left(\chi^{2}=47.2, d f=1, p<.001\right)$. In contrast, serious mental health problems were related to lower rates of adoption $(\mathrm{SED}=9.1 \%$ vs. Not SED $=17.0 \%)\left(\chi^{2}\right.$ $=123.34, d f=1, p<.001)$.

The primary reason for removal also had a significant bivariate association with adoption $\left(\chi^{2}\right.$ $=30.21, d f=3, p<.001)$. Children who entered foster care with the primary reason of neglect were the most likely to exit to adoption $(21.5 \%)$, followed by the "other" category (12.2\%), and physical abuse $(9.9 \%)$. Adoption rates were the lowest for children who entered foster care with sexual abuse as the primary reason $(8.8 \%)$.

Having a history of prior removals into foster care was associated with a reduction in adoption rates $($ Had prior removal $(\mathrm{s})=7.6 \%$, No prior removal $=14.5 \%)\left(\chi^{2}=7.89, d f=1, p=\right.$ $.005)$.

Children's experience of sibling placements significantly influenced rates of adoption $\left(\chi^{2}=\right.$ 68.83, $d f=3, p<.001)$. Children that experienced completely intact sibling placements were the 
most likely to exit to adoption (19.0\%), followed by children that experienced partially intact placements $(12.9 \%)$, and then children who did not have siblings in placement (i.e., no concurrent foster care episode) (12.3\%). The lowest rate of adoption occurred for children who were completely separated from their siblings with concurrent foster care episodes $(8.1 \%)$.

Early stability was significantly associated with higher rates of adoption at the bivariate level $($ early stability $=15.7 \%$, no early stability $=6.5 \%)\left(\chi^{2}=39.74, d f=1, p<.001\right)$.

Finally, children who ran away one or more times while in foster care had significantly lower rates of adoption than children who did not runaway while in foster care $(0.6 \%$ vs. $15.3 \%)\left(\chi^{2}=\right.$ 51.40, $d f=1, p<.001)$.

The independent variables that did not have statistically significant associations with adoption included gender $\left(\chi^{2}=0.16, d f=1, p<.688\right)$, race $\left(\chi^{2}=9.56, d f=2, p=.008\right)$, and initial placement type $\left(\chi^{2}=7.72, d f=2, p=.021\right)$. 
Table 4.6 Proportion of Exits to Adoption and Bivariate Survival Analysis

\begin{tabular}{|c|c|c|c|c|c|}
\hline & $\begin{array}{r}\text { Sample } \\
\mathrm{N}\end{array}$ & $\begin{array}{r}\text { Adoption } \\
\mathrm{n}\end{array}$ & $\begin{array}{r}\text { Adoption } \\
\% \\
\end{array}$ & $\begin{array}{r}\text { Log-rank } \\
\chi^{2}(\mathrm{df})\end{array}$ & $p$-value \\
\hline & 3,351 & 467 & 13.9 & - & - \\
\hline Gender & & & & $0.16(1)$ & .688 \\
\hline Female & 1,634 & 238 & 14.6 & & \\
\hline Male & 1,717 & 229 & 13.3 & & \\
\hline Age at entry & & & & $295.58(4)$ & $<.001$ \\
\hline 0 to $1 \mathrm{yrs}$ & 618 & 234 & 37.9 & & \\
\hline 2 to $5 \mathrm{yrs}$ & 668 & 131 & 19.6 & & \\
\hline 6 to $9 \mathrm{yrs}$ & 531 & 62 & 11.7 & & \\
\hline 10 to $13 \mathrm{yrs}$ & 549 & 32 & 5.8 & & \\
\hline 14 to $17 \mathrm{yrs}$ & 985 & 8 & 0.8 & & \\
\hline Race & & & & $9.56(2)$ & .008 \\
\hline White & 2,721 & 384 & 14.1 & & \\
\hline African American & 531 & 74 & 13.9 & & \\
\hline Other & 99 & 9 & 9.1 & & \\
\hline Disability & & & & $47.2(1)$ & $<.001$ \\
\hline No disability & 2,563 & 214 & 8.3 & & \\
\hline Has disability & 788 & 253 & 32.1 & & \\
\hline Mental health & & & & $123.34(1)$ & $<.001$ \\
\hline Not SED & 2,044 & 348 & 17.0 & & \\
\hline SED & 1,307 & 119 & 9.1 & & \\
\hline Reason for removal & & & & $30.21(3)$ & $<.001$ \\
\hline Neglect & 806 & 173 & 21.5 & & \\
\hline Physical abuse & 467 & 46 & 9.9 & & \\
\hline Sexual abuse & 171 & 15 & 8.8 & & \\
\hline Other & 1,907 & 233 & 12.2 & & \\
\hline Prior removal history & & & & $7.89(1)$ & .005 \\
\hline No prior removal(s) & 3,063 & 445 & 14.5 & & \\
\hline Has prior removal(s) & 288 & 22 & 7.6 & & \\
\hline Initial placement type & & & & $7.72(2)$ & .021 \\
\hline Kinship care & 480 & 19 & 4.0 & & \\
\hline Family foster care & 2,701 & 434 & 16.1 & & \\
\hline Group or residential & 170 & 14 & 8.2 & & \\
\hline Sibling placements & & & & $68.83(3)$ & $<.001$ \\
\hline Completely separated & 172 & 14 & 8.1 & & \\
\hline Partially intact & 757 & 98 & 12.9 & & \\
\hline Completely intact & 854 & 162 & 19.0 & & \\
\hline No siblings in placement & 1,568 & 193 & 12.3 & & \\
\hline Early stability & & & & $39.74(1)$ & $<.001$ \\
\hline No early stability & 633 & 41 & 6.5 & & \\
\hline Early stability & 2,718 & 426 & 15.7 & & \\
\hline Runaways & & & & $51.40(1)$ & $<.001$ \\
\hline No runaway events & 3,041 & 465 & 15.3 & & \\
\hline Runaway events & 310 & 2 & 0.6 & & \\
\hline
\end{tabular}




\section{Multivariate Analyses}

\section{Competing Risks Preliminary Analyses}

The first step of the competing risks analysis was to observe time to foster care exit for the different types of permanency - reunification, guardianship, and adoption. Figure 4.5 shows plots of the three types of permanency exit. Table 4.7 shows the results of the overall and paired comparisons, all of which were statistically significant using the Wilcoxon (Gehan) statistic ( $p=$ $.000)$. These results indicate that the time to exit was significantly different among these three types of permanency. As previously noted, exits from foster care occurred more quickly for children reunifying with family, followed by exits to guardianship, and then adoption. If these findings were not statistically significant then it would have been appropriate to examine foster care exits to permanency as a single type of exit, any permanency.

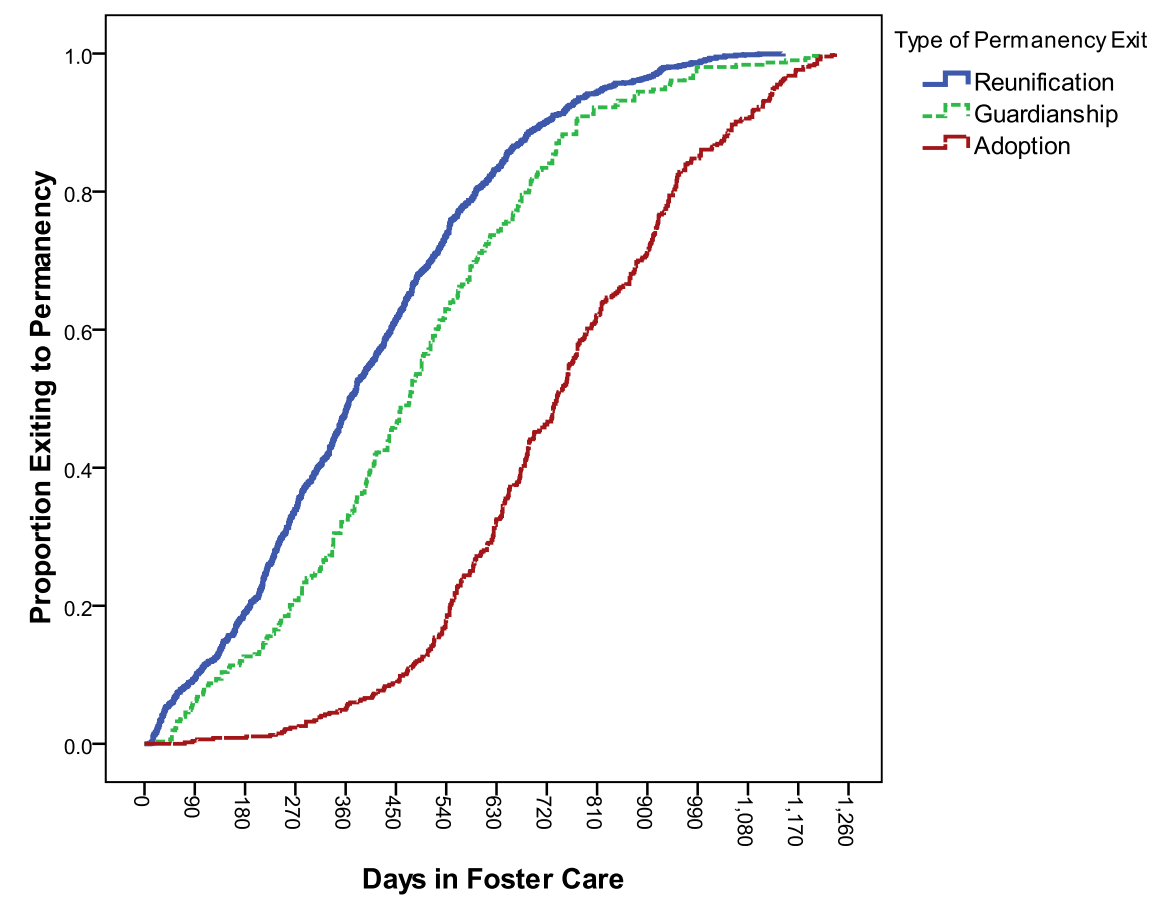

Figure 4.5 Time to Foster Care Exits to Permanency By Type Of Permanency 
Table 4.7 Overall and Paired Comparisons of Permanency Exit Types

\begin{tabular}{lrr}
\hline Comparison & Wilcoxon (Gehan) & \\
Overall & Statistic $(\boldsymbol{d} f)$ & $\boldsymbol{p}$ \\
Reunification vs. Guardianship & $561.29(2)$ & .000 \\
Reunification vs. Adoption & $31.45(1)$ & .000 \\
Guardianship vs. Adoption & $546.32(1)$ & .000 \\
\hline
\end{tabular}

The next step in the competing risks analysis was to determine whether an overall model that does not distinguish between exit types is improved upon by using separate models for each exit type. Four separate Cox regression models were run to ascertain a log-likelihood value for each model: 1) an overall model that did not differentiate exit type, 2) a reunification model, 3) a guardianship model, and 4) an adoption model. As explained in chapter 3 (page 55) a likelihoodratio chi-square statistic was calculated from the output of all four models. Table 4.8 displays the output from these calculations. The results demonstrated that the overall model was improved upon by the differentiating models $\left(\chi^{2}=846.85, d f=40, p<.001\right)$. Thus, competing risks analysis proceeded with running multivariate Cox regression models for reunification, guardianship, and adoption.

Table 4.8 Likelihood-Ratio Chi-Square Statistics for Comparing Overall Model to Three Differentiating Models

\begin{tabular}{rrrrr}
\hline & \multicolumn{4}{c}{$\begin{array}{c}\text { Likelihood-Ratio } \\
\text { Chi-Square }\end{array}$} \\
Model & Likelihood & $\begin{array}{r}\text { (-2*Log Likelihood) } \\
\boldsymbol{d} \boldsymbol{f}\end{array}$ & $\boldsymbol{p}$ \\
\hline Overall & -18316.54 & 36633.07 & 20 & - \\
Reunification & -12866.41 & 25732.82 & 20 & - \\
Guardianship & -2116.77 & 4233.55 & 20 & - \\
Adoption & -2909.92 & 5819.85 & 20 & - \\
\hline Overall - Sum of 3 Differentiating Models & & 35786.22 & 60 & - \\
\hline
\end{tabular}


Results of each model are described below and displayed in tables. The dependent variable was time to exit measured in days. Each of the models included a common set of 11 independent variables as outlined in chapter 3 . In addition, time interactions were entered into the models as indicated by visual and statistical procedures that assessed the proportional hazards assumption. Results of each regression model are shown in tables that provide information on the overall model chi-square, as well as hazard ratio, robust standard error, regression coefficient, Wald chisquare, $p$-values, and 95\% confidence interval for the hazard ratios. Hazard ratios correspond to the percentage change in the hazard rate for a particular value of the variable relative to the reference category for that variable, while controlling for all other variables. Reference categories are presented in parentheses. A hazard ratio significantly less than one indicates a decrease in the probability of exiting to that permanency outcome for that value relative to the reference category. A hazard ratio significantly greater than one indicates an increase in probability of exiting to that permanency outcome for that value relative to the reference category. A hazard ratio equal to one means there is no difference between a particular value and the reference category in terms of probability of exit to that outcome.

\section{Reunification Model}

Reunification was the most common type of permanent exit in this study with $52.1 \%$ of children $(n=1,747)$ experiencing reunification at a median time of 366 days. Results of the Cox regression model for exits to reunification showed that inclusion of covariates (i.e., independent variables $)$ significantly improved model fit over that of the baseline hazard model $\left(\chi^{2}=520.26\right.$, $d f=22, p=.0000)$. When all other variables were held constant, a number of significant relationships were observed between child and placement characteristics and reunification. Table 4.9 displays the reunification Cox regression model results. 
Child's gender was the only variable in the multivariate model that did not significantly influence rates of reunification $(\mathrm{HR}=1.08, p=.097)$.

Child's age at entry to foster care was statically significant for all age groups with rates of reunification increasing with age. Children who entered foster care between the ages of 2 and 5 were $61 \%$ more likely to experience reunification than infants $(\mathrm{HR}=1.61, p=.000)$. For those who entered foster care between the ages of 6 and 9, they were twice as likely to exit to reunification as infants $(\mathrm{HR}=2.03, p=.000)$. Youth who entered care in their early teen years (10 to 13 years old) were slightly more than twice as likely to exit to reunification as infants (HR $=2.10, p=.000$ ). Finally, youth in the oldest age group (14 to $17 \mathrm{yrs}$ ) were 2.6 times more likely to reunify than children who entered care as an infant $(\mathrm{HR}=2.60, p=.000)$.

Race was significantly associated with reunification, but only for one of the groups. Children in the "other" race category had significantly higher rates of reunification; they were nearly oneand-one-half times more likely to reunify than White children $(\mathrm{HR}=1.47, p=.015)$. Although African American children had slightly lower rates of reunification than White children the difference was not statistically significant $(\mathrm{HR}=0.83, p=.083)$.

Both disability of any kind and serious mental health problems were associated with a lower likelihood of reunification (disability, $\mathrm{HR}=0.32, p=.000$; mental health, $\mathrm{HR}=0.10, p=.000$ ). Children with a disability were $68 \%$ less likely to exit to reunification than children without a disability (i.e., $100 *(0.32-1)=68 \%)$. Similarly, children with an SED were $90 \%$ less likely to exit to reunification as compared to children without an SED.

Reason for removal was related to rates of reunification for some of the subgroups. As compared to children who entered care for the primary reason of neglect, reunification was $36 \%$ more likely for children who entered care due to physical abuse $(\mathrm{HR}=1.36, p=.005)$ and $38 \%$ 
more likely for children who entered care due to sexual abuse $(\mathrm{HR}=1.38, p=.051)$. There was no statistically significant difference in exits to reunification between children who entered foster care for "other" reasons and children who entered care for neglect.

A history of prior removals was associated with lower rates of reunification $(\mathrm{HR}=0.80, p=$ .048). Children with prior removals were $20 \%$ less likely to exit to reunification than children without prior removals.

Initial placement type was significantly associated with reunification, but only for children initially placed in family foster care. Children whose initial placement was in family foster care were $24 \%$ less likely to exit to reunification than children who were initially placed in a kinship placement $(\mathrm{HR}=0.76, p=.002)$. Rates of reunification were slightly higher but not significantly different for children initially in a group or residential setting as compared to children initially in kinship placements $(\mathrm{HR}=1.31, p=.066)$.

Sibling placements were significant for reunification rates. Children with completely intact sibling placements were $46 \%$ more likely to exit to reunification than children with sibling placements that were completely separated $(\mathrm{HR}=1.46, p=.016)$. Children with no siblings in placement were also more likely to reunify than children who were completely separated from their siblings $(\mathrm{HR}=1.34, p=.042)$. In contrast, rates of reunification did not differ between children with sibling placements that were completely separated and children with partially intact sibling placements $(\mathrm{HR}=0.90, p=.487)$.

Early stability was significantly associated with reunification. Children who experienced early placement stability in foster care were more than seven times likely to exit to reunification than children who did not experience early placement stability $(\mathrm{HR}=7.88, p=.000)$. 
Reunification rates were significantly influenced by runaways. Children with runaway events in foster care were about half as likely to exit to reunification as children who did not runaway in foster care $(\mathrm{HR}=0.47, p=.000)$.

Finally, the time interaction variables for mental health and early stability showed significant relationships with reunification (mental health, $\mathrm{HR}=1.38, p=.000$; early stability, $\mathrm{HR}=0.70, p$ $=.000$ ). These results indicate that children with an SED were less likely to exit to reunification than children without an SED, but the difference in reunification rates decreased over time. For example, the regression coefficients for mental health and the time interaction with mental health demonstrates the change in the hazard ratio as time passes by entering the number of days into the calculation of the hazard ratio. The hazard ratio for children with an SED is 0.10 as they enter foster care $(\exp (-2.282333+(\log (1) * 0.3214399))=0.10), 0.23$ at one year $(\exp (-$ $2.282333+(\log (365) * 0.3214399))=0.23)$, and 0.25 at two years $(\exp (-2.282333+(\log (760) *$ $0.3214399))=0.25)$. This means that at entry children with an SED were $90 \%$ less likely to exit to reunification than children without an SED. By the one year and two year points children with an SED were $77 \%$ and $75 \%$ less likely to reunify than children without an SED, respectively. So, the hazard ratio decreased over time, but having serious mental health problems remained significantly associated with lower rates of reunification. The same equation can be used with the regression coefficients for early stability and its time interaction term. Initially, children with early stability were more than seven times more likely to exit to reunification than children without early stability $(\exp (2.064251+(\log (1) *-0.3578604))=7.88)$. By the one year point, the hazard ratio dropped to $3.15(\exp (2.064251+(\log (365) *-0.3578604))=3.15)$ and by the two year point it is $2.83(\exp (2.064251+(\log (760) *-0.3578604))=2.83)$. Again, the significant time interactions indicate that the hazard ratio changes over time (i.e., is not 
proportional). In the case of early stability, the likelihood of reunification remained higher for children with early stability as compared to children without early stability, though the difference in rates of reunification decreased over time. 
Table 4.9 Cox Regression Model for Exits to Reunification

\begin{tabular}{|c|c|c|c|c|c|c|c|}
\hline & \multirow{2}{*}{$\begin{array}{r}\text { Hazard } \\
\text { Ratio } \\
\end{array}$} & \multirow{2}{*}{$\begin{array}{r}\text { Robust } \\
\text { Std. Error }\end{array}$} & \multirow{2}{*}{$\begin{array}{l}\text { Regr } \\
\text { Coeff. }\end{array}$} & \multirow[b]{2}{*}{ Wald $\chi^{2}$} & \multirow[b]{2}{*}{$p$} & \multicolumn{2}{|c|}{ Hazard Ratio $95 \%$ CI } \\
\hline & & & & & & Lower & Upper \\
\hline \multicolumn{8}{|l|}{$\begin{array}{r}\text { Gender } \\
\text { (Female) }\end{array}$} \\
\hline Male & 1.08 & 0.05 & 0.08 & 1.66 & .097 & 0.99 & 1.19 \\
\hline \multicolumn{8}{|l|}{$\begin{array}{r}\text { Age at entry } \\
(0 \text { to } 1 \text { yrs })\end{array}$} \\
\hline 2 to $5 \mathrm{yrs}$ & 1.61 & 0.14 & 0.48 & 5.72 & .000 & 1.37 & 1.90 \\
\hline 6 to $9 \mathrm{yrs}$ & 2.03 & 0.19 & 0.71 & 7.65 & .000 & 1.69 & 2.43 \\
\hline 10 to $13 \mathrm{yrs}$ & 2.10 & 0.21 & 0.74 & 7.71 & .000 & 1.74 & 2.54 \\
\hline 14 to $17 \mathrm{yrs}$ & 2.60 & 0.24 & 0.95 & 10.20 & .000 & 2.16 & 3.12 \\
\hline \multicolumn{8}{|l|}{$\begin{array}{r}\text { Race } \\
\text { (White) }\end{array}$} \\
\hline African American & 0.83 & 0.09 & -0.18 & -1.73 & .083 & 0.68 & 1.02 \\
\hline Other & 1.47 & 0.23 & 0.38 & 2.43 & .015 & 1.08 & 2.00 \\
\hline \multicolumn{8}{|l|}{ Disability } \\
\hline Has disability & 0.32 & 0.03 & -1.15 & -12.74 & .000 & 0.27 & 0.38 \\
\hline \multicolumn{8}{|l|}{$\begin{array}{r}\text { Mental health } \\
\text { (Not SED) }\end{array}$} \\
\hline SED & 0.10 & 0.04 & -2.28 & -5.21 & .000 & 0.04 & 0.24 \\
\hline \multicolumn{8}{|l|}{$\begin{array}{r}\text { Reason for removal } \\
\text { (Neglect) }\end{array}$} \\
\hline Physical abuse & 1.36 & 0.15 & 0.31 & 2.78 & .005 & 1.10 & 1.70 \\
\hline Sexual abuse & 1.38 & 0.23 & 0.32 & 1.95 & .051 & 0.99 & 1.91 \\
\hline Other & 1.08 & 0.09 & 0.08 & 0.92 & .359 & 0.91 & 1.28 \\
\hline \multicolumn{8}{|l|}{$\begin{array}{l}\text { Prior removal history } \\
(\text { No prior removal(s)) }\end{array}$} \\
\hline Has prior removal(s) & 0.80 & 0.09 & -0.23 & -1.98 & .048 & 0.63 & 1.00 \\
\hline \multicolumn{8}{|l|}{$\begin{array}{r}\text { Initial placement type } \\
\text { (Kinship care) }\end{array}$} \\
\hline Family foster care & 0.76 & 0.07 & -0.28 & -3.07 & .002 & 0.63 & 0.90 \\
\hline Group or residential & 1.31 & 0.19 & 0.27 & 1.84 & .066 & 0.98 & 1.74 \\
\hline \multirow{2}{*}{\multicolumn{8}{|c|}{$\begin{array}{r}\text { Sibling placements } \\
\text { (Completely separated) }\end{array}$}} \\
\hline & & & & & & & \\
\hline Partially intact & 0.90 & 0.14 & -0.11 & -0.69 & .487 & 0.65 & 1.22 \\
\hline Completely intact & 1.46 & 0.23 & 0.38 & 2.40 & .016 & 1.07 & 1.98 \\
\hline No siblings in placement & 1.34 & 0.19 & 0.29 & 2.04 & .042 & 1.01 & 1.77 \\
\hline \multicolumn{8}{|l|}{$\begin{array}{r}\text { Early stability } \\
\text { (No early stability) }\end{array}$} \\
\hline Early stability & 7.88 & 4.53 & 2.06 & 3.59 & .000 & 2.55 & 24.31 \\
\hline \multirow{2}{*}{\multicolumn{8}{|c|}{$\begin{array}{r}\text { Runaways } \\
\text { (No runaway events) }\end{array}$}} \\
\hline & & & & & & & \\
\hline Runaway events & 0.47 & 0.05 & -0.79 & -6.93 & .000 & 0.36 & 0.57 \\
\hline \multicolumn{8}{|l|}{ Time interactions } \\
\hline Mental Health $* \ln (t)$ & 1.38 & 0.10 & 0.32 & 4.29 & .000 & 1.19 & 1.60 \\
\hline Early Stability $* \ln (\mathrm{t})$ & 0.70 & 0.07 & -0.36 & -3.68 & .000 & 0.58 & 0.85 \\
\hline \multicolumn{8}{|c|}{ est of null hypothesis (all parameters = 0): } \\
\hline & Withou & Covariates & With & ovariates & $\overline{\text { Model } \chi^{2}}$ & $d f$ & \\
\hline$-2 \log L$ & & $26,476.34$ & & $25,724.31$ & 520.26 & 22 & .0000 \\
\hline
\end{tabular}

Reference category is in parentheses. Number of events $=1,747$; Censored $=1,604(47.9 \%)$; Total $=3,351$. 


\section{Guardianship Model}

Guardianship was the least common path to permanency with $9.2 \%$ of the children leaving foster care for this reason $(n=308)$. The median time to guardianship was 474 days. The Cox regression model for guardianship is presented in Table 4.10. Results of the model indicated that inclusion of covariates significantly improved model fit over that of the baseline model $\left(\chi^{2}=\right.$ 236.04, $d f=20, p=.0000)$. When all other variables were held constant, four independent variables were shown to have significant relationships with exiting to guardianship.

First, age at entry to foster care was significantly associated with exits to guardianship and the risk for guardianship increased with age. Children who entered foster care between the ages of 2 and 5 were more than one-and-one-half times as likely to experience guardianship as infants $(\mathrm{HR}=1.57 ; p=.037)$. For those who entered foster care between the ages of 6 and 9 , they were about twice as likely to exit to guardianship as infants $(\mathrm{HR}=2.09 ; p=.004)$. Youth who entered care in their early teen years (10 to 13 years old) were nearly four times as likely to exit to guardianship as infants $(\mathrm{HR}=3.96 ; p=.000)$. Older teens $(14-17$ years old $)$ were about fourand-one-half times as likely to exit to guardianship as infants $(\mathrm{HR}=4.46, p=.000)$.

Second, disability was associated with a significant reduction in guardianship rates (HR = $0.36, p=.000$ ). Children with a disability were $64 \%$ less likely to exit to guardianship than children without a disability.

The third significant variable in the guardianship model is initial placement type. Children who entered foster care with an initial placement in family foster care were $82 \%$ less likely to exit to guardianship than children who were initially placed into kinship care $(\mathrm{HR}=0.18 ; p=$ .000). Likewise, children whose initial placement was in a group or residential setting had significantly lower rates of guardianship as compared to children who were initially placed into 
kinship care. Children whose initial placement was in group or residential setting were $71 \%$ less likely to exit to guardianship than children in kinship care $(\mathrm{HR}=0.29, p=.001)$.

Fourth, runaways were significantly associated with lower rates of exits to guardianship. Children who had runaway events in foster care were about half as likely to experience guardianship as children who did not runaway while in foster care $(\mathrm{HR}=0.51 ; p=.042)$.

Independent variables that did not have significant association with guardianship include gender $(\mathrm{HR}=0.94 ; p=.588)$, race (African American, $\mathrm{HR}=0.72, p=.186 ;$ Other, $\mathrm{HR}=1.18 ; p$ $=.706)$, mental health $(\mathrm{HR}=0.81, p=.132)$, reason for removal (physical abuse, $\mathrm{HR}=0.92, p=$ .779 ; sexual abuse, $\mathrm{HR}=0.90, p=.786$; other, $\mathrm{HR}=0.78, p=.192)$, prior removal history $(\mathrm{HR}$ $=1.45, p=.173)$, and early stability $(\mathrm{HR}=1.01, p=.978)$. 
Table 4.10 Cox Regression Model for Exits to Guardianship

\begin{tabular}{|c|c|c|c|c|c|c|c|}
\hline & \multirow{2}{*}{$\begin{array}{r}\text { Hazard } \\
\text { Ratio } \\
\end{array}$} & \multirow{2}{*}{$\begin{array}{r}\text { Robust } \\
\text { Std. Error } \\
\end{array}$} & \multirow{2}{*}{$\begin{array}{l}\text { Regr } \\
\text { Coeff. }\end{array}$} & \multirow[b]{2}{*}{ Wald $\chi^{2}$} & \multicolumn{3}{|c|}{ Hazard Ratio 95\% CI } \\
\hline & & & & & $p$ & Lower & Upper \\
\hline \multicolumn{8}{|l|}{$\begin{array}{l}\text { Gender } \\
\text { (Female) }\end{array}$} \\
\hline \multicolumn{8}{|l|}{$\begin{array}{r}\text { Age at entry } \\
(0 \text { to } 1 \text { yrs })\end{array}$} \\
\hline 2 to 5 yrs & 1.57 & 0.34 & 0.45 & 2.09 & .037 & 1.03 & 2.41 \\
\hline 6 to $9 \mathrm{yrs}$ & 2.09 & 0.53 & 0.73 & 2.92 & .004 & 1.27 & 3.42 \\
\hline 10 to $13 \mathrm{yrs}$ & 3.96 & 1.00 & 1.38 & 5.43 & .000 & 2.41 & 6.51 \\
\hline 14 to $17 \mathrm{yrs}$ & 4.46 & 1.14 & 1.50 & 5.83 & .000 & 2.70 & 7.38 \\
\hline \multicolumn{8}{|l|}{$\begin{array}{r}\text { Race } \\
\text { (White) }\end{array}$} \\
\hline African American & 0.72 & 0.18 & -0.33 & -1.32 & .186 & 0.44 & 1.17 \\
\hline Other & 1.18 & 0.53 & 0.17 & 0.38 & .706 & 0.49 & 2.83 \\
\hline \multicolumn{8}{|l|}{$\begin{array}{r}\text { Disability } \\
\text { (No disability) }\end{array}$} \\
\hline \multicolumn{8}{|l|}{$\begin{array}{r}\text { Mental health } \\
\text { (Not SED) }\end{array}$} \\
\hline SED & 0.81 & 0.11 & -0.21 & -1.51 & .132 & 0.61 & 1.07 \\
\hline \multicolumn{8}{|l|}{$\begin{array}{r}\text { Reason for removal } \\
\text { (Neglect) }\end{array}$} \\
\hline Physical abuse & 0.92 & 0.25 & -0.08 & -0.28 & .779 & 0.54 & 1.58 \\
\hline Sexual abuse & 0.90 & 0.36 & -0.11 & -0.27 & .786 & 0.41 & 1.95 \\
\hline Other & 0.78 & 0.15 & -0.25 & -1.31 & .192 & 0.54 & 1.13 \\
\hline \multicolumn{8}{|l|}{$\begin{array}{l}\text { Prior removal history } \\
(\text { No prior removal(s)) }\end{array}$} \\
\hline Has prior removal(s) & 1.45 & 0.40 & 0.37 & 1.36 & .173 & 0.85 & 2.49 \\
\hline \multicolumn{8}{|l|}{$\begin{array}{r}\text { Initial placement type } \\
\text { (Kinship care) }\end{array}$} \\
\hline Family foster care & 0.18 & 0.03 & -1.70 & -9.27 & .000 & 0.13 & 0.26 \\
\hline Group or residential & 0.29 & 0.11 & -1.23 & -3.24 & .001 & 0.14 & 0.61 \\
\hline \multicolumn{8}{|l|}{$\begin{array}{l}\text { Sibling placements } \\
\text { (Completely separated) }\end{array}$} \\
\hline Partially intact & 1.10 & 0.43 & 0.09 & 0.24 & .812 & 0.51 & 2.37 \\
\hline Completely intact & 1.69 & 0.66 & 0.53 & 1.35 & .178 & 0.79 & 3.65 \\
\hline No siblings in placement & 1.19 & 0.42 & 0.18 & 0.50 & .616 & 0.60 & 2.38 \\
\hline $\begin{array}{r}\text { Early stability } \\
\text { (No early stability) }\end{array}$ & & & & & & & \\
\hline Early stability & 1.01 & 0.23 & 0.01 & 0.03 & .978 & 0.65 & 1.57 \\
\hline Runaways & & & & & & & \\
\hline (No runaway events) & & & & & & & \\
\hline Runaway events & 0.51 & 0.17 & -0.68 & -2.03 & .042 & 0.27 & 0.98 \\
\hline \multicolumn{8}{|c|}{ Test of null hypothesis (all parameters $=0$ ): } \\
\hline & Without & Covariates & With & ovariates & Model $\chi^{2}$ & $d f$ & $p$ \\
\hline & & $4,561.86$ & & $4,233.55$ & 236.04 & 20 & .000 \\
\hline
\end{tabular}

Reference category is in parentheses. Number of events $=308$; Censored $=3,025(90.3 \%)$; Total $=3,351$. 


\section{Adoption Model}

About $14 \%$ of the children in the study sample exited to adoption $(n=467,13.9 \%)$, with a median time to adoption of 737 days. The Cox regression model for adoption is presented in Table 4.11. Inclusion of covariates in the adoption model significantly improved model fit over that of the baseline hazard model $\left(\chi^{2}=287.39, d f=20, p=.000\right)$. When all other variables were held constant, a number of statistically significant relationships emerged between independent variables and exits to adoption.

Age at entry was a significant contributor to adoption exits with increasing age being associated with a decreasing probability of adoption. Children who entered foster care between the ages of 2 and 5 were about half as likely to experience adoption as infants ( $\mathrm{HR}=.56, p=$ $.000)$. For those who entered foster care between the ages of 6 and 9 , they were $60 \%$ less likely to exit to adoption than infants $(\mathrm{HR}=0.40, p=.000)$. Youth who entered care in early adolescence (10 to 13 years old) were $75 \%$ less likely to exit to adoption than infants (HR $=0.24$, $p=.000$ ). The oldest age group, youth who entered between the ages of 14 to 17 , were $93 \%$ less likely to experience adoption than infants $(\mathrm{HR}=0.07, p=.000)$.

Race was significantly associated with adoption rates. African American children were $38 \%$ less likely to experience adoption as White children $(\mathrm{H}=0.62, p=.006)$. No statistically significant differences were observed for adoption rates between children in the "other" race category and White children.

Disability and mental health problems were both associated with adoption, though in different directions. Children with a disability of any kind were more than twice as likely to exit to adoption as children without a disability $(\mathrm{HR}=2.18, p=.000)$. On the other hand, children 
with an serious mental health problems (i.e., an SED) were about half as likely to exit to adoption as children without mental health problems $(\mathrm{HR}=0.55, p=.000)$.

Several placement episode characteristics were also important in the adoption multivariate model. Children whose initial placement in foster care was in family foster care were more than twice as likely to exit to adoption than children who were initially placed into kinship care (HR $=$ $2.25, p=.004)$. The initial placement type of group or residential setting was not related to exits to adoption $(\mathrm{HR}=2.04, p=.068)$.

Sibling placements significantly affected adoption rates. Children who experienced partially intact sibling placements were not significantly different in rates of adoption than children who experienced completely separated sibling placements $(\mathrm{HR}=1.02, p=0.947)$. Also, children who did not have siblings in placement were not significantly different in rates of adoption than children who experienced completely separated sibling placements $(\mathrm{HR}=1.81, p=.062)$. In contrast, children who experienced completely intact sibling placements were almost twice as likely to exit to adoption than children who experienced completely separated sibling placements $(\mathrm{HR}=1.90, p=.054)$.

Rates of adoption were significantly different for children who experienced early stability in foster care as compared to those who did have early stability in foster care $(\mathrm{HR}=1.82, p=.002)$. Children with early stability were $82 \%$ more likely to exit to adoption than children who did not experience early stability.

Finally, runaways were significantly associated with exits to adoption. Children with runaway events were $77 \%$ less likely to exit to as compared to children without runaway rates $(\mathrm{HR}=0.23, p=.031)$. 
Three additional independent variables were not significantly associated with exits to adoption: gender $(\mathrm{HR}=1.08, p=.407)$; reason for removal (physical abuse, $\mathrm{HR}=0.76, p=$ .221 ; sexual abuse, $\mathrm{HR}=1.32, p=.475$; other, $\mathrm{HR}=0.84, p=.203$ ); and prior removal history $(\mathrm{HR}=0.86, p=.574)$. 
Table 4.11 Cox Regression Model for Exits to Adoption

\begin{tabular}{|c|c|c|c|c|c|c|c|}
\hline & \multirow{2}{*}{$\begin{array}{r}\text { Hazard } \\
\text { Ratio }\end{array}$} & \multirow{2}{*}{$\begin{array}{r}\text { Robust } \\
\text { Std. Error }\end{array}$} & \multirow{2}{*}{$\begin{array}{l}\text { Regr } \\
\text { Coeff. }\end{array}$} & \multirow[b]{2}{*}{ Wald $\chi^{2}$} & \multirow[b]{2}{*}{$p$} & \multicolumn{2}{|c|}{ Hazard Ratio 95\% CI } \\
\hline & & & & & & Lower & Upper \\
\hline \multicolumn{8}{|l|}{$\begin{array}{r}\text { Gender } \\
\text { (Female) }\end{array}$} \\
\hline Male & 1.08 & 0.10 & 0.08 & 0.83 & 407 & 0.90 & 1.30 \\
\hline \multicolumn{8}{|l|}{ Age at entry } \\
\hline 2 to $5 \mathrm{yrs}$ & 0.56 & 0.06 & -0.58 & -5.05 & .000 & 0.44 & 0.70 \\
\hline 6 to $9 \mathrm{yrs}$ & 0.40 & 0.07 & -0.93 & -5.33 & .000 & 0.28 & 0.56 \\
\hline 10 to $13 \mathrm{yrs}$ & 0.24 & 0.05 & -1.43 & -6.45 & .000 & 0.15 & 0.37 \\
\hline 14 to $17 \mathrm{yrs}$ & 0.07 & 0.03 & -2.59 & -6.40 & .000 & 0.03 & 0.17 \\
\hline \multicolumn{8}{|l|}{$\begin{array}{r}\text { Race } \\
\text { (White) }\end{array}$} \\
\hline African American & 0.62 & 0.11 & -0.48 & -2.76 & .006 & 0.44 & 0.87 \\
\hline Other & 1.19 & 0.51 & 0.17 & 0.41 & .685 & 0.51 & 2.76 \\
\hline \multicolumn{8}{|l|}{ Disability } \\
\hline Has disability & 2.18 & 0.25 & 0.78 & 6.91 & .000 & 1.75 & 2.72 \\
\hline \multicolumn{8}{|l|}{$\begin{array}{r}\text { Mental health } \\
\text { (Not SED) }\end{array}$} \\
\hline SED & 0.55 & 0.08 & -0.60 & -4.36 & .000 & 0.42 & 0.72 \\
\hline \multicolumn{8}{|l|}{$\begin{array}{r}\text { Reason for removal } \\
\text { (Neglect) }\end{array}$} \\
\hline Physical abuse & 0.76 & 0.17 & -0.28 & -1.22 & .221 & 0.49 & 1.18 \\
\hline Sexual abuse & 1.32 & 0.51 & 0.28 & 0.71 & .475 & 0.62 & 2.82 \\
\hline Other & 0.84 & 0.11 & -0.17 & -1.27 & .203 & 0.64 & 1.10 \\
\hline \multicolumn{8}{|l|}{$\begin{array}{r}\text { Prior removal history } \\
\text { (No prior removal(s)) }\end{array}$} \\
\hline Has prior removal(s) & 0.86 & 0.23 & -0.15 & -0.56 & .574 & 0.51 & 1.45 \\
\hline \multicolumn{8}{|l|}{$\begin{array}{r}\text { Initial placement type } \\
\text { (Kinship care) }\end{array}$} \\
\hline Family foster care & 2.25 & 0.62 & 0.81 & 2.91 & .004 & 1.30 & 3.87 \\
\hline Group or residential & 2.04 & 0.80 & 0.71 & 1.83 & .068 & 0.95 & 4.40 \\
\hline \multicolumn{8}{|l|}{$\begin{array}{r}\text { Sibling placements } \\
\text { (Completely separated) }\end{array}$} \\
\hline Partially intact & 1.02 & 0.33 & 0.02 & 0.07 & .947 & 0.54 & 1.94 \\
\hline Completely intact & 1.90 & 0.63 & 0.64 & 1.93 & .054 & 0.99 & 3.65 \\
\hline No siblings in placement & 1.81 & 0.58 & 0.59 & 1.87 & .062 & 0.97 & 3.38 \\
\hline \multicolumn{8}{|l|}{$\begin{array}{r}\text { Early stability } \\
\text { (No early stability) }\end{array}$} \\
\hline Early stability & 1.82 & 0.36 & 0.60 & 3.08 & .002 & 1.24 & 2.67 \\
\hline \multicolumn{8}{|l|}{$\begin{array}{r}\text { Runaways } \\
\text { (No runaway events) }\end{array}$} \\
\hline Runaway events & 0.23 & 0.16 & -1.46 & -2.16 & .031 & 0.06 & 0.87 \\
\hline \multicolumn{8}{|c|}{ Test of null hypothesis (all parameters $=0$ ) } \\
\hline & Withor & Covariates & With $C$ & ovariates & Model $\chi^{2}$ & $d f$ & $p$ \\
\hline$-2 \log L$ & & $6,315.26$ & & $5,819.84$ & 287.39 & 20 & .000 \\
\hline
\end{tabular}

Reference category is in parentheses. Number of events = 467; Censored = 2,704 (80.7\%); Total = 3,351. 


\section{Multicollinearity}

Multicollinearity was assessed by observing the correlation matrix of regression coefficients for each Cox regression model (Garson, 2008). Correlations of the regression coefficients representing each pair of independent variables were examined and none were correlated at levels considered large. In all three models the largest correlations existed between two sets of variables: 1) mental health and age, and 2) early stability and runaways. Nearly all of these correlations would be considered small by conventional guidelines (i.e., between .14 to .26 ) (Cohen, 1988). The exceptions were three correlations in the adoption model that represented the relationships between mental health and the three youngest age categories $(0-1,2-5,6-9)$. These correlations ranged from .29 to .33 and can be considered medium-sized correlations (Cohen, 1988).

Multicollinearity does not bias overall model results, but can produce large standard errors in the related variables. The risk is that a non-significant variable will be falsely rejected. All of the variables observed as having potential problems with multicollinearity were found to be statistically significant in the reunification and adoption models. In contrast, the guardianship model showed that both mental health and early stability were not statistically significant, which could be related to problems of multicollinearity. In response, effect sizes of mental health and early stability were carefully examined in the guardianship model. The effect size of early stability was miniscule and it seems correct to conclude that it is not statistically significant (HR $=1.01)$. The effect size of mental health was weak $(H R=0.81)$, presenting some ambiguity about whether it should be rejected as having a significant relationship with guardianship. Besides multicollinearity, a lack of power in the guardianship model could lead to not detecting a 
significant relationship between mental health and guardianship. Hence, interpretation of the significance of mental health in the guardianship model was treated cautiously.

\section{Comparison of Three Cox Regression Models}

Competing risks analyses resulted in three multivariate Cox regression models, one for each outcome variable. Table 4.12 displays the reunification, guardianship, and adoption models' hazard ratios, the corresponding $p$-values, and interpretation of the effect size as weak, small, medium, large, and very large according to guidelines suggested by Rosenthal (1996).

Study results were interpreted by considering statistical significance, effect size, and practical significance. This multi-pronged approach to interpretation was used for several reasons. First, large samples can sometimes lead to many statistically significant findings even when the relationships could be considered trivial (Durlak, 2009; Vaske, Gliner, \& Morgan, 2002). Multicollinearity is another common issue in social science research and can disguise the statistical significance of independent variables. Furthermore, this study's power analyses indicated that the adoption and guardianship models could lack power to identify statistically significant relationships when the hazard ratio is below 1.8 (or using the reverse value, greater than about .61) (see page 57).

Interpretation of study results then began with using statistical significance as an initial gauge of potentially important variables. In addition, effect sizes, or in this case, hazard ratios were considered for interpreting the importance of variables, including observation of effect sizes across the three regression models (Rutledge \& Loh, 2004). Interpretation of effect sizes was also aided by several additional strategies. First, 95\% confidence intervals around hazard ratios were presented to show a range of probable effect sizes (Coe, 2002; Colegrave \& Ruxton, 2003). Second, established guidelines were used to identify effect sizes as small, medium, large, or very 
large (Rosenthal, 1996). Third, this study's effect sizes were considered in the context of similar research by comparing to the effect sizes of three similar competing risks analyses of foster care exits (Connell et al, 2006; Courtney \& Wong, 1996; McDonald et al., 2007). Finally, in addition to statistical significance and effect size, practical significance was also considered. In sum, thorough examination of the performance of predictor variables concluded with judging variables with hazard ratios greater than about 1.5 , or less than about 0.67 , as notable predictors of permanency.

By observing independent variables across the three Cox regression models and using the criteria outlined above to judge the relationships between dependent and independent variables, the following are identified as notable predictors of permanency: age at entry, race, disability, mental health, initial placement type, sibling placements, and runaways. Further discussion of each type of permanency and these important predictors is presented in Chapter 5. 
Table 4.12 Hazard Ratios from Cox Regression Models of Reunification, Guardianship, and Adoption

\begin{tabular}{|c|c|c|c|c|c|c|c|c|c|}
\hline & Reunif & & Effect & Guard. & & Effect & Adopt. & & Effect \\
\hline & HR & $p$ & Size $^{1}$ & HR & $p$ & Size & HR & $p$ & Size \\
\hline $\begin{array}{r}\text { Gender } \\
\text { (Female) }\end{array}$ & & & & & & & & & \\
\hline Male & 1.08 & .097 & NS & 0.94 & .588 & NS & 1.08 & .407 & NS \\
\hline $\begin{array}{r}\text { Age at entry } \\
(0 \text { to } 1 \mathrm{yrs})\end{array}$ & & & & & & & & & \\
\hline 2 to $5 \mathrm{yrs}$ & 1.61 & .000 & $* *$ & 1.57 & .037 & $* *$ & 0.56 & .000 & ** \\
\hline 6 to $9 \mathrm{yrs}$ & 2.03 & .000 & $* *$ & 2.09 & .004 & $* *$ & 0.40 & .000 & $* * *$ \\
\hline 10 to $13 \mathrm{yrs}$ & 2.10 & .000 & ** & 3.96 & .000 & $* * * *$ & 0.24 & .000 & $* * * *$ \\
\hline 14 to $17 \mathrm{yrs}$ & 2.60 & .000 & $* * *$ & 4.46 & .000 & $* * * *$ & 0.07 & .000 & $* * * * *$ \\
\hline $\begin{array}{r}\text { Race } \\
\text { (White) }\end{array}$ & & & & & & & & & \\
\hline African American & 0.83 & .083 & NS & 0.72 & 186 & NS & 0.62 & .006 & $* *$ \\
\hline Other & 1.47 & .015 & $* *$ & 1.18 & .706 & NS & 1.19 & .685 & NS \\
\hline $\begin{array}{r}\text { Disability } \\
\text { (No disability) }\end{array}$ & & & & & & & & & \\
\hline Has disability & 0.32 & .000 & $* * *$ & 0.36 & .000 & $* * *$ & 2.18 & .000 & $* *$ \\
\hline $\begin{array}{r}\text { Mental health } \\
\text { (Not SED) }\end{array}$ & & & & & & & & & \\
\hline SED & 0.10 & .000 & $* * * * *$ & 0.81 & .132 & $\mathrm{NS}^{2}$ & 0.55 & .000 & $* *$ \\
\hline $\begin{array}{r}\text { Reason for removal } \\
\text { (Neglect) }\end{array}$ & & & & & & & & & \\
\hline Physical abuse & 1.36 & .005 & * & 0.92 & .779 & NS & 0.76 & .221 & NS \\
\hline Sexual abuse & 1.38 & .051 & * & 0.90 & .786 & NS & 1.32 & 475 & NS \\
\hline Other & 1.08 & .359 & NS & 0.78 & 192 & NS & 0.84 & 203 & NS \\
\hline $\begin{array}{r}\text { Prior removal history } \\
\text { (No prior removal(s)) }\end{array}$ & & & & & & & & & \\
\hline Has prior removal(s) & 0.80 & .048 & * & 1.45 & 173 & NS & 0.86 & .574 & NS \\
\hline $\begin{array}{l}\text { Initial placement type } \\
\text { (Kinship care) }\end{array}$ & & & & & & & & & \\
\hline Family foster care & 0.76 & .002 & * & 0.18 & .000 & $* * * *$ & 2.25 & .004 & ** \\
\hline Group or residential & 1.31 & .066 & NS & 0.29 & .001 & $* * * *$ & 2.04 & .068 & NS \\
\hline $\begin{array}{l}\text { Sibling placements } \\
\text { (Completely separated) }\end{array}$ & & & & & & & & & \\
\hline Partially intact & 0.90 & .487 & NS & 1.10 & .812 & NS & 1.02 & 947 & NS \\
\hline Completely intact & 1.46 & .016 & $* *$ & 1.69 & .178 & $\mathrm{NS}^{2}$ & 1.90 & .054 & $* *$ \\
\hline No sibs in placement & 1.34 & .042 & $*$ & 1.19 & .616 & NS & 1.81 & .062 & NS \\
\hline $\begin{array}{r}\text { Early stability } \\
\text { (No early stability) }\end{array}$ & & & & & & & & & \\
\hline Early stability & 7.88 & .000 & $* * * *$ & 1.01 & .978 & NS & 1.82 & .002 & ** \\
\hline Runaways & & & & & & & & & \\
\hline (No runaway events) & & & & & & & & & \\
\hline Runaway events & 0.47 & .000 & $* * *$ & 0.51 & .042 & $* * *$ & 0.23 & .031 & $* * * *$ \\
\hline Time interactions & & & & & & & & & \\
\hline Mental Health $* \ln (t))$ & 1.38 & .000 & * & - & - & - & - & - & - \\
\hline Early Stability $* \ln (\mathrm{t})$ & 0.70 & .000 & * & - & - & - & - & - & - \\
\hline
\end{tabular}

${ }^{1}$ Effect size of hazard ratio: *, weak = below 1.5 (above reverse 0.67 ); **, small = 1.5 (reverse value of 0.67 ); ***, medium $=2.5($ or 0.4$) ; * * *$, large $=$ about $4($ or 0.25$) ; * * * *$, very large $=10($ or .10$)($ Rosenthal, 1996). NS $=$ not statistically significant.

${ }^{2}$ Findings on these variables are cautiously interpreted as a potentially important predictor according to the explanation on page 91 . 


\section{Chapter 5: Discussion and Implications}

This study used longitudinal data from an entry cohort of 3,351 children in Kansas foster care to conduct competing risks survival analyses and identify important predictors of exit to three types of permanency: reunification, guardianship, and adoption. The findings offer a number of opportunities and considerations for social work theory, practice, policy, and research. This chapter first presents a discussion of the study's major findings and how these findings correspond with existing knowledge of foster care exits to permanency. Second, the chapter explores implications of major findings in relation to social work theory, practice, policy, and research. Finally, study limitations are summarized and followed by conclusions.

\section{Discussion}

This study observed that children in foster care exit to different types of permanency at different rates. Reunification occurs the most quickly, followed by guardianship, and then adoption. Several child and placement characteristics were identified as significant predictors of these permanency outcomes, with the patterns and influences of predictors varying according to type of permanency. Important predictors within outcomes and across outcomes are outlined below.

\section{Important Predictors Within Permanency Outcomes}

Reunification. Notable predictors of reunification were age, race, disability, mental health, sibling placements, early stability, and runaways. Children who were older teens, were in the “other" race category, did not have any disability, did not have a mental health problem, had completely intact sibling placements, experienced two or fewer placements in their first 100 days of foster care, and did not runaway while in foster care were more likely to exit to reunification than their comparison groups. Three variables - reason for removal, prior removal, and initial 
placement type - had statistically significant associations with reunification but were not identified here as notable predictors due to weak effect sizes. Each of these variables had a hazard ratio of approximately 0.80 . As noted in chapter 3 (p. 57), the reunification model was observed as having sufficient power to detect even small differences in hazard ratios. Thus, these variables should be noted as being statistically significant, but may have less practical significance as the other variables in the reunification model.

Guardianship. The strongest predictors of guardianship were age, disability, initial placement type, and runaways. Children who were older teens, did not have a disability, did not have a mental health problem, were initially placed in kinship care, had intact sibling placements, and did not runaway while in foster care were more likely to exit to guardianship than their comparison groups. In acknowledgment of possible issues with statistical power in the guardianship model, two additional variables are cautiously interpreted as important to guardianship: mental health and sibling placement.

Adoption. Adoption was highly influenced by eight of the eleven variables: age, race, disability, mental health, initial placement type, sibling placements, early stability, and runaways. Children who entered foster care as an infant, were White, had a disability, did not have a mental health problem, had completely intact sibling placements, experienced two or fewer placements in their first 100 days of foster care, and did not runaway while in foster care were more likely to exit to adoption than their comparison groups.

\section{Important Predictors Across Permanency Outcomes}

Across all three permanency outcomes, the following variables were recognized as the chief predictors of permanency: age, race, disability, mental health, initial placement type, sibling placements, early stability, and runaways. From these variables, three key categories of 
permanency predictors emerge: demographic characteristics, clinical needs, and characteristics related to continuity and connections. A discussion of each category follows.

Demographic characteristics. Demographic characteristics of age and race were important predictors of permanency. Age at foster care entry was important for all three types of permanency while controlling for all other independent variables. Both reunification and guardianship rates increased with older age while adoption rates decreased with older age.

Findings on age and reunification are consistent with some prior studies and contradictory with others. Like this study, many studies have identified infants as experiencing significantly lower rates of reunification than all other age groups (Barth, 1997; Connell, et al., 2006; Courtney, et al., 1997; Courtney \& Wong, 1996; Goerge, 1990; Vogel, 1999). In contrast, findings on older teens and reunification were not as consistent in the foster care research. This study observed that older teens experienced the highest rates of reunification while controlling for all other variables. Most prior research has identified older teens as having lower rates of reunification than preschoolers and school-aged children (e.g., Connell, et al., 2006; Courtney \& Wong, 1996). One exception is a multi-state longitudinal analysis that found patterns related to age and exits to reunification were quite similar to those identified in the current study (Wulczyn, 2003).

The fact that reunification varied by age does not have a straight forward explanation. Although developmental needs are unique to each age, it is not necessarily obvious that age should be a differentiator for reunification. Permanency is important to children of all ages. Why should four year olds take longer to reunify with parents than fourteen year olds? Certainly, young children are considered more vulnerable and lacking self-preservation or selfcare skills as compared to a teenager. Child welfare workers and courts thus may find it easier to 
reunify a teenager that has some abilities for self-protection. On the other hand, lengthy foster care stays are generally unacceptable for children of all ages. A two-year stay in foster care for a child that enters at age four represents one-third of his or her life. Age differences in reunification suggest the need for further consideration.

Guardianship was most likely for children 10 and older. A finding that age significantly influences guardianship is novel, though not surprising. This pattern appears to reflect Kansas state policy that generally restricted guardianship to include youth 14 years and older. Age limitations for guardianship, however, could be questioned and will be discussed further in relation to social work policy. Additionally, the lack of similar age and guardianship findings in prior research may be attributed to methodological limitations. That is, prior studies may have obscured the influence of age on guardianship because guardianship was combined with other outcomes (e.g., reunification or adoption) and rarely studied as its own type of permanency exit.

Exits to adoption were also highly influenced by age. While infants were less likely to experience reunification or guardianship, they were significantly more likely to be adopted than children of all other ages. Furthermore, the adoption model indicated a consistent pattern whereby increasing age was associated with a decreasing likelihood of adoption. These findings on the association between age and adoption are not surprising as they are similar to numerous studies of adoption (e.g., Barth, 1997; Smith, 2003, Snowden et al., 2008) and likely reflect societal preferences for adoption of babies and young children.

In spite of some contrasting findings, age was generally shown in this study, and others, to be one of the most important predictors of permanency of all kinds. Children of different ages have typically experienced different paths to permanency. 
Race was the second demographic characteristic observed as an important predictor of permanency. Like age, findings on race varied according to type of permanency. While children of other races were more likely to experience reunification than White children, there were no significant differences in reunification rates between African American and White children. In contrast, adoption was less likely for African American children as compared to White children. Race was not a significant predictor of guardianship.

The race and reunification finding was a welcome shift from prior research that has shown lower rates of reunification for African American children (Connell et al., 2006; Courtney et al., 1994; Courtney et al., 1997; Courtney \& Wong, 1996; Wells \& Guo, 1999; Wulczyn, 2003). On the other hand, the adoption model indicated that African American children were less likely to be adopted than White children. Although the bivariate adoption analyses showed race was not statistically significant with a Bonferroni-corrected alpha $=.005$, it bordered on being statistically significant with a $p$-value of .008 . It is important to note that in the multivariate model the effect size was small ( $\mathrm{HR}=0.62, p=.006)$, but this finding is considered practically significant due to substantial concerns about disproportionality in child welfare. This study's finding on race and adoption is consistent with the majority of prior research (Barth, 1997; Courtney \& Wong, 1996; McDonald et al., 2007; Smith, 2003; Snowden et al., 2008; Wulczyn, 2003). One study of the trends in adoption rates among racial groups found that the discrepancy in rates between White and African American children decreased from 1990 to 1996 (Wulczyn, 2003). Nevertheless, this study's finding indicates the need for continued attention.

Clinical needs. The second category of important predictors of permanency is related to clinical needs of the child. Disabilities and mental health problems significantly impact a child's path to permanency. First, a child's disability status played a role in all three types of 
permanency; however, it influenced exits to reunification and guardianship differently than exits to adoption. Disability was associated with a decreased likelihood of reunification and guardianship. Children with disabilities experienced about one-third of the chance for reunification and guardianship as compared to children without disabilities. In contrast, disability influenced adoption in the opposite direction. Children with a disability were more than twice as likely to exit to adoption as children without a disability. Thus, disability was a risk factor for reunification and guardianship, and a protective factor for adoption.

Comparison of these findings to previous studies is constrained by substantial differences in the measurement and operationalization of disability. Among two comparable studies, one found that disability reduced reunification and adoption rates (Courtney \& Wong, 1996) and the other found that disability reduced reunification rates, but did not significantly affect adoption rates (Connell et al., 2006). A national adoption study by Snowden and colleagues (2008) indicated that children with physical disabilities were more likely to be adopted while the presence of vision or hearing disabilities were associated with a lower likelihood of adoption. The present study did not distinguish types of disability yet found disability of any kind was associated with a higher likelihood of adoption and was a potential obstacle for reunification and guardianship. The discrepancies in these findings prompted further descriptive analyses of the data. Among adoptions for children with disabilities, the rate of adoptions was far higher among children with physical disabilities and speech disabilities as compared to children with no disability or other types of disabilities, such as learning disabilities and emotional disabilities. Thus, this study's findings appear to support the findings by Snowden et al. (2008) that indicated physical disabilities were significantly associated with increased likelihood of adoption. 
Second, the presence of serious mental health problems also influenced all three types of permanency, though this was more definitive for reunification and adoption. The relationship between mental health and guardianship was less clear. Although mental health was statistically significant in the bivariate survival analysis of guardianship, it was not statistically significant in the multivariate model. As previously noted, this may be due to possible statistical power issues in the guardianship Cox regression model. However, the direction of the relationship indicated that mental health problems decrease the likelihood of guardianship.

It was clear that having a serious mental health problem posed considerable risk for not achieving reunification and adoption. Children with an SED had $1 / 10^{\text {th }}$ the chance of reunification when compared to children without an SED. The time interaction variable with mental health problems further signified that, although the effect of mental health decreased over time, it remained a significant impediment to reunification. The effect of mental health problems was not as large for adoption, but was still notable. Children with an SED were about half as likely to be adopted as children without an SED. These findings are generally consistent with prior research, which indicated that mental health problems inhibit reunification (Becker et al., 2007; Connell et al., 2006; Landsverk et al., 1996; McDonald et al., 2007; Romney et al., 2005) and adoption (Connell et al., 2006; Snowden et al., 2008). Only one other study is known to have evaluated the relationship between children's emotional and behavioral problems and guardianship, and it found that emotional and behavioral problems have a statistically significant relationship with reductions in relative guardianship rates, though the effect size was small (McDonald et al., 2007).

In combination, the findings that observed disabilities and mental health problems as risk factors of reunification are especially troubling. They lead to speculation about biological 
families struggling to meet their children's physical health and mental health needs. This topic deserves further exploration in order to determine whether access and availability of services is associated with foster care entry and/or reunification.

Placement Characteristics Related to Continuity and Connections. Several predictor variables represent the concepts of continuity and connections. These include initial placement type, sibling placements, early stability, and runaways. Initial placement type indicates whether a child was placed with relatives or kin, hence a connection to extended family or other significant adult caregivers. Sibling placements measured whether children were continually placed with all of their siblings in foster care. It can be a proxy for both connections to siblings and continuity of sibling relationships. Early stability indicated whether children had continuity or stability in placement settings during the first 100 days of foster care. Finally, runaways were another measure of stability that also indicated whether children had continuity in placement settings. As a group, a general pattern of significant findings on these four variables suggest that permanency is promoted by providing children with continuity and connections. Findings on each of the four variables are discussed below.

First, initial placement type was statistically significant in all three models of permanency, though the strength and direction of the relationship varied. Children initially placed in kinship care as compared to children initially placed in family foster care were more likely to reunify, more likely to exit to guardianship, and less likely to be adopted. The strength of this relationship was weak in the reunification model, small in the adoption model, and notably large in the guardianship model. There were not significant differences between children initially placed in kinship care and children initially placed in group or residential care except for in the guardianship model, which showed guardianship was more likely for children in kinship care. 
Finding kinship care related to a higher likelihood of reunification, even though small, was somewhat unexpected because a number of other studies have shown that kinship care was associated with a lower likelihood of reunification (e.g., Connell et al., 2006; Courtney \& Wong, 1996). Yet, two recent studies demonstrated that kinship placements did not lower the likelihood of exits to permanency (Koh \& Testa, 2008; Wulczyn et al., 2007). Wulczyn and colleagues (2007) also showed that the median duration for children in kinship care decreased from 15 months in 2000 to 14 months in 2004 . This study confirmed that kinship placements did not adversely affect rates of reunification or guardianship. In fact, in the case of guardianship, kinship placements were noted as facilitating permanency.

The initial placement type findings for guardianship and adoption seem logical and consistent. That is, children placed with relatives or kin were more likely to experience guardianship, but were less likely to be adopted. A possible explanation is that guardianship is more likely to occur with relatives; thus, being placed with relatives facilitates guardianship. The findings on adoption and initial placement type were not statistically significant in the bivariate analyses, but were in the multivariate analyses after controlling for other variables. Prior multivariate research has indicated similar findings (Wulczyn, 2003). Furthermore, although some research has indicated that kinship care does not impede adoption rates (Connell et al., 2006; Koh \& Testa, 2008; Winokur et al., 2008), it makes sense that adoption would be less likely for children in kinship care if relatives are more comfortable with guardianship arrangements than adoptions (Testa, 2002). In sum, the findings on initial placement type indicated that connections to family or kin were important for reunification and even more so for guardianship. 
Second, sibling placements significantly affected exit rates for all three types of permanency, though the findings for reunification and adoption were more explicit than those for guardianship. Specifically, children who experienced completely intact sibling placements were about 1-1/2 times more likely to exit to reunification and twice as likely to exit to adoption when compared to children whose sibling placements were completely separated. A similar trend is noted for guardianship although the model did not show it was statistically significant. Again, issues with statistical power in the guardianship model suggest that sibling placements can be cautiously interpreted as having a positive benefit for guardianship. The relationship between reunification and children without any siblings in placement was also significant, and in the direction of higher reunification rates, though the effect size was weak. In other words, not having siblings in placement was slightly more advantageous for reunification than having sibling in placement and being separated from them.

Prior research on sibling placements is rare and particularly limited by methodological variations. This study's findings were similar to two others that generally found that keeping siblings together while in foster care contributed to exits to permanency (Albert \& King, 2008; Leathers, 2005). Importantly, partially intact sibling placements did not promote any type of permanency exit in the present study. This suggests that sibling placements were beneficial to permanency when all siblings in placement were kept together consistently and continuously throughout an entire placement episode.

Third, early stability played an important role for exits to reunification and adoption, but was not significant for exits to guardianship. Children with early stability had higher rates of reunification and adoption. For adoption, the effect size of early stability ranged from weak to medium as shown by a $95 \%$ confidence interval around the hazard ratio $\left(C I_{.95}=1.24,2.67\right)$. In 
the reunification model the effect size of early stability ranged from medium to very large $\left(C I_{.95}\right.$ $=2.55,24.31)$. Furthermore, the time interaction for this variable indicated that the influence of early stability decreased over time, but children who experienced early stability continued to have higher rates of reunification when compared to children who did not experience early stability. These findings are novel because measures of early stability have not been routinely used in foster care exit research.

The non-significant relationship between early stability and guardianship is notable, especially in light of the relatively large influence it had on reunification and adoption. The bivariate survival analyses that included early stability as a single predictor of guardianship showed a statistically significant relationship. However, in the multivariate guardianship model early stability was not statistically significant while controlling for all other variables. These findings leave unanswered questions about the role of placement stability for exits to guardianship. Future investigations may offer additional insights by examining the reasons for placement changes and testing additional measures of stability.

Fourth, runaway events were associated with lower rates of reunification, guardianship, and adoption. Moreover, the size of the relationships between runaways and permanency exits were considered medium in the reunification and guardianship models, and large in the adoption model. These findings were new because runaways have not been used as an independent variable in foster care exit research. While additional research is needed to corroborate these findings, at this point it appears that the instability of runaway events is a significant impediment to all types of permanency. 


\section{Other Variables}

Three independent variables were not included in the prior discussion of important predictors due to a lack of statistical significance or weak effect size. The findings on gender, reason for removal, and prior removal are discussed below.

Gender was not significant for any type of permanency in the multivariate Cox regression models. It was statistically significant in the bivariate reunification analyses, but this association did not hold up in a multivariate model that controlled for all other variables. Overall, this study's findings on gender support similar findings of many previous foster care exit studies (e.g., Barth, 1997; Courtney \& Wong, 1996; Wells \& Guo, 1999).

Reason for removal was statistically significant with a weak effect size in the reunification model $(\mathrm{HR}=1.38)$; it was not statistically significant for the models representing guardianship and adoption. Children who entered foster care for reasons of physical abuse or sexual abuse were somewhat more likely to exit to reunification than children who entered foster care due to neglect, though the strength of these associations were weak. Comparison to prior research on reason for removal and permanency outcomes is complicated by inconsistent methods and contradictory results. Moreover, states' unique definitions and varying legal thresholds for child maltreatment further restrict cross-study comparisons. Findings on reason for removal may be most appropriately applied to the state from which data were derived.

Several other points may help explain findings on reason for removal. As noted in the methodology chapter, reason for removal was limited as a simplistic variable that represents a complex construct - type of child maltreatment. Since children may experience multiple types of maltreatment, a single reason for removal is an imperfect measure. Second, primary reason for removal is supposed to reflect the reason used in the petition to the court to remove children 
from their parents. If social workers or courts are partial to some reasons and not others, then this variable may be further constrained. Third, reason for removal findings may be affected by the high proportion of cases that entered foster care for reasons other than abuse or neglect (56.9\%). The "other" category includes a broad range of 15 additional reasons. Among these other reasons the two most frequent were caregiver inability to cope and child behavior problems. One reason that was strikingly low was parental substance abuse, recorded as the primary reason for removal in only $8.4 \%$ of these cases. This value seems markedly low in light of multiple studies that have suggested the prevalence of parental substance abuse in foster care ranges from $50 \%$ to $79 \%$ (Testa \& Smith, 2009). Further, this discrepancy on parental substance abuse is noted because other investigations have identified parental substance abuse as being associated with lower rates of reunification (Brook \& McDonald, 2009) and higher rates of reentry (Wulczyn, 2009). Interestingly, various findings in this study showed that children who entered for "other" reasons were generally indistinguishable from children who entered for neglect. In sum, findings on reason for removal pose additional questions that may be worthy of further inquiry, particularly questions about the influence of parental substance abuse and poverty on permanency.

Prior removal history was statistically significant in the reunification model with a small effect size, and was not statistically significant in the guardianship and adoption models. Reunification rates were significantly lower for children with a history of prior removals than children without a history of prior removals. These findings are generally consistent with prior research on reunification which demonstrates that prior removals reduce reunification rates (Connell et al., 2006; Goerge, 1990; McDonald et al., 2007). Although the finding for prior removal and guardianship was not statistically significant and the effect size was small $(\mathrm{HR}=$ 
1.45), the direction of the relationship is noted as increasing in guardianship exits. Comparable results on guardianship are rare. One study found that prior removals reduce guardianship, which conflicts with this study's findings (McDonald et al., 2007). Existing literature on prior removals and adoption indicated mixed findings (Connell et al., 2006; Smith, 2003; Snowden et al., 2008).

\section{Implications}

This study may contribute to social work in a number of ways. Implications for social work theory, practice, policy, and research are presented below.

\section{Social Work Theory}

Although pioneers of the permanency planning movement identified several underlying theories and values, minimal theory development has occurred since (Maluccio, et al., 1986). The current state of permanency theory appears to be in the early stages of theory building, taking the form of an inductive, research-to-theory approach (Carlile \& Christensen, 2005; Lynham, 2002). Prior foster care research largely lacks theory that clearly articulates hypotheses that should be tested as some scholars have recommended (Sherraden, 2000; Wells \& Guo, 1999). Foster care research may benefit by articulating a comprehensive theory of permanency. As a step in this direction, the present study's findings are used as a springboard to discuss permanency theory in relation to the theoretical framework presented in chapter 1.

Primordial solidarities, bureaucratic institutions \& social capital. This study's findings support a theoretical framework that balances the contrasting principles of primordial solidarities and bureaucratic institutions, as well as an application of the ideas of social capital theory. Most notably, findings on connections and continuity suggest that both primordial solidarities and bureaucratic institutions play a role in facilitating permanency. Two predictor variables support 
the principle of primordial solidarities: 1) initial placement with relatives or kin, and 2) intact, continuous placements with siblings. Both of these variables demonstrated that connections to family were positively associated with certain types of permanency. Two other findings, early stability and the absence of runaway events, may suggest that the principle of bureaucratic institutions is at work. These variables' positive associations with permanency suggest that bureaucratic institutions that ensure stability may be important to successful permanency outcomes. Taken together, these findings imply that bonding social capital made available from family connections and bridging social capital routed through bureaucratic structures can both work in favor of positive foster care outcomes. Thus, it makes sense that a theory of permanency incorporates the principles of primordial solidarities as well as bureaucratic institutions, and the influences of both bonding and bridging social capital.

Another implication is drawn from the concepts of bonding and bridging social capital and the place of family in permanency theory. Consistent with the principle of primordial solidarities and bonding social capital, the forerunners of the permanency planning movement underscored the primacy of the biological family (Maluccio, et al., 1986). However, permanency may be constrained if family is limited only to nuclear family or even biological family. Foster care practice and research has affirmed the importance of extended family and fictive kin (e.g., Testa, 2008a; Testa, 2008b; Testa \& Slack, 2002; Vericker, Macomber, \& Geen, 2008). This study also showed the potential positive contribution of relative or kin placements. An essential dimension of permanency theory, then, may be to expand notions of family and connectedness, recognizing the potential benefits of both bonding and bridging social capital. Permanency theory should look within the family for essential supports, such as those provided by continuity of sibling relationships, but also understand the potential for connection beyond the nuclear family to 
include other connections such as those with extended family, fictive kin, and other individuals with whom children may establish caring, lifelong relationships.

Bio-ecological perspective. Several other implications for theory emerge from considering the study's findings in light of the bio-ecological perspective. First, the bio-ecological perspective implies the need for age-differentiated child welfare practice (Wulczyn, et al., 2005). Children and youth of all ages address developmental tasks and milestones that are likely constrained by instability in living arrangements and inconsistency in caregiving and other significant relationships. Continuity and connections then may operate differently at different ages and stages. Although scholars have frequently opted to use attachment theory as the primary theoretical foundation for understanding permanency, attachment theory alone is insufficient to hypothesize the dynamics of children's paths to permanency because it is usually focused on infants and very young children. This study found that nearly two-thirds of the children who did not attain permanency were older children and teens. Additionally, with the passage of the Foster Care Independence Act of 1999 (Public Law 106-169) policy makers formally acknowledged that healthy youth development requires additional supports among young adults exiting foster care without permanency.

More critical thought is needed to expand permanency theory beyond attachment theory so that it considers the diverse population of children in foster care, including a large proportion of older children and adolescents. A comprehensive permanency theory, like practice, must be agedifferentiated. Youth development theory may help address these gaps in a theory for permanency and is congruent with the bio-ecological perspective. Youth development theory posits that positive youth development is supported by three essential environmental protective factors: caring relationships, high expectation messages, and opportunities for participation and 
contribution (Benard, 2003, 2006). In sum, a theoretical framework for permanency will be enhanced by integrating attachment theory alongside several other complementary theories, including a bio-ecological perspective and youth development theory, thereby acknowledging the importance of a developmentally sensitive approach (Berrick, Needell, Barth, \& JonsonReid, 1998).

A second major implication from viewing the study's findings in light of the bio-ecological perspective is related to the influence of culture. The significant associations between race and permanency clearly align with the tenets of the bio-ecological perspective. In short, this perspective acknowledges an interactional dynamic between individuals and their environment, highlighting the importance of families' and children's racial and ethnic identities. Permanency theory must also incorporate culture and race into understanding children's pathways to permanency.

Finally, the bio-ecological perspective also suggests additional dimensions of permanency that were absent from this study and have yet to be well-articulated in foster care research in general. These include dimensions related to the community-level and socioeconomic forces that affect child welfare outcomes. For example, the influences of poverty on families, neighborhoods, and communities are significant and detrimental, yet they are not clearly articulated by permanency theory or research. Lindsey and Shlonsky (2008) draw attention to this gap in child welfare research:

Child maltreatment is not an isolated event. Its occurrence is inextricably bound with the health of the community and the extent to which viable preventive services are readily available... The child protection paradigm may have been an appropriate response to the discovery of child abuse, but it is not a remedy for the shortcomings of poverty, inequality, and discrimination, all of which are so deeply embedded in many communities within industrialized nations... The paradigm needs to shift from child protection to the promotion of a combination 
of child well-being, including economic and social well-being, and the more traditional focus on child protection from potential harm. (p. 377)

\section{Social Work Practice}

Social workers will benefit from knowledge of the predictors of permanency. When data are specific to different types of permanency there is potential for even further benefit because practice interventions may be more specific and well-targeted (Smokowski, Mann, Reynolds, \& Fraser, 2004). Results of analyses such as those presented here can be shared with administrators, supervisors, and frontline staff, allowing key stakeholders to interpret findings for the local level and to develop appropriately targeted responses. Ideas for practice implications are provided below for each category of permanency predictors.

Demographic characteristics. This study's findings suggest that the demographic characteristics of age and race are both important to permanency. Although social work practice cannot change the race or age of children, it is important to raise awareness that these characteristics significantly influence permanency. Child welfare practice should be agedifferentiated. It is not clear that all or even most social workers are sensitive to issues of child development (Berrick, et al., 1998). One practice implication is to ensure that social workers and other child welfare decision-makers have knowledge of children's and youth's developmental needs and how these could impact child welfare decisions. Moreover, knowledge of trauma and its interaction with developmental stages is highly relevant for delivering services to this population of children (National Child Traumatic Stress Network, 2008). For example, social workers and foster parents would benefit from understanding how a history of abuse, neglect, or other trauma can impact a youth's experience of developmental stages such as a lag in the key milestones of toddlerhood or difficulty with the identity developmental tasks of adolescence. 
Partnerships with other practitioners such as early childhood experts may assist with developmentally appropriate child welfare practice.

Race proved important to children's experiences of reunification and adoption. Most critical is the study's finding that African American children experience lower rates of adoption than White children, providing further evidence of disproportionality in child welfare. Multiple strategies will likely be needed to address racial inequities. Clearly, cultural competence is an essential component of social work practice that will help address equity in permanency outcomes for African American children. Additionally, special initiatives to increase adoptions through recruitment of adoptive parents, especially for African American children, should continue. Practice must also be individualized to shift permanency goals according to the best cultural fit for each child and family. Guardianship is considered a particularly promising strategy for the African American community (GAO, 2007). So, if a child is connected with a family, relative or non-relative, and neither reunification or adoption are appropriate or palatable options, then guardianship should be considered a viable option and aggressively pursued. Other ideas and example strategies could be culled from a national project to reduce racial inequity in child welfare, called the Casey-CSSP Alliance for Racial Equity in Child Welfare (see www.casey.org). In a recent report, the Alliance's activities with ten partner jurisdictions across the country are described as encompassing a systematic and sequenced approach that includes: 1) highlighting the problem of racial inequity, 2) using data to analyze and understand the problem, 3) including communities in the discussion, 4) expanding services and supports to families and neighborhoods experiencing the highest levels of disproportionality, 5) enacting policy changes, 6) implementing ongoing evaluation strategies to track progress, and 7) seeking 
external funding to support their work (Center for Community Partnerships in Child Welfare, 2006).

Clinical needs. Findings on the second category of predictors, clinical needs, suggest areas practitioners may target during assessment and service planning. The two clinical needs with significant influence on permanency outcomes were the presence of a disability and serious mental health problems. Disabilities and mental health problems reduced the likelihood of permanency, with the exception of disabilities positive effect on adoption rates. Notwithstanding the protective capacity of disabilities on adoptions, child welfare practice must recognize disabilities and mental health problems as potential obstacles of permanency, particularly reunification and guardianship. As children enter foster care they should be screened for immediate or urgent medical and mental health needs. Following the guidelines of the American Academy of Pediatrics, (American Academy of Pediatrics, 2002) "all children in foster care should receive comprehensive physical and mental health and developmental evaluations within one month of placement" (p. 539). Specialized assessments may be required by qualified providers and trained practitioners other than child welfare workers and will, therefore, necessitate establishing good working relationships and smooth procedures among different service systems. At minimum, collaborative efforts will need to include the court system, educational system, the medical community, and the behavioral health system.

Beyond assessment, service plans and permanency plans must address children's needs related to disabilities and mental health problems. As children exit foster care, after-care or postpermanency services should also consider their clinical needs. Best practice includes ensuring access to evidence-based services that address disabilities and mental health needs and, thereby, 
support permanency (Landsverk, Burns, Stambaugh, \& Reutz, 2006; Landsverk, Burns, Stambaugh, \& Reutz, 2009).

In regards to the potential protective capacity of child disabilities for adoption, social workers may use this knowledge to target recruitment efforts with adults who are interested in adopting children with special needs, especially physical disabilities. Practically speaking, adoptive parents will likely need post-permanency services.

Continuity and connections. Finally, findings on continuity and connections suggest several important practice implications. First and foremost, decisions about and actions for permanence must begin immediately as children enter foster care, not as they approach a regulatory deadline. Early stability findings suggested the importance of continuity even during the early days of foster care. Organizational structures and procedures must be established to strongly discourage multiple placement moves even during the first three months in foster care. It is important that individual and organizational practices expect and allow a child to be placed in the best placement in the first few days of care. Foster care agencies can help to ensure the best placements possible by using a centralized database that contains necessary information for establishing good fit between a child and a foster home placement. A centralized placement system will permit information to be easily and readily accessed by social workers across a state, allowing them to locate a placement setting with the best fit possible. Moreover, information systems can be used for real-time tracking of children's continuity and connections while in foster care so agency staff have a handle on the experiences of the children in its care. At minimum, practice can include monthly data reporting that tracks important measures of continuity and connections. For example, a report by Harvard University's Kennedy School of Government prepared for the District of Columbia's Department of Child and Family Services 
established performance measures for six objectives and suggested they be measured monthly. The six objectives included: 1) placements are stable, 2) moves promote permanency, 3) children rarely move, 4) group care is brief, 5) children live in families, and 6) stable families become permanent (Ahluwalia \& Zemler, 2003).

Organizational procedures should aim to place children with kin and siblings whenever possible. Efforts to identify relative placement options could be ramped up by implementing intensive search for relatives and kin during a child's first 72 hours in foster care. Foster care agencies may need to hire staff from local communities who have special skills for locating relatives, facilitating relative placements, and supporting relatives in local communities. Additional strategies can be employed to keep children connected to family, kin, and other important relationships. According to this study's findings, sibling placements will be most beneficial when they are continuously intact. Professionals and foster parents should be informed of the potential benefits of stable placements and connections to family. In addition to providing foster parents with information and training, respite care and other community-based supports could be routinely provided in an attempt to proactively maintain stable placements.

Findings on runaways in foster care were also part of the continuity and connections predictors. Running away certainly creates placement instability for a youth. It may be further compounded when courts treat a runaway event as a status offense and send a youth to a juvenile detention center. As an alternative to seeing runaways as acting-out or unruly behavior, it can also be viewed as signal of unmet needs or problems. A report by the Chapin Hall Center found that youth who ran away from foster care frequently explained their runaway behavior as attempting to reconnect with family or friends (Courtney et al., 2005). One practice implication for permanency outcomes would be to create interventions and supports that assist youth with 
being connected in their foster care placements (for example, Clark et al., 2008). Youth development theory suggests that these connections are essential as are opportunities for contribution and participation. Thus, youth-led planning meetings may be an example of another promising practice for permanency.

In conclusion, implications for social work practice clearly indicate that social workers be informed about the important predictors of permanency. Moreover, this recommendation applies to social work practitioners, supervisors, and administrators and has implications for training and supervisory activities. The gravity of permanency decisions suggests that these decisions be made as a team and that standardized processes be used to promote objective, fair, and effective permanency decisions (Berrick, 2009). Finally, in consideration of the multiple systems that impact children in foster care, implications for disseminating knowledge on the risk and protective factors of permanency should also extend to key stakeholders of all relevant systems.

\section{Social Work Policy}

Child welfare policy should strive to balance the principles of primordial solidarities and bureaucratic institutions. Reunification is and should be the first permanency goal for nearly all children who enter foster care. Nevertheless, policy can also advance children's connections to siblings, extended family, and other caring adults as well as strategies that facilitate stability and continuity in living arrangements. One policy suggestion would be to provide foster parents with financial incentives to keep siblings together and maintain children in stable placements. Incentives could also be employed at the federal level to promote state information systems that account for and maintain children in stable placements.

An area of concern for social policy relates to the timeliness of permanency. This study's observation period ranged from 2-1/2 to 3-1/2 years (30-42 months), and at the end of this period 
approximately 1 in 7 children, about 14\%, remained in foster care. Another $10 \%$ of the entry cohort exited foster care without a permanent living arrangement. So, for one-quarter of the children in this annual entry cohort, foster care proved to provide neither temporary care nor permanency. Hence, foster care drift remains a serious problem. This study suggests that much more work must occur before foster care can be considered temporary. Concurrent planning, which allows efforts to simultaneously focus on two or more permanency paths, should be standard policy and practice. Still, there is a critical need to identify additional policy innovations that will encourage more timely exits and will increase the proportion of children leaving foster care with legal connections to a permanent, lifelong family. Some scholars make a case for Title IV-E Waiver Demonstrations as the appropriate tool to test novel approaches with methodologically sound research. Testa (2010b) suggested: "By encouraging rigorous evaluations to identify valid models and to eliminate erroneous hypotheses, waiver demonstrations promised to advance best practice and contribute to the evidence base of what works best for children and families" (p. 284). Unfortunately, the authority of the Administration for Children and Families to grant new Title IV-E Waiver demonstrations expired in March 2006. Reinstatement of these demonstrations or the development of an alternative policy mechanism is needed to induce states to test creative, new approaches for permanency.

A range of policy strategies should be carefully considered to balance permanency options. This study observed reunification occurred the most frequently and on the shortest time line. Guardianship occurred with the least frequency but with the second shortest time line. Finally, adoption was second in terms of frequency but took the longest to achieve. Current policy establishes a hierarchy of permanency: reunification, adoption, and then guardianship (National 
Council of Juvenile and Family Court Judges, 2000). Adoption is preferred over guardianship primarily because it is viewed as more legally binding than guardianship (Testa, 2005). Yet, proponents of guardianship counter that, although guardianship may not be perceived as legally binding, it is advantageous in providing children with lasting connections (Marvin, 2005; Testa, 2005). The findings of this study did not speak to whether permanency was lasting. However, they demonstrated that guardianship generally occurred more quickly than adoption and that connections to family were important predictors of all types of permanency. If more timely permanency is a policy objective, then improvements may be made by promoting guardianship for more children in foster care. States may benefit from taking advantage of subsidized guardianships that are now provided by a recent law, the Fostering Connections to Success and Improving Adoptions Act - Public Law 110-351 (Children's Defense Fund \& Center for Law and Social Policy, 2008). Importantly, this new law stipulates that eligibility for the guardianship subsidies may not be limited by a child's age under 18 years old or a child's special needs (Vermont Subsidized Permanent Guardianship Subcommittee, 2009, p. 11). This law then is consistent with previously noted concerns about age limits for guardianship. Also, the Fostering Connections law and expansion of guardianship may help address racial equity in permanency outcomes if some communities, such as the African American community, view guardianship as a more culturally acceptable solution. The Fostering Connections law can provide the necessary financial and service supports needed for increasing exits to guardianship; yet, states are not required to implement subsidized guardianships but can choose to opt-in for these new provisions. Additionally, Fostering Connections includes an adoption rule-out provision that needs further clarification. Above all, social policy should be designed to consider 
the unique needs and circumstances of each child's case so that the best approach to permanency can be implemented.

Policy strategies that promote permanency outcomes must include both directives and funding. The current financing structure of foster care is constrained in a number of ways. First, Title IV-E, the primary funding stream for foster care, is inflexible and misaligned with the advancement of permanency outcomes (Geen, 2003; Wulczyn, et al., 2005). Title IV-E incents states to keep children in foster care. That is, states receive funding based on the number of children who are in foster care rather than the attainment of permanency outcomes. Title IV-E, specifically, and child welfare funding, generally, could be restructured to encourage innovation and reward progress toward permanency (Testa, 2010b). Examples of more flexible and outcomes-oriented funding include allowing states to reinvest cost-savings into other types of services and use IV-E funds for individualized services that accelerate permanency and support post-permanency (Casey Family Programs, 2008). Some states have begun to amend state funding mechanisms to promote permanency, such as reimbursing foster care at higher rates until a certain month in care (e.g., 15-18 months) or reimbursing family-based or kin foster care at higher rates than more restrictive congregate settings (Pennsylvania Partnerships for Children, 2009).

The second major constraint of child welfare financing is its complex and fragmented approach that makes it difficult and cumbersome for states to optimize funding opportunities (Murray, 2004). The current financing structure has also been described as creating national inequities in foster care (Geen, 2003; Zappala, 2007). Child advocates argue that the link between Title IV-E funds and eligibility for the now obsolete Aid to Families with Dependent Children (AFDC) is neither fair nor sensible. The fairness claims refer to the enormous 
administrative burden on states that are required by the AFDC eligibility rules. State's success at making its way through this complex process is very uneven. Even more, the link to AFDC is criticized because it is calculated from outdated 1996 poverty thresholds. Alternatively, foster care financing structures could be reconfigured so Title IV-E funding was calculated with an appropriate inflation-adjusted index.

Social policy and corresponding funding mechanisms should recognize that the problems faced by families and children are intertwined in multiple systems. Policy and practice solutions then must be flexible enough to include strategies that involve and coordinate all relevant systems. Drawing from this study's findings that disabilities and mental health are two significant barriers of permanency, Medicaid policy is an area for potential change. Medicaid and child welfare policy should not only direct the implementation of screening, assessment, and evidence-based services for children's physical, developmental, and mental health needs; these policies should also establish the funding mechanisms that reimburse them. Quite simply, Medicaid policy must authorize the services needed to respond to children's disabilities and mental health problems in order to ensure children's clinical needs do not inhibit permanency, not to mention attainment of child-well being outcomes.

\section{Social Work Research}

This study further clarified the usefulness of a competing risks approach for foster care research. Competing risks analysis was applied for the first time with a dataset from Kansas, showing this approach in a new child welfare setting - one with a privatized structure. Hence, this study replicated competing risks and verified its usefulness. Further replication and demonstration of the usefulness of the competing risks approach may suggest extension to other 
foster care settings. Additionally, future use of competing risks analysis should define guardianship as a permanency outcome distinct from reunification and adoption.

Another implication for research pertains to the use of state administrative databases. This study used data from two state databases, one from child welfare and one from mental health. Foster care research may benefit from linking additional state databases that would allow the inclusion of additional variables, such as parent and family demographic, clinical, and service characteristics. Future research will also benefit from learning more about the influence of different service interventions on permanency outcomes. An additional improvement in foster care research includes establishing common operational definitions that would allow clearer cross-study comparison of results.

Further research is needed to understand the impact of poverty and other socioeconomic factors on permanency outcomes. Two separate findings on reunification point to concerns about family poverty and its potential as a risk factor for reunification. First, the fact that those families who experience neglect are less likely to reunify than families who experience physical or sexual abuse may allude to the complexity and chronicity of the effects of poverty. Second, the finding that younger children are less likely to be reunified could also be related to poverty. Although social workers may be reluctant to reunify young children based upon a child's vulnerability and capacity for self-protection, it is also known that poverty is more prevalent among families with young children. Questions arise about availability and accessibility of services prior to foster care placement. Empirical studies are needed to gather more information on the role of poverty and permanency outcomes.

Foster care exit research would also be complemented by qualitative studies that would document the perspectives of children in foster care, biological parents, foster parents, child 
welfare workers, and other key stakeholders. The findings of this study suggest priorities for qualitative study might include exploration of the relationship between age and permanency decisions as well as the influence of race and culture in foster care.

Finally, since this study's findings demonstrated the importance of continuity and connections, future research could focus on refining measures of these constructs. For example, placement stability could be defined in different ways. It could be useful to determine whether planned placement changes affect permanency in the same way as disruptions or unplanned placement changes. Similarly, information on why siblings are separated could be informative. The measurement of placement type could also be adapted to observe where a child spent the majority of time in foster care not just the first place in foster care, though this will require more labor-intensive data preparation. These kinds of refinements could provide additional information that helps broaden our understandings of continuity and connections and how they impact permanency.

\section{Limitations}

The administrative child welfare data used in this study has yielded important information about the predictors of permanency. Administrative data afford a variety of advantages including the ability to study foster care exits over time with a sizable sample. The fact that these data are longitudinal and the sample size is large provides important benefits for examining bivariate and multivariate patterns. Nonetheless, this study leaves several unanswered questions and major limitations should be noted.

First, this study was limited because foster care exits are not amenable to experimental manipulation. Many of the independent variables used in this study could not be randomly 
assigned to children and could not be manipulated. Thus, this study was limited to understanding significant relationships without the ability to draw causal inferences.

The second major limitation of the study is related to its definition of permanency and its inclusion of select variables. Permanency was studied here as an exit from foster care, although it may be studied on a longer time line by examining re-entry rates after exit from foster care. Also, this study may not have included all variables relevant to permanency. The bio-ecological perspective suggests various other potentially influential variables. For example, this study did not include biological parent and family characteristics, such as family income, parental substance abuse, or parental mental illness. Information was missing on foster parents, caseworkers, agencies, communities, and court systems. As previously noted, the study was also limited in understanding permanency patterns among different ethnic groups as there was no measure of ethnicity.

Finally, this study used a single state's data from a one-year entry cohort. It is impossible to know with certainty whether these data are generalizable to other states or another time period, although several key findings were consistent with a recent multi-year and multi-state analysis (Wulczyn, et al., 2007). There is potential that this study's entry cohort of children is unique from another year's entry cohort, though there is no obvious information to signify this. In addition, the variability that exists in state child welfare policy further complicates the generalizability of any single state study. As previously noted, states may benefit from statespecific competing risks analyses that identify permanency patterns unique to a given locale.

\section{Conclusion}

Current child welfare policy asserts three central outcomes for children in foster care: safety, permanency, and well-being. This study sought to explore the differential influences of select 
child and placement characteristics on three separate types of permanency. The primary findings from this study make a number of important contributions to the existing knowledge on foster care exits to permanency as summarized below.

This study's design and analyses, while having limitations, offered several benefits for foster care exit research. The use of a competing risks approach permitted the study to identify similarities and differences in predictors of three specific types of permanency. This expands the current knowledge of foster care exits by showing that different permanency paths may have common as well as unique risk and protective factors. Notably, the study used a broad population of children in foster care rather than relying on a narrowly-defined subpopulation. Additionally, although placement stability and sibling placements were discussed in the foster care literature as important for permanency, their inclusion in prior multivariate studies was rare. The findings presented here contribute to existing knowledge of foster care exits by including these measures and demonstrating their significance in multivariate models of permanency.

This study's findings both corroborated and expanded the existing literature on permanency, offering several important implications for social work practice. Consistent with the majority of other empirical studies, findings from this study confirmed the significance of the demographic characteristics of age and race as well as children's clinical needs related to disabilities and serious mental health problems. In particular, age and health status considerably influenced children's experience of permanency. Greater attention is needed to ensure social work practice is age-differentiated and culturally appropriate, and that children's' needs related to disabilities and mental health problems are addressed. The study's novel contribution, though not necessarily surprising, emerged from findings on continuity and connections. As a whole, the results for kin placements, sibling placements, early stability, and absence of runaway events 
offer new insight into the importance of social work practices and policies that strive to keep children connected to family and stable in their placements.

Primary findings on three key categories of important predictors also suggested implications for social work theory. In short, these findings reinforce the need for permanency theory that balances the primordial solidarities principle that stresses family connections with the bureaucratic institutions principle that emphasizes structures for ensuring stability. Plus, findings were consistent with integrating bio-ecological perpective into permanency theory.

Finally, this study's findings provide further justification for social workers to actively engage in the social policy arena. Several major findings indicated concerns for social policy. Foster care drift remains a serious problem for many children. Policies are needed to improve and expand timely permanency for more children. Suggestions for policy improvements include expanding guardianship as a viable option for more children and revising federal policy to promote the discovery and implementation of new, creative approaches to permanency. Social work policy could be greatly enhanced by reforming the current financing structure to be more flexible and better aligned with the promotion of permanency outcomes.

The challenge for social work is to take the next steps to use information from empirical research and to develop child welfare practice and policy strategies that will improve permanency outcomes. Ideally, this study will contribute to social work's understanding of the pathways to permanency and help promote policy and practice changes that will better support positive outcomes for a vulnerable population of children. 


\section{References}

Ahluwalia, S., \& Zemler, M. (2003). Stability in Foster Care: Measuring and Promoting Placements that Lead to Permanent Homes. Cambridge, MA: Kennedy School of Government, Harvard University.

Albert, V. N., \& King, W. C. (2008). Survival analyses of the dynamics of sibling experiences in foster care. Families in Society, 89(4), 533-541.

Allison, P. D. (1995). Survival analysis using SAS: A practical guide. Cary, NC: SAS Publishing.

Allison, P. D. (2004). Event history analysis. In M. B. Hardy, A. (Ed.), Handbook of data analysis. Thousand Oaks, CA: Sage Publications.

American Academy of Pediatrics. (2002). Health care of y oung children in foster care. Pediatrics, 109(3).

Antler, J., \& Antler, S. (1979). From child rescue to family protection: The evolution of the child protective movement in the United States. Children and Youth Services Review, 1(2), 177-204.

Barbell, K., \& Freundlich, M. (2001). Foster care today: Casey Family Programs.

Barth, R. P. (1997). Effects of age and race on the odds of adoption versus remaining in longterm out-of-home care. Child Welfare, 76(2), 285-308.

Bass, S., Shields, M. K., \& Behrman, R. E. (2004). Children, families, and foster care: Analysis and recommendations. The Future of Children, 14(1), 5-29.

Becker, M. A., Jordan, N., \& Larsen, R. (2007). Predictors of successful permanency planning and length of stay in foster care: The role of race, diagnosis and place of residence. Children and Youth Services Review, 29(8), 1102-1113.

Benard, B. (2003). Resiliency: What We Have Learned. San Francisco, CA: WestEd. 
Benard, B. (2006). Using strengths-based practice to tap the resilience of families. In D. Saleebey (Ed.), The Strengths Perspective in Social Work Practice. New York, NY: Allyn \& Bacon.

Benedict, M. I., \& White, R. B. (1991). Factors associated with foster care length of stay. Child Welfare, 70(1), 45-58.

Berrick, J. D. (2009). Take Me Home: Protecting America's Vulnerable Children and Families. New York, NY: Oxford University Press.

Berrick, J. D., Needell, B., Barth, R. B., \& Jonson-Reid, M. (1998). The Tender Years: Toward Developmentally Sensitive Child Welfare Services for Very Young Children. New York Oxford University Press.

Bremner, R. H. (Ed.). (1971). Children and youth in America: A documentary history, 18651965 (Vol. 2). Cambridge, MA: Harvard University Press.

Bronfenbrenner, U. (1979). The Ecology of Human Development. Cambridge, MA: Harvard University Press.

Brook, J., \& McDonald, T. (2009). The impact of parental substance aube on the stability of family reunifications from foster care. Children and Youth Services Review, 31(193-198).

Brown, J. D., \& Bednar, L. M. (2006). Foster parent perceptions of placement breakdown. Children and Youth Services Review, 28(12), 1497-1511.

Burns, B. J., Phillips, S. D., Wagner, H. R., Barth, R. P., Kolko, D. J., Campbell, Y., et al. (2004). Mental health need and access to mental health services by youths involved with child welfare: A national survey. J. Am. Acad. Child Adolesc. Psychiatry, 43, 960.

Cantor, A. B. (2003). SAS Survival Analysis Techniques for Medical Research. Cary, NC: SAS Institute Inc.

Carlile, P. R., \& Christensen, C. M. (2005). The cycles of theory building in management research, Version 6.0. Working Knowledge. Harvard Business School. Retrieved from http://hbswk.hbs.edu/cgi-bin/print?id=5422 
Casey Family Programs. (2008). Child welfare finance reform principles. Seattle, WA: Casey Family Programs.

Center for Community Partnerships in Child Welfare. (2006). Places to Watch: Promising Practices to Address Racial Disproportionality in Child Welfare. Washington, DC: Center for the Study of Social Policy.

Children's Defense Fund \& Center for Law and Social Policy. (2008). Foster Connection to Success and Increasing Adoptions Act Will Improve Outcomes for Children and Youth in Foster Care. Washington, DC: Children's Defense Fund. Retrieved from http://www.childrensdefense.org/child-research-data-publications/data/FCSIAAsummary.pdf.

Chipungu, S. S., \& Bent-Goodley, T. B. (2004). Meeting the challenges of contemporary foster care. The Future of Children, 14(1), 75-93.

Clark, H. B., Crosland, K. A., Geller, D., Cripe, M., Kenney, T., Neff, B., et al. (2008). A functional approach to reducing runaway behavior and stabilizing placements for adolescents in foster care. Research on Social Work Practice, 18(5), 429-441.

Coe, R. (2002). It's the Effect Size, Studpid: What effect size is and why it is important. Paper presented at the Annual Conference of the British Educational Research Association, University of Exeter, England.

Colegrave, N., \& Ruxton, G. D. (2003). Confidence intervals are a more useful complement to nonsignificant tests than are power calculations. Behavioral Ecology, 14(3), 446-447. doi: 10.1093/beheco/14.3.446

Connell, C. M., Katz, K. H., Saunders, L., \& Tebes, J. K. (2006). Leaving foster care--the influence of child and case characteristics on foster care exit rates. Children and Youth Services Review, 28(7), 780-798.

Cook, J. F. (1995). A HISTORY OF PLACING-OUT: THE ORPHAN TRAINS. Child Welfare, 74(1), 181-197.

Courtney, M. E. (1994). Factors associated with the reunification of foster children with their families. Social Service Review, 68, 81-108. 
Courtney, M. E., Dworsky, A., Cusick, G. R., Keller, T., Havlicek, J., Perez, A., et al. (2007). Midwest evaluation of the adult functioning of former foster youth.

Courtney, M. E., Needell, B., \& Wulczyn, F. (2004). Unintended consequences of the push for accountability: the case of national child welfare performance standards. Children and Youth Services Review, 26(12), 1141-1154.

Courtney, M. E., Piliavin, I., \& Wright, B. R. E. (1997). Transitions from and returns to out of home care. Social Service Review, 71, 652-667.

Courtney, M. E., Skyles, A., Miranda, G., Zinn, A., Howard, E., \& Goerge, R. M. (2005). Youth Who Run Away from Out-of-Home Care Retrieved January 9, 2010, from www.chapinhall.org

Courtney, M. E., \& Wong, Y. I. (1996). Comparing the timing of exits from substitute care. Children and Youth Services Review, 18(4-5), 307-334.

Curtis, P. A. (1999). Introduction: The chronic nature of the foster care crisis. In P. A. Curtis, G. Dale \& J. C. Kendall (Eds.), The foster care crisis: Translating research into policy and practice (pp. 1-14). Lincoln, NE: University of Nebraska Press.

D'Andrade, A., Osterling, K. L., \& Austin, M. J. (2008). Understanding and measuring child welfare outcomes. Journal of Evidence-Based Social Work, 5(1-2), 135.

Davis, I. P., Landsverk, J., Newton, R., \& Ganger, W. (1996). Parental visiting and foster care reunification. Children and Youth Services Review, 18(4-5), 363-382.

Durlak, J. A. (2009). How to select, calculate, and interpret effect sizes. Journal of Pediatric Psychology, 34(9), 917-928. doi: doi:10.1093/jpepsy/jsp004

Fanshel, D., Finch, S. J., \& Grundy, J. E. (1989). Modes of Exit from Foster Family Care and Adjustment at Time of Departure of Children with Unstable Life Histories. Child Welfare, 68(4), 391-402.

Fein, E., Maluccio, A. N., \& Kluger, M. P. (1990). No More Partings: An Examination of LongTerm Foster Care. Washington, DC: Child Welfare League of America. 
Fram, M. S., \& Altshuler, S. J. (2009). Social capital theory: Another lens for school social workers to use to support students living in foster care. School Social Work Journal, $33(2), 1-25$.

Garson, D. (2008). “Cox Regression” from Statnotes: Topics in multivariate analysis. Retrieved from http://www2.chass.ncsu.edu/garson/pa765/statnote.htm

Geen, R. (2003). Improving Child Welfare Agency Performance through Fiscal Reforms: An Assessment of Recent Proposals. Paper presented at the Joint Center on Poverty Research Conference, Washtington, DC.

Geenen, S., \& Powers, L. E. (2007). "Tomorrow is another problem": The experiences of youth in foster care during their transition into adulthood. Children and Youth Services Review, 29(8), 1085-1101.

Gendell, S. J. (2001). In search of permanency: A reflection on the first 3 years of the Adoption and Safe Families Act Implementation. Family Court Review, 39(1), 25-42.

Glisson, C., Bailey, J. W., \& Post, J. A. (2000). Predicting the time children spend in state custody. Social Service Review, 74, 253-280.

Goerge, R. M. (1990). The reunification process in substitute care. Social Service Review, 64, 422-457.

Gordon, R. (1999). Drifting through Byzantium: The promise and failure of the Adoptions and Safe Families Act. Minnesota Law Review, 83, 637-700.

Guo, S., \& Wells, K. (2003). Research on the timing of foster care outcomes: One methodological problem and approaches to its solution. Social Service Review, 77, 1-24.

Hacsi, T. (1995). FROM INDENTURE TO FAMILY FOSTER CARE: A BRIEF HISTORY OF CHILD PLACING. Child Welfare, 74(1), 162-180.

Hardy, M. (2004). Summarizing distributions. In M. B. Hardy, A. (Ed.), Handbook of data analysis. Thousand Oaks, CA: Sage Publications. 
Harris, M. S., \& Courtney, M. W. (2003). The interaction of race, ethnicity and family structure with respect to the timing of family reunification. Children \& Youth Services Review, 25(5/6), 409-429.

Herrick, M. A., Williams, J., \& Pecora, P. J. (2004). Measuring placement and living situation change in foster care. Paper presented at the 18th Annual Conference on Treatment Foster Care, Nashville, TN. http://www.ffta.org/research_outcomes/abstracts18 herrick.pdf

Hill, R. B. (2006). Synthesis of research on disproportionality in child welfare: An update: Casey-CSSP Alliance for Racial Equity in the Child Welfare System.

James, S., Landsverk, J., \& Slymen, D. J. (2004). Placement movement in out-of-home care: patterns and predictors. Children and Youth Services Review, 26, 185-206.

Jimenez, M. A. (1990). Permanency planning and the Child Abuse Prevention and Treatment Act: The paradox of child welfare policy. Journal of Sociology \& Social Welfare, 17(3), 55-72.

Jonson-Reid, M., Drake, B., \& Kohl, P. L. (2009). Is the overrepresentation of the poor in child welfare caseloads due to bias or need? Children and Youth Services Review, 31(3), 422427.

Kadushin, A., \& Martin, J. A. (1988). Child welfare services (4th ed.). New York: Macmillan.

Kapp, S. A., McDonald, T. P., \& Diamond, K. L. (2001). The path to adoption for children of color. Child Abuse \& Neglect, 25, 215-229.

Kelly, P. J. (2004). A review of software packages for analyzing correlated survival data. The American Statistician, 58(4), 337-342.

Kemp, S. P., \& Bodonyi, J. M. (2000). Infants who stay in foster care: child characteristics \& permanency outcomes of legally free children placed as infants. Child and Family Social Work, 5, 95-106.

Kempe, C. H., Silverman, F. N., Steele, B. F., Droegemuller, W., \& Silver, H. K. (1962). The battered child syndrome. Journal of the American Medical Association, 181, 17-24. 
Koh, E., \& Testa, M. F. (2008). Propensity score matching of children in kin and nonkin foster care: Do permanency outcomes till differ? Social Work Research, 32(Social Work Research), 105-116.

Landsverk, J. A., Burns, B. J., Stambaugh, L. F., \& Reutz, J. A. (2006). Mental Health Care for Children and Adolescents in Foster Care: Review of Research Literature. Retrieved from www.casey.org

Landsverk, J. A., Burns, B. J., Stambaugh, L. F., \& Reutz, J. A. R. (2009). Psychosocial Interventions for Children and Adolescents in Foster Care: Review of Research Literature. [Article]. Child Welfare, 88(1), 49-69.

Landsverk, J. A., Davis, I., Ganger, W., Newton, R., \& Johnson, I. (1996). Impact of child psychosocial functioning on reunification from out-of-home placement. Children and Youth Services Review, 18(4-5), 447-462.

Leathers, S. J. (2005). Separation from siblings: Associations with placement adaptation and outcomes among adolescents in long-term foster care. Children and Youth Services Review, 27(7), 793-819.

Leslie, L. K., Hurlburt, M. S., James, S., Landsverk, J., Slymen, D. J., \& Zhang, J. (2005). Relationship between entry into child welfare and mental health service use. Psychiatric Services, 56(8), 981.

Lindsey, D. (1991). Factors affecting the foster care placement decision: An analysis of national survey data. American Journal of Orthopsychiatry, 61(2), 272-281.

Lindsey, D., \& Shlonsky, A. (2008). Closing reflection: Future research directions and a new paradigm. In D. Lindsey \& A. Shlonsky (Eds.), Child Welfare Research: Advances for Practice and Policy. New York, NY: Oxford University Press.

Lynham, S. A. (2002). The general method of theory-building research in applied disciplines. Advances in Developing Human Resources, 4(3), 221-241.

Mallon, G. P., \& Hess, P. M. (Eds.). (2005). Child welfare for the 21 st century: A handbook of practices, policies and programs. New York: Columbia University Press. 
Maluccio, A. N., Fein, E., \& Olmstead, K. A. (1986). Permanency planning for children: Concepts and methods. New York: Routledge Kegan \& Paul.

Marten, J. (2004). Childhood and Child Welfare in the Progressive Era: A Brief History with Documents. New York: Bedford/St. Martin's.

Marvin, R. S. (2005). Quality of permanency - lasting or binding? Legal status v. relationships. Virginia Journal of Social Policy \& the Law, 12(3), 535-545.

Massinga, R., \& Pecora, P. J. (2004). Providing better opportunities for older children in the child welfare system. Future of Children, 14(1), 151-173.

McDonald, T. P., Allen, R. I., Westerfelt, A., \& Piliavin, I. (1996). Assessing the long-term effects of foster care: A research synthesis. Edison, NJ: Child Welfare League of America.

McDonald, T. P., Poertner, J., \& Jennings, M. A. (2007). Permanency for children in foster care: A competing risks analysis. Journal of Social Service Research, 33(4), 45-56.

McMillen, J. C., Scott, L. D., Zima, B. T., Ollie, M. T., Munson, M. R., \& Spitznagel, E. (2004). Use of mental health services among older youths in foster care. Psychiatric Services, $55(7), 811$.

McMurtry, S. L., \& Lie, G. (1992). Differential exit rates of minority children in foster care. Child Abuse \& Neglect, 28(1), 42-49.

Murray, K. O. (2004). The federal legal framework for child welfare. Retrieved June 15, 2008, from Pew Commission on Children in Foster Care www.kidsarewaiting.org/tools/reports/files/0015.pdf

National Child Traumatic Stress Network. (2008). Child welfare trauma training toolkit: Comprehensive guide (2nd ed.). Los Angeles, CA \& Durham, NC: National Center for Child Traumatic Stress.

National Council of Juvenile and Family Court Judges. (2000). Adoption and Permanency Guidelines: Improving Court Practice in Child Abuse and Neglect Cases. Reno, NV: National Council of Juvenile and Family Court Judges. 
Newton, R. R., Litrownik, A. J., \& Landsverk, J. A. (2000). Children and youth in foster care: Disentangling the relationship between problem behaviors and number of placements. Child Abuse \& Neglect, 24(10), 1363-1374.

Oosterman, M., Schuengel, C., Slot, N. W., Bullens, R. A. R., \& Doreleijers, T. A. H. (2007). Disruptions in foster care: A review and meta analysis. Children \& Youth Services Review, 29, 53-76.

Pabustan-Claar, J. (2007). Achieving permanence in foster care for young children: A comparison of kinship and nonkinship placements. Journal of Ethnic \& Cultural Diversity, 16(1/2), 61-94.

Park, J. M., Metraux, S., \& Culhane, D. P. (2005). Childhood out-of-home placement and dynamics of public shelter utilization among young homeless adults. Children \& Youth Services Review, 27(5), 533-546.

Park, J. M., \& Ryan, J. P. (2009). Placement and permanency outcomes for children in out of home care by prior inpatient mental health treatment. Research on Social Work Practice, $19(1), 42-51$.

Pecora, P. J. (2006). Child welfare policies and programs. In J. M. F. Jenson, Mark W. (Ed.), Social policy for children and families: A risk and resilience perspective. (pp. 19-66). Thousand Oaks, CA: Sage Publications.

Pecora, P. J., Whittaker, J. K., Maluccio, A. N., \& Barth, R. B. (2000). The child welfare challenge: Policy, practice, and research (2nd ed.). New York: Aldine De Gruyter.

Pedhazur, E. J. (1982). Multiple regression in behavioral research. Fort Worth, TX: Harcourt Brace College Publishers.

Pedhazur, E. J., \& Schmelkin, L. P. (1991). Measurement, design and analysis: An integrated approach. Hillsdale, NJ: Lawrence Erlbaum Associates, Publishers.

Pennsylvania Partnerships for Children. (2009). Frequently Asked Questions on Pennsylvania Proposed Child Welfare Financing Reform: September 2009: Pennsylvania Partnerships for Children. 
Potter, C. C., \& Klein-Rothschild, S. (2002). Getting home on time: Predicting timely permanence for young children child welfare. Child Welfare, 81(2), 123-150.

Raghavan, R., Inkelas, M., Franke, T., \& Halfon, N. (2007). Administrative Barriers to the Adoption of High-Quality Mental Health Services for Children in Foster Care: A National Study. Administration and Policy in Mental Health and Mental Health Services Research, 34(3), 191-201.

Romney, S. C., Litrownik, A. J., Newton, R. R., \& Lau, A. (2005). The relationship between child disability and living arrangement in child welfare. Child Welfare, 85(6), 965-984.

Rosenberg, S. A., \& Robinson, C. C. (2004). Out-of-home placement for young children with developmental and medical conditions. Children and Youth Services Review, 26(8), 711723.

Rosenfeld, A. A., Pilowsky, D. J., Fine, P., Thorpe, M., Fein, E., Simms, M. D., et al. (1997). Foster care: An update. Journal of the American Academy of Child and Adolescent Psychiatry, 36(4), 448-457.

Rosenthal, J. A. (1996). Qualitative Descriptors of Strength of Association and Effect Size. Journal of Social Service Research, 21(4), 37 - 59.

Rubin, A., \& Babbie, E. (1989). Research methods for social work. Belmont, CA: Wadsworth Publishing Co.

Rubin, D. M., Downes, K. J., O'Reilly, A. L. R., Mekonnen, R., Luan, X., \& Localio, R. (2008). Impact of kinship care on behavioral well-being for children in out-of-home care. Archives of Pediatric and Adolescent Medicine, 162(6), 550-556.

Rubin, D. M., O'Reilly, A. L. R., Luan, X., \& Localio, A. R. (2007). The impact of placement stability on behavioral well-being for children in foster care. Pediatrics, 119(2), 336.

Rutledge, T., \& Loh, C. (2004). Effect sizes and statistical testing in the determination of clinical significance in behavioral medicine research. Annals of Behavioral Medicine, 27(2), 138145 .

Ryan, J. P., Garnier, P., Zyphur, M., \& Zhai, F. (2006). Investigating the effects of caseworker characteristics in child welfare. Children and Youth Services Review, 28(9), 993-1006. 
Sherraden, M. (2000). Asking questions well: The role of theory in applied social research. Paper presented at the Twelfth National Symposium on Doctoral Research in Social Work, College of Social Work, Ohio State University.

Shlonsky, A., Festinger, T., \& Brookhart, M. A. (2006). Is survival the fittest? A post hoc evaluation of event history estimations in an experimental design. Children and Youth Services Review, 28, 841-852.

Singer, J. D., \& Willet, J. B. (1991). Modeling the days of our lives: Using survival analysis when designing and analyzing longitudinal studies of duration and the timing of events. Psychological Bulletin, 110(2), 268-290.

Smith, B. D. (2003). After Parental Rights are Terminated: Factors Associated with Exiting Foster Care. Children and Youth Services Review, 25(12), 965-985.

Smokowski, P. R., Mann, E. A., Reynolds, A. J., \& Fraser, M. W. (2004). Childhood risk and protective factors and late adolescent adjustment in inner city minority youth. Children and Youth Services Review, 26(1), 63-91.

Snowden, J., Leon, S., \& Sieracki, J. (2008). Predictors of children in foster care being adopted: A classification tree analysis. Children and Youth Services Review, 30(11), 1318-1327.

StataCorp. (2007). Stata Statistical Software: Release 10. College Station, TX: StataCorp LP.

Steffensmeier, J. M. B., \& Jones, B. S. (2004). Event history modeling: A guide for social scientists. New York: Cambridge University Press.

Stone, S. (2007). Child maltreatment, out-of-home placement and academic vulnerability: A fifteen-year review of evidence and future directions. Children and Youth Services Review, 29(2), 139-161.

Testa, M. F. (2002). Kinship Care and Permanency. Journal of Social Service Research, 28(1), $25-43$.

Testa, M. F. (2005). The quality of permanence - lasting or binding? Subsidized guardianship and kinship foster care as alternatives to adoption. Virginia Journal of Social Policy \& the Law, 12(3), 499-534. 
Testa, M. F. (2008a). New permanency strategies for children in foster care. In D. Lindsey \& A. Shlonsky (Eds.), Child Welfare Research. New York: Oxford University Press.

Testa, M. F. (2008b). Subsidized guardianship: Testing the effectiveness of an idea whose time has finally come. Urbana-Champaign: Children and Family Research Center, School of Social Work, The University of Illinois at Urbana-Champaign.

Testa, M. F. (2010a). Data for policy planning and analysis. In M. F. Testa \& J. Poertner (Eds.), Fostering Accountability: Using Evidence to Guide and Improve Child Welfare Policy (pp. 136-165). New York: Oxford University Press.

Testa, M. F. (2010b). Flexibility, innovation, and experimentation: The rise and fall of child welfare waiver demonstrations. In M. F. Testa \& J. Poertner (Eds.), Fostering Accountability: Using Evidence to Guide and Improve Child Welfare Policy (pp. 269290). New York, NY: Oxford University Press.

Testa, M. F., \& Poertner, J. (2010). Child welfare in the twenty-first century: Outcomes, value tensions, and agency risks. In M. F. Testa \& J. Poertner (Eds.), Fostering Accountability: Using Evidence to Guide and Improve Child Welfare Policy. New York, NY: Oxford University Press.

Testa, M. F., \& Slack, K. S. (2002). The gift of kinship foster care. Children and Youth Services Review, 24(1/2), 79-108.

Testa, M. F., \& Smith, B. (2009). Prevention and drug treatment. Future of Children, 19(2), 147168.

Tilbury, C., \& Osmond, J. (2006). Permanency planning in foster care: A research review and guidelines for practitioners. Australian Social Work, 59(3), 265-280.

Trattner, W. I. (1999). From poor law to welfare state: A history of social welfare in America: Free Press.

U.S. Census Bureau. (2009, September 4). State and County Quick Facts. Retrieved October 29, 2009, from http://quickfacts.census.gov/qfd/states/20000.html

U.S. Department of Health and Human Services Administration on Children Youth and Families. (2007). Adoption and Foster Care Analysis and Reporting System [AFCARS], Technical 
bulletin \#14, disability information, May 2007. Retrieved from

http://www.acf.hhs.gov/programs/cb/systems/afcars/techbulletin/tb14.pdf

U.S. Department of Health and Human Services Administration on Children Youth and Families. (2008). The AFCARS report, preliminary FY 2006 estimates as of January 2008.

Retrieved from

http://www.acf.hhs.gov/programs/cb/stats_research/afcars/tar/report14.htm.

U.S. Department of Health and Human Services Administration on Children Youth and Families. (2009a). The AFCARS report, preliminary FY 2007 estimates as of October 2009. Retrieved from http://www.acf.hhs.gov/programs/cb/stats_research/afcars/tar/report15.pdf.

U.S. Department of Health and Human Services Administration on Children Youth and Families. (2009b). Trends in Foster Care and Adoption - FY2002-FY2008. Retrieved from http://www.acf.hhs.gov/programs/cb/stats_research/afcars/trends.htm.

U.S. Department of Health and Human Services Administration on Children Youth and Families. (n.d.). Child welfare outcomes 2002-2005, report to Congress.: Retrieved from http://www.acf.hhs.gov/programs/cb/pubs/cwo05/index.htm

U.S. Government Accountability Office [GAO]. (2007). African American Children in Foster Care: Additional HHS Assitance Needed to Help States Reduce the Proportion in Care. Washington DC: U.S. Government Retrieved from http://www.gao.gov/new.items/d07816.pdf.

Usher, C. L., Randolph, K. A., \& Gogan, H. C. (1999). Placement patterns in foster care. Social Service Review, March, 22-36.

Vaske, J. J., Gliner, J. A., \& Morgan, G. A. (2002). Communicating judgments about practical significance: Effect size, confidence intervals, and odds ratios. Human Dimensions of Wildlife, 7, 287-300.

Vericker, T., Macomber, J., \& Geen, R. (2008). The story behind kinship care caseload dynamics: An analysis of AFCARS data, 2000-2003. Children and Youth Services Review, 30, 437-451. 
Vermont Subsidized Permanent Guardianship Subcommittee. (2009). Report to the Justice for Children Task Force. Montpelier, VT: Office of the Defender General. Retrieved from http://defgen.vermont.gov/sites/defgen/files/Permanent_Guardianship_Report.pdf.

Vogel, C. A. (1999). Using administrative databases to examine factors affecting length of stay in substitute care. Children \& Youth Services Review, 21(8), 677-690.

Waldfogel, J. (2000). Child welfare research: How adequate are the data? Children and Youth Services Review, 22(9-10), 705-741.

Webb, M. B., \& Harden, B. J. (2003). Beyond child protection: Promoting mental health for children and families in the child welfare system. Journal of Emotional and Behavioral Disorders, 11(1), 49.

Webster, D., Barth, R. P., \& Needell, B. (2000). Placement Stability for Children in Out-ofHome Care: A Longitudinal Analysis. Child Welfare, 79(5), 614-632.

Wells, K., \& Guo, S. (1999). Reunification and reentry of foster children. Children \& Youth Services Review, 21(4), 273-294.

Winokur, M. A., Crawford, G. A., Longobard, R. C., \& Valentine, D. P. (2008). Matched comparison of children in kinship care \& foster care on child welfare outcomes. Families in Society, 89(3), 338-346.

Wulczyn, F. (1996). A statistical and methodological framework for analyzing foster care experiences of children. Social Service Review, 70, 318-329.

Wulczyn, F. (2003). Closing the gap: are changing exit patterns reducing the time African American children spend in foster care relative to Caucasian children? [doi: DOI: 10.1016/S0190-7409(03)00030-6]. Children and Youth Services Review, 25(5-6), 431462.

Wulczyn, F. (2009). Epidemiological perspectives on maltreatment prevention. Future of Children, 19(2), 39-66.

Wulczyn, F., Barth, R. P., Yuan, Y.-Y. T., Harden, B. J., \& Landsverk, J. A. (2005). Beyond Common Sense: Child Welfare, Child Well-Being and the Evidence for Policy Reform. Piscataway, NJ: Aldine Transactions. 
Wulczyn, F., Chen, L., \& Hislop, K. B. (2007). Foster Care Dynamics 2000-2005: A Report From the Multistate Foster Care Data Archive. Chicago: Chapin Hall Center for Children at the University of Chicago.

Wulczyn, F., \& Zimmerman, E. (2005). Sibling placements in longitudinal perspective. Children and Youth Services Review, 27(7), 741-763.

Yampolskaya, S., Armstrong, M. I., \& Vargo, A. C. (2007). Factors associated with exiting and reentry into out-of-home care under Community-Based Care in Florida. Children and Youth Services Review, 29(10), 1352-1367.

Yampolskaya, S., Kershaw, M. A., \& Banks, S. (2006). Predictors of successful discharge from out-of-home care among children with complex needs. Journal of Child \& Family Studies, 15, 195-205.

Zappala, M. (2007). Title IV-E DemonstrationPrograms: Pointing the Way to Reform. Adoption Advocate, (4). Retrieved from www.adoptioncouncil.org/documents/AAWaiverDemonstrations.pdf

Zeller, D. E., \& Gamble, T. J. (2007). Improving child welfare performance: Retrospective and prospective approaches. Child Welfare, 86(1), 97-122.

Zima, B. T., Bussing, R., Freeman, S., Yang, X., Belin, T. R., \& Forness, S. R. (2000). Behavior problems, academic skill delays, and school failure among school-aged children in foster care: Their relationship to placement characteristics. Journal of Child and Family Studies, 9(1), 87-103. 


\section{Appendix A Studies Included In the Literature Review of Foster Care Exits}

\begin{tabular}{|c|c|c|c|c|c|c|}
\hline Authors & $\mathbf{N}$ & $\begin{array}{c}\text { Sample } \\
\text { Description \& } \\
\text { Location }\end{array}$ & $\begin{array}{l}\text { Observation } \\
\text { Period }\end{array}$ & Study Focus & $\begin{array}{c}\text { Dependent/ } \\
\text { Outcome } \\
\text { Variable } \\
\end{array}$ & $\begin{array}{l}\text { Statistical } \\
\text { Techniques }\end{array}$ \\
\hline $\begin{array}{l}\text { Albert \& } \\
\text { King } 2008\end{array}$ & 602 & $\begin{array}{l}\text { Children with at } \\
\text { least one sibling in } \\
\text { long-term foster } \\
\text { care, in first episode } \\
\text { of care, Nevada }\end{array}$ & 18 months & $\begin{array}{l}\text { Sibling } \\
\text { placements }\end{array}$ & Reunification & $\begin{array}{l}\text { Event history } \\
\text { analysis } \\
\text { (pairwise) }\end{array}$ \\
\hline Barth 1997 & 3,873 & $\begin{array}{l}\text { Children entering } \\
\text { foster care for the } \\
\text { first time in } 1988 \\
\text { who were under } 6 \\
\text { years old, and spent } \\
\text { the majority of } \\
\text { placement in } \\
\text { nonkin family } \\
\text { foster care, } \\
\text { California }\end{array}$ & 6 years & $\begin{array}{l}\text { Age, race, and } \\
\text { adoption }\end{array}$ & $\begin{array}{l}\text { Adoption } \\
\text { Reunification } \\
\text { (incl relative } \\
\text { guardian) } \\
\text { Other } \\
\text { (guardian, } \\
\text { runaway, etc) }\end{array}$ & Logit analysis \\
\hline $\begin{array}{l}\text { Becker, et } \\
\text { al. } 2007\end{array}$ & 7,807 & $\begin{array}{l}\text { Children entering } \\
\text { foster care in } 1998 \\
\text { to } 1999 \text { with a } \\
\text { minimum stay of } 30 \\
\text { days, Florida }\end{array}$ & 1 year & & $\begin{array}{l}\text { Any successful } \\
\text { permanency exit }\end{array}$ & $\begin{array}{l}\text { Logistic } \\
\text { regression }\end{array}$ \\
\hline $\begin{array}{l}\text { Benedict \& } \\
\text { White } 1991\end{array}$ & 689 & $\begin{array}{l}\text { Children entering } \\
\text { foster care for first } \\
\text { time between } 1980 \\
\text { and 1983, Maryland }\end{array}$ & $\begin{array}{l}3 \text { to } 6 \text { years/ } \\
\text { until } 1986\end{array}$ & & $\begin{array}{l}\text { Any permanent } \\
\text { exit }\end{array}$ & $\begin{array}{l}\text { Event history } \\
\text { analysis }\end{array}$ \\
\hline $\begin{array}{l}\text { Connell, et } \\
\text { al. } 2006\end{array}$ & 5,909 & $\begin{array}{l}\text { Children entering } \\
\text { foster care for first } \\
\text { time in } 1998 \text { to } \\
\text { 2002, Rhode Island }\end{array}$ & Unknown & & $\begin{array}{l}\text { Adoption } \\
\text { Reunification } \\
\text { (incl relative } \\
\text { guardian) } \\
\text { AWOL }\end{array}$ & $\begin{array}{l}\text { Event history } \\
\text { analysis/compe } \\
\text { ting risks }\end{array}$ \\
\hline $\begin{array}{l}\text { Courtney } \\
1994\end{array}$ & 8,748 & $\begin{array}{l}\text { Random sample of } \\
\text { children entering } \\
\text { foster care for first } \\
\text { time between } 1998 \\
\text { and } 1991, \\
\text { California }\end{array}$ & 3 years & $\begin{array}{l}\text { Kin versus } \\
\text { nonkin } \\
\text { placements }\end{array}$ & Reunification & $\begin{array}{l}\text { Event history } \\
\text { analysis/one } \\
\text { model for each } \\
\text { group }\end{array}$ \\
\hline $\begin{array}{l}\text { Courtney, } \\
\text { et al } 1997\end{array}$ & 21,484 & $\begin{array}{l}\text { Children entering } \\
\text { foster care for first } \\
\text { time in } 1988 \text { who } \\
\text { were } 12 \text { years or } \\
\text { younger at time of } \\
\text { placement, } \\
\text { California }\end{array}$ & 4 years & $\begin{array}{l}\text { Reunification } \\
\text { and re-entry }\end{array}$ & Reunification & $\begin{array}{l}\text { Bivariate } \\
\text { probit analysis }\end{array}$ \\
\hline
\end{tabular}




\begin{tabular}{|c|c|c|c|c|c|c|}
\hline Authors & $\mathbf{N}$ & $\begin{array}{c}\text { Sample } \\
\text { Description \& } \\
\text { Location }\end{array}$ & $\begin{array}{l}\text { Observation } \\
\text { Period }\end{array}$ & Study Focus & $\begin{array}{c}\text { Dependent/ } \\
\text { Outcome } \\
\text { Variable } \\
\end{array}$ & $\begin{array}{l}\text { Statistical } \\
\text { Techniques }\end{array}$ \\
\hline $\begin{array}{l}\text { Courtney \& } \\
\text { Wong } 1996\end{array}$ & 8,625 & $\begin{array}{l}\text { Children entering } \\
\text { foster care for first } \\
\text { time in } 1988 \text { who } \\
\text { were } 16 \text { years or } \\
\text { younger at time of } \\
\text { placement, } \\
\text { California }\end{array}$ & 4 years & & $\begin{array}{l}\text { Adoption } \\
\text { Reunification } \\
\text { (incl relative or } \\
\text { guardian) } \\
\text { Running Away }\end{array}$ & $\begin{array}{l}\text { Event history } \\
\text { analysis/compe } \\
\text { ting risks }\end{array}$ \\
\hline $\begin{array}{l}\text { Davis, et al } \\
1996\end{array}$ & 922 & $\begin{array}{l}\text { Children entering } \\
\text { foster care in } 1990 \\
\text { and } 1991 \text {, who were } \\
12 \text { years or younger } \\
\text { and in care for a } \\
\text { minimum of } 72 \\
\text { hours, San Diego } \\
\text { County, CA }\end{array}$ & 1 year & $\begin{array}{l}\text { Parental } \\
\text { visiting }\end{array}$ & Reunification & $\begin{array}{l}\text { Logistic } \\
\text { regression } \\
\text { (forward } \\
\text { stepwise) }\end{array}$ \\
\hline $\begin{array}{l}\text { Glisson, et } \\
\text { al. } 2000\end{array}$ & 700 & $\begin{array}{l}\text { Children entering } \\
\text { foster care during } 1 \\
\text { year, who were at } \\
\text { least } 5 \text { years old }\end{array}$ & 3 years & Length of stay & Any exit & $\begin{array}{l}\text { Event history } \\
\text { analysis }\end{array}$ \\
\hline $\begin{array}{l}\text { Goerge } \\
1990\end{array}$ & $\sim 1,200$ & $\begin{array}{l}\text { Children entering } \\
\text { foster care } 1976 \text { to } \\
1984, \text { Illinois }\end{array}$ & 8 years & & Reunification & $\begin{array}{l}\text { Event history } \\
\text { analysis }\end{array}$ \\
\hline $\begin{array}{l}\text { Harris \& } \\
\text { Courtney } \\
2003\end{array}$ & 9,162 & $\begin{array}{l}\text { Random sample of } \\
\text { children entering } \\
\text { foster care for first } \\
\text { time in } 1992 \text { to } \\
\text { 1996, California }\end{array}$ & Unknown & $\begin{array}{l}\text { Race, } \\
\text { ethnicity, and } \\
\text { family } \\
\text { structure }\end{array}$ & Reunification & $\begin{array}{l}\text { Event history } \\
\text { analysis }\end{array}$ \\
\hline $\begin{array}{l}\text { Kapp, et al } \\
2001\end{array}$ & 1,550 & $\begin{array}{l}\text { Children with goal } \\
\text { of adoption as of } \\
\text { December } 1997 \text {, } \\
\text { Kansas }\end{array}$ & Unknown & $\begin{array}{l}\text { Race and } \\
\text { adoption }\end{array}$ & Adoption & $\begin{array}{l}\text { Event history } \\
\text { analysis }\end{array}$ \\
\hline $\begin{array}{l}\text { Kemp \& } \\
\text { Bodonyi } \\
2000\end{array}$ & 458 & $\begin{array}{l}\text { Children who were } \\
\text { legally free for } \\
\text { adoption and placed } \\
\text { in foster care as } \\
\text { infants as of June } \\
1995, \text { Washington } \\
\text { state }\end{array}$ & Unknown & $\begin{array}{l}\text { Infants and } \\
\text { adoption }\end{array}$ & Adoption & $\begin{array}{l}\text { Event history } \\
\text { analysis }\end{array}$ \\
\hline $\begin{array}{l}\text { Koh \& } \\
\text { Testa } 2008\end{array}$ & 3,000 & $\begin{array}{l}\text { Random sample of } \\
\text { children entering } \\
\text { foster care for first } \\
\text { time before October } \\
2004 \text { in AFCARS } \\
\text { records for } 1997 \text { to } \\
2007 \text { with kin and } \\
\text { nonkin placements, } \\
\text { Illinois }\end{array}$ & 3 years min & $\begin{array}{l}\text { Kin and } \\
\text { nonkin } \\
\text { placements }\end{array}$ & $\begin{array}{l}\text { Reunification } \\
\text { (excl relative } \\
\text { custody) } \\
\text { Adoption (inlc } \\
\text { guardian) }\end{array}$ & $\begin{array}{l}\text { Event history } \\
\text { analysis }\end{array}$ \\
\hline
\end{tabular}




\begin{tabular}{|c|c|c|c|c|c|c|}
\hline Authors & $\mathbf{N}$ & $\begin{array}{c}\text { Sample } \\
\text { Description \& } \\
\text { Location }\end{array}$ & $\begin{array}{l}\text { Observation } \\
\text { Period }\end{array}$ & Study Focus & $\begin{array}{c}\text { Dependent/ } \\
\text { Outcome } \\
\text { Variable } \\
\end{array}$ & $\begin{array}{c}\text { Statistical } \\
\text { Techniques }\end{array}$ \\
\hline $\begin{array}{l}\text { Landsverk, } \\
\text { et al. } 1996\end{array}$ & 699 & $\begin{array}{l}\text { Children entering } \\
\text { foster care in } 1990 \\
\text { to } 1991 \text { who } \\
\text { remained in care at } \\
\text { least } 5 \text { months and } \\
\text { who were between } \\
2 \text { and } 16 \text { years old; } \\
\text { Agreed to } \\
\text { interviews, } \\
\text { San Diego Co, CA }\end{array}$ & 18 months & $\begin{array}{l}\text { Child } \\
\text { psychosocial } \\
\text { functioning }\end{array}$ & Reunification & $\begin{array}{l}\text { Logistic } \\
\text { regression } \\
\text { (backwards } \\
\text { stepwise; one } \\
\text { model for each } \\
\text { group) }\end{array}$ \\
\hline $\begin{array}{l}\text { Leathers } \\
2005\end{array}$ & 197 & $\begin{array}{l}\text { Randomly selected } \\
\text { youth who were } 12- \\
13 \text { years old in } \\
\text { long-term } \\
\text { traditional family } \\
\text { foster care in } 1997, \\
\text { Illinois }\end{array}$ & 5 years & $\begin{array}{l}\text { Sibling } \\
\text { placements }\end{array}$ & $\begin{array}{l}\text { Reunification } \\
\text { Adoption } \\
\text { Guardianship }\end{array}$ & \\
\hline $\begin{array}{l}\text { McDonald, } \\
\text { et al. } 2007\end{array}$ & 24,511 & $\begin{array}{l}\text { Children entering } \\
\text { foster care in } 2000 \\
\text { to } 2003 \text { who were } \\
\text { in care for a } \\
\text { minimum of } 3 \text { days, } \\
\text { Oklahoma }\end{array}$ & Unknown & & $\begin{array}{l}\text { Adoption } \\
\text { Relative } \\
\text { Custody } \\
\text { Relative } \\
\text { guardianship } \\
\text { Reunification } \\
\text { Emancipation }\end{array}$ & $\begin{array}{l}\text { Event history } \\
\text { analysis/compe } \\
\text { ting risks }\end{array}$ \\
\hline $\begin{array}{l}\text { McMurtry } \\
\text { \& Lie } 1992\end{array}$ & 775 & $\begin{array}{l}\text { Stratified random } \\
\text { sample of children } \\
\text { entering foster care } \\
\text { in } 1979 \text { to } 1984 \\
\text { who were in care } \\
\text { for a minimum of } 6 \\
\text { months and were } \\
\text { less than } 17.5 \text { years } \\
\text { old, Marciopa } \\
\text { County, AZ }\end{array}$ & 2 years min & $\begin{array}{l}\text { Race and } \\
\text { ethnicity }\end{array}$ & $\begin{array}{l}\text { Adoption } \\
\text { Reunification } \\
\text { Other success } \\
\text { (e.g., long term } \\
\text { foster care) }\end{array}$ & $\begin{array}{l}\text { Event history } \\
\text { analysis }\end{array}$ \\
\hline $\begin{array}{l}\text { Pabustan- } \\
\text { Claar } 2007\end{array}$ & 1,215 & $\begin{array}{l}\text { Children entering } \\
\text { foster care in } 2000 \\
\text { to } 2003 \text { who were } 4 \\
\text { to } 11 \text { years old, } \\
\text { were in family or } \\
\text { kin foster care, but } \\
\text { not higher levels of } \\
\text { care }\end{array}$ & 6 month min & $\begin{array}{l}\text { Young } \\
\text { children }\end{array}$ & $\begin{array}{l}\text { Any permanent } \\
\text { exit } \\
\text { (reunification, } \\
\text { adoption/ } \\
\text { guardianship) }\end{array}$ & $\begin{array}{l}\text { Multivariate } \\
\text { logit analysis }\end{array}$ \\
\hline
\end{tabular}




\begin{tabular}{|c|c|c|c|c|c|c|}
\hline Authors & $\mathbf{N}$ & $\begin{array}{c}\text { Sample } \\
\text { Description \& } \\
\text { Location }\end{array}$ & $\begin{array}{l}\text { Observation } \\
\text { Period }\end{array}$ & Study Focus & $\begin{array}{l}\text { Dependent/ } \\
\text { Outcome } \\
\text { Variable }\end{array}$ & $\begin{array}{l}\text { Statistical } \\
\text { Techniques }\end{array}$ \\
\hline $\begin{array}{l}\text { Park \& } \\
\text { Ryan } 2009\end{array}$ & 5,978 & $\begin{array}{l}\text { Children entering } \\
\text { foster care for the } \\
\text { first time in } 1997 \text { to } \\
2001 \text { who were } 3 \text { to } \\
18 \text { years old, } \\
\text { Illinois }\end{array}$ & 4 year min & $\begin{array}{l}\text { Prior inpatient } \\
\text { mental health } \\
\text { treatment }\end{array}$ & $\begin{array}{l}\text { Any permanent } \\
\text { exit (adoption, } \\
\text { reunification, } \\
\text { guardianship) }\end{array}$ & $\begin{array}{l}\text { Logistic } \\
\text { regression } \\
\text { Even history } \\
\text { analysis }\end{array}$ \\
\hline $\begin{array}{l}\text { Potter \& } \\
\text { Klein- } \\
\text { Rothschild } \\
2002\end{array}$ & 125 & $\begin{array}{l}\text { Children entering } \\
\text { foster care for the } \\
\text { first time in } 1997 \text { to } \\
1998 \text { who were } 6 \\
\text { years old and } \\
\text { younger, and } \\
\text { participating in a } \\
\text { permanency } \\
\text { planning project, } \\
\text { Colorado (county) }\end{array}$ & 1 year & $\begin{array}{l}\text { Young } \\
\text { children and } \\
\text { expedited } \\
\text { permanency } \\
\text { project }\end{array}$ & $\begin{array}{l}\text { Any permanent } \\
\text { exit }\end{array}$ & $\begin{array}{l}\text { Logistic } \\
\text { regression } \\
\text { (backwards } \\
\text { stepwise) }\end{array}$ \\
\hline $\begin{array}{l}\text { Romney et } \\
\text { al., } 2005\end{array}$ & 277 & $\begin{array}{l}\text { Children entering } \\
\text { foster care in } 1990 \\
\text { to } 1991 \text { who were } 4 \\
\text { years old and } \\
\text { younger, and were } \\
\text { in care at least } 5 \\
\text { months, San Diego } \\
\text { Co, CA }\end{array}$ & 2 years & $\begin{array}{l}\text { Young } \\
\text { children and } \\
\text { disability } \\
\text { status }\end{array}$ & $\begin{array}{l}\text { Adoption } \\
\text { Reunification }\end{array}$ & $\begin{array}{l}\text { Multinomial } \\
\text { logistic } \\
\text { regression }\end{array}$ \\
\hline $\begin{array}{l}\text { Rosenberg } \\
\text { \& Robinson } \\
2004\end{array}$ & 105,071 & $\begin{array}{l}\text { All children in } \\
\text { AFCARS database } \\
\text { under the age of } 3 \\
\text { in } 1999, \text { National }\end{array}$ & Cross-sectional & $\begin{array}{l}\text { Young } \\
\text { children }\end{array}$ & Reunification & $\begin{array}{l}\text { Analysis of } \\
\text { variance }\end{array}$ \\
\hline $\begin{array}{l}\text { Ryan, et al. } \\
2006\end{array}$ & 5,726 & $\begin{array}{l}\text { Children entering } \\
\text { foster for the first } \\
\text { time in } 1995 \text { and } \\
\text { who exited by Dec } \\
\text { 2004, Illinois }\end{array}$ & 9 years & $\begin{array}{l}\text { Caseworker } \\
\text { factors }\end{array}$ & Reunification & $\begin{array}{l}\text { Structural } \\
\text { equation } \\
\text { modeling with } \\
\text { Mplus }\end{array}$ \\
\hline Smith 2003 & 1,995 & $\begin{array}{l}\text { Children who } \\
\text { became eligible for } \\
\text { adoption in Oct } \\
\text { 1997, National }\end{array}$ & 1 year & $\begin{array}{l}\text { Exiting after } \\
\text { termination of } \\
\text { parental rights }\end{array}$ & Adoption & $\begin{array}{l}\text { Event history } \\
\text { analysis }\end{array}$ \\
\hline $\begin{array}{l}\text { Snowden et } \\
\text { al., } 2008\end{array}$ & 60,000 & $\begin{array}{l}\text { Random selection } \\
\text { of children in } 2003 \\
\text { AFCARS data; Half } \\
\text { adopted and half } \\
\text { not adopted }\end{array}$ & Unknown & Adoption & Adoption & $\begin{array}{l}\text { Optimal data } \\
\text { analysis }\end{array}$ \\
\hline Vogel 1999 & 1,418 & $\begin{array}{l}\text { Children entering } \\
\text { foster care for the } \\
\text { first time in } 1992 \text { to } \\
\text { 1993, Philadelphia, } \\
\text { PA }\end{array}$ & 14 months & & $\begin{array}{l}\text { Any permanent } \\
\text { exit } \\
\text { (reunification, } \\
\text { adoption, and } \\
\text { independent } \\
\text { living) }\end{array}$ & $\begin{array}{l}\text { Event history } \\
\text { analysis }\end{array}$ \\
\hline
\end{tabular}




\begin{tabular}{|c|c|c|c|c|c|c|}
\hline Authors & $\mathbf{N}$ & $\begin{array}{c}\text { Sample } \\
\text { Description \& } \\
\text { Location }\end{array}$ & $\begin{array}{l}\text { Observation } \\
\text { Period }\end{array}$ & Study Focus & $\begin{array}{l}\text { Dependent/ } \\
\text { Outcome } \\
\text { Variable }\end{array}$ & $\begin{array}{l}\text { Statistical } \\
\text { Techniques }\end{array}$ \\
\hline $\begin{array}{l}\text { Wells \& } \\
\text { Guo } 1999\end{array}$ & 2,616 & $\begin{array}{l}\text { Children entering } \\
\text { foster care for the } \\
\text { first time in } 1992 \text { to } \\
1993 \text { who were } 15 \\
\text { years old or } \\
\text { younger and placed } \\
\text { in family foster } \\
\text { care, group care, or } \\
\text { institutional care, } \\
\text { Cuyahoga County, } \\
\text { OH }\end{array}$ & 2 years & & Reunification & $\begin{array}{l}\text { Event history } \\
\text { analysis }\end{array}$ \\
\hline $\begin{array}{l}\text { Winokur, et } \\
\text { al. } 2008\end{array}$ & 1,377 & $\begin{array}{l}\text { Children entering } \\
\text { foster care for the } \\
\text { first time in } 2002 \text {, } \\
\text { who stayed in care } \\
\text { for at least } 60 \text { days, } \\
\text { and ninety percent } \\
\text { of their time in care } \\
\text { was in nonkin or } \\
\text { kin foster homes, } \\
\text { Colorado (12 } \\
\text { counties) }\end{array}$ & 3 years & $\begin{array}{l}\text { Kin and } \\
\text { nonkin } \\
\text { placements }\end{array}$ & $\begin{array}{l}\text { Adoption (incl } \\
\text { placed for } \\
\text { adoption) } \\
\text { Reunification } \\
\text { Guardianship }\end{array}$ & $\begin{array}{l}\text { Paired samples } \\
\text { t-test }\end{array}$ \\
\hline $\begin{array}{l}\text { Yampolskaya } \\
\text { et al. } 2006\end{array}$ & 147 & $\begin{array}{l}\text { Children entering } \\
\text { foster care in } 2001 \\
\text { to } 2003 \text { and served } \\
\text { by a local program, } \\
\text { Florida (one } \\
\text { program) }\end{array}$ & 2 years & $\begin{array}{l}\text { Health status/ } \\
\text { complex needs }\end{array}$ & $\begin{array}{l}\text { Any permanent } \\
\text { exit }\end{array}$ & $\begin{array}{l}\text { Event history } \\
\text { analysis }\end{array}$ \\
\hline $\begin{array}{l}\text { Yampolskaya } \\
\text { et al. } 2007\end{array}$ & 34,503 & $\begin{array}{l}\text { Children entering } \\
\text { foster care in } 2001 \\
\text { to } 2003 \text {, Florida }\end{array}$ & $\begin{array}{l}1 \text { to } 2 \text { years, } \\
\text { depending on } \\
\text { whether } \\
\text { parental rights } \\
\text { terminated }\end{array}$ & $\begin{array}{l}\text { Different legal } \\
\text { status - } \\
\text { parental rights } \\
\text { termination }\end{array}$ & $\begin{array}{l}\text { Any permanent } \\
\text { exit (adoption, } \\
\text { reunification, } \\
\text { long-term } \\
\text { placement with } \\
\text { relatives) }\end{array}$ & $\begin{array}{l}\text { Event history } \\
\text { analysis }\end{array}$ \\
\hline
\end{tabular}

